\title{
Gender and Workaholism: A Study of New Zealand Academics
}

\author{
By \\ Amanda Lea Smith
}

\author{
A Thesis \\ submitted to Victoria University of Wellington \\ in fulfillment of the \\ requirements of the degree of \\ Master of Commerce and Administration
}

Victoria University of Wellington

2011 


\section{Abstract}

The aim of this study was to examine gender's impact on Workaholism and, in particular, the correlates of 'Workaholism' characteristics (Work Involvement, Drive and Work Enjoyment). The Literature review draws attention to the various definitions developed, providing the source and foundation of the definition used in this study. This thesis defines Workaholism as the tendency towards heavy work investment and involvement (the behavioural dimension) with considerable allocation of time to workrelated activities and work-related thoughts and the combination of high-drive with lowenjoyment (the cognitive dimension), which manifests itself in working compulsively and being obsessed with work for reasons that are not derived from external necessity.

A sample of 331 New Zealand academic employees from the eight different universities completed a web-based survey measuring 'Workaholism', Workaholism perceptions, hours worked and gender perceptions. Results show that there are differences in the degree of Workaholism and Workaholism-related variables between genders in academics in New Zealand. Furthermore, it was found that there was a statistically significant difference between genders in Work Involvement and Drive - females were found to exhibit more of both characteristics. No significant difference between genders in Work Enjoyment was found. Again, there is no significant difference between genders in Workaholism perceptions. There was, however, a significant difference between genders in the proportion of overworkers.

These findings provide insight into possible directions for future research as well as potentially influencing treatment for work addiction. In order for this knowledge to directly contribute towards benefiting practitioners further study is needed, leading to the ability to allow actions taken to reduce/prevent Workaholism to be tailored to the specific needs of employees. By understanding gender differences and the individual's perception of their own Workaholism, treatment could be tailored specifically for the individual. The current study suggests that blanket policies designed to promote worklife balance are unlikely to benefit all employees. 


\section{Acknowledgements}

Completing this thesis has been a long journey which couldn't have been done without the support of some important people.

I would like to thank my supervisors, Dr Kala Retna and Dr Eric Chong for their provision of constructive feedback and all important guidance on my work.

Additionally, I would like to thank Dr Lois Smith. Your advice was of great value in making this thesis sound.

I am deeply appreciative of my husband who was always there for me and helped me keep going through the year. To my parents, Anthony and Jennifer Crabbe, thank you for your constant support. I could not have done it without your encouragement. It was through my parents that my interest in this topic was developed, one being a Workaholic and the other a Work Enthusiast. Having watched the effects on them motivated this study and cultivated my belief that society should recognise the negative effects of Workaholism and should stop seeing it as something positive

This would not be complete without a thank you to my university colleagues and friends for your encouragement and distraction that got me to this point.

Finally, I would like to thanks the participants of this study, without whom its completion would not have be possible. 


\section{Table of Contents}

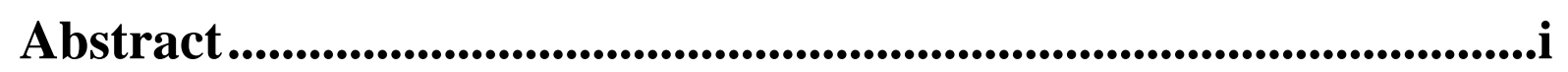

Acknowledgements ............................................................................................ ii

List of Tables ..................................................................................... vii

List of Figures........................................................................................... viii

Chapter 1: Introduction ...............................................................................1

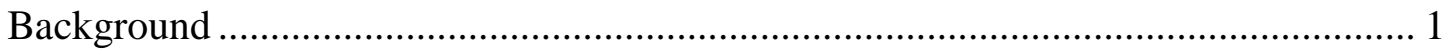

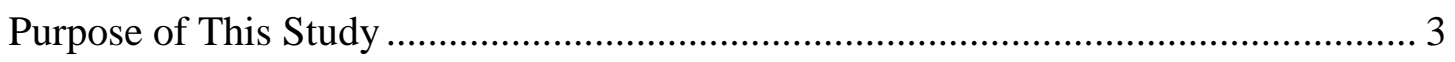

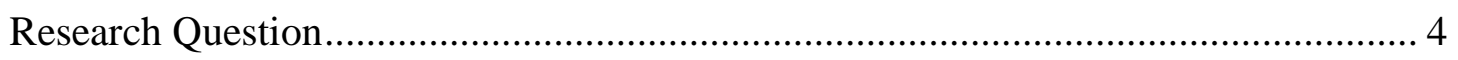

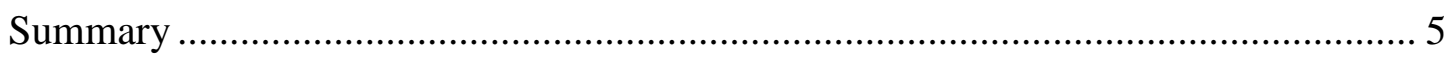

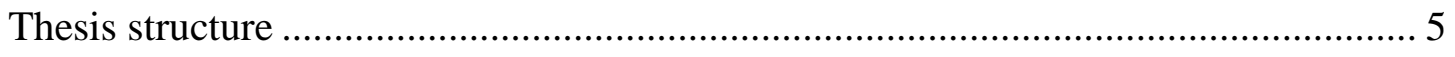

Chapter Two: Antecedents of Workaholism .................................................. 5

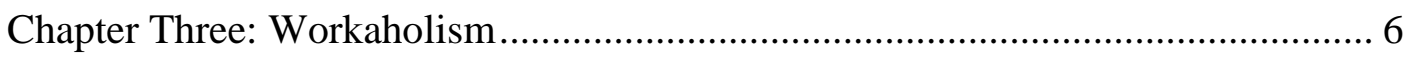

Chapter Four: Gender, Culture and Context ..................................................... 6

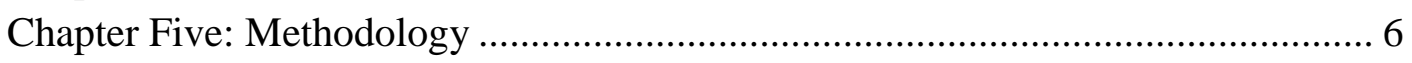

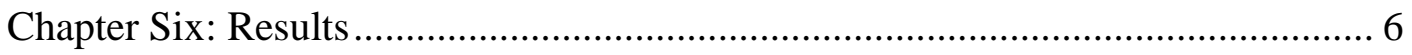

Chapter Seven: Discussion, Contribution, Limitations and areas for Future

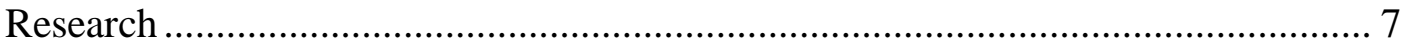

\section{Chapter 2: Antecedents of Workaholism ..............................................8}

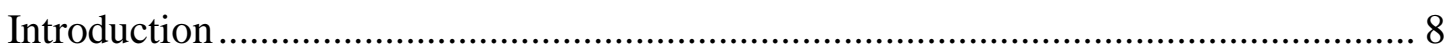

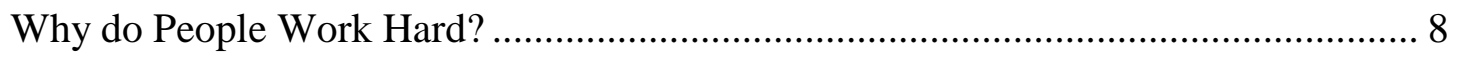

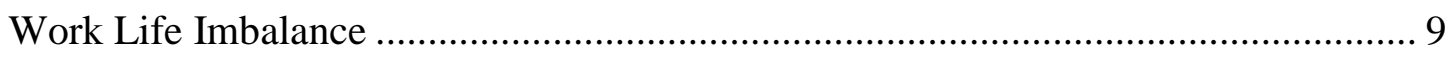

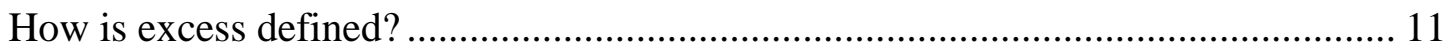

Long hours, Overemployment and Overwork ................................................. 11

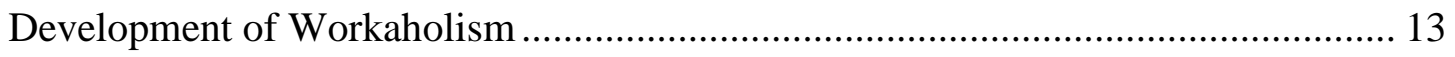

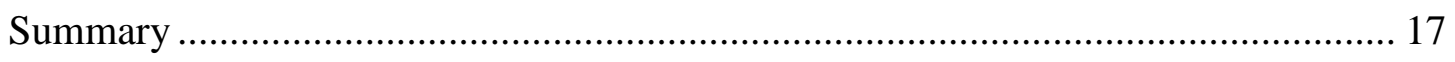




\section{Chapter 3: Workaholism.}

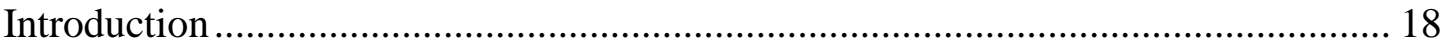

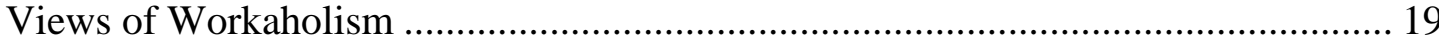

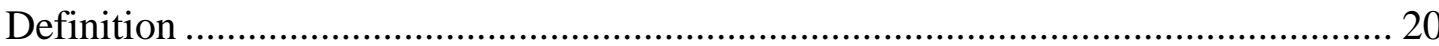

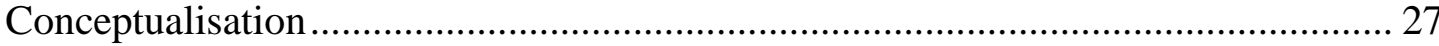

Consequences of Workaholism in the Workplace ................................................ 33

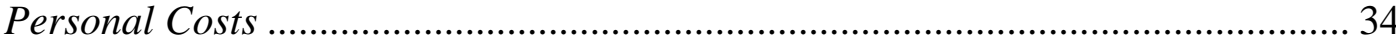

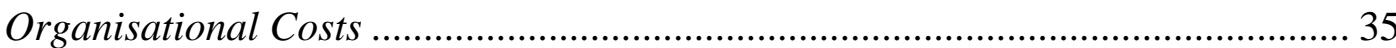

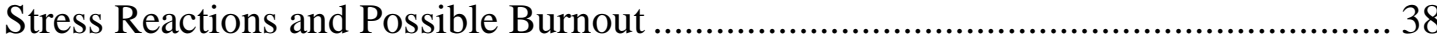

Current Methods of Addressing Workaholism ....................................................... 40

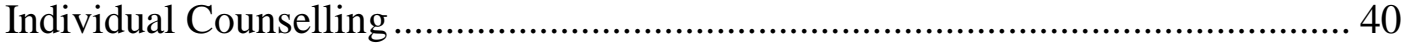

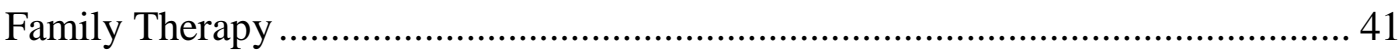

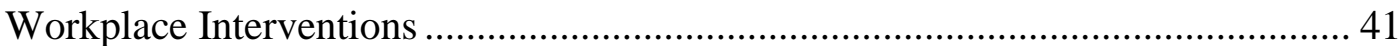

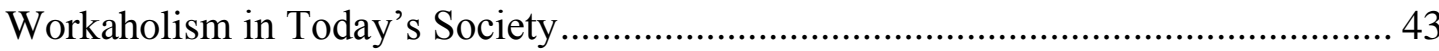

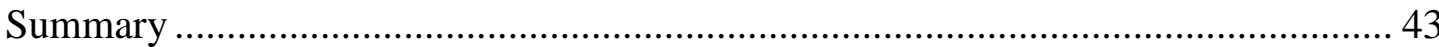

\section{Chapter 4: Gender, Culture and Context ............................................46}

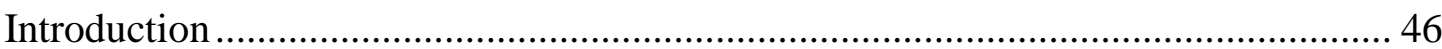

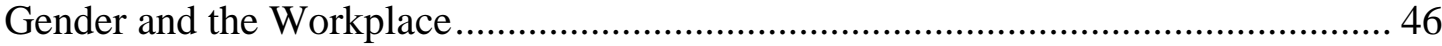

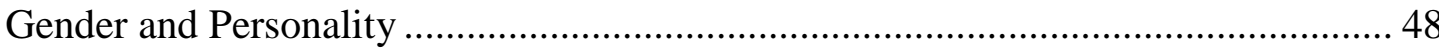

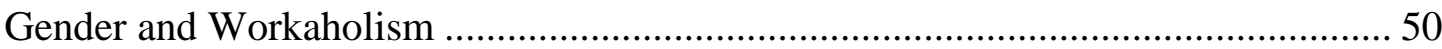

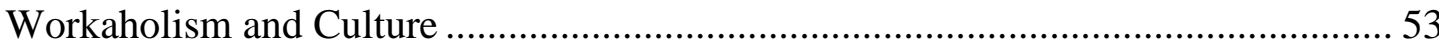

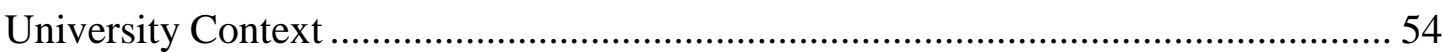

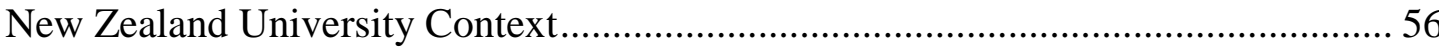

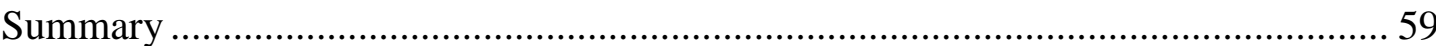

\section{Chapter 5: Methodology ............................................................................61}

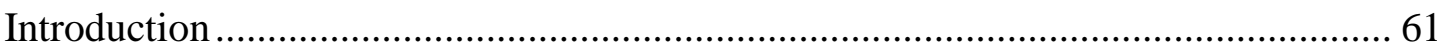

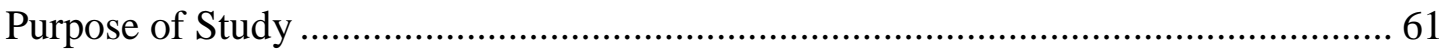

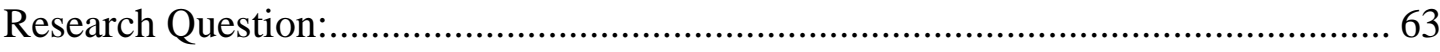

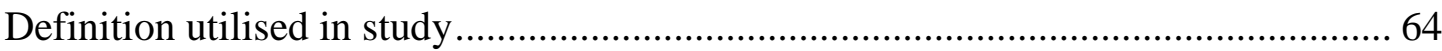

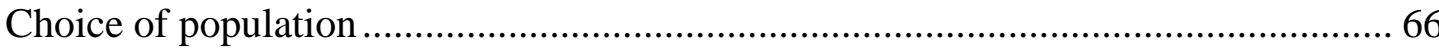

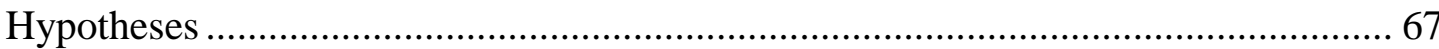

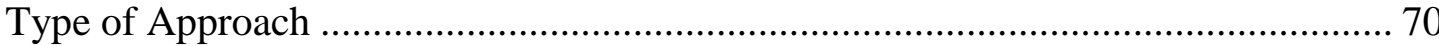

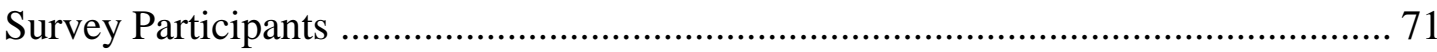

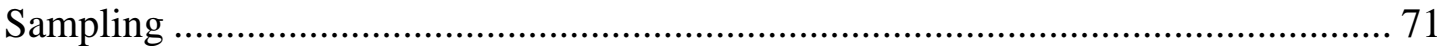

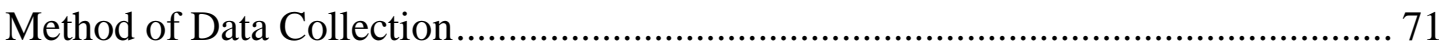

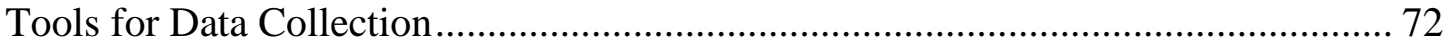




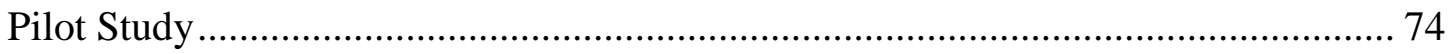

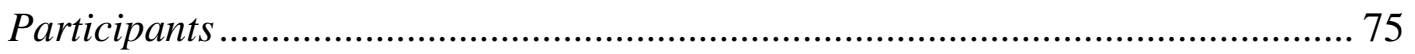

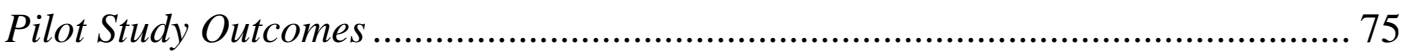

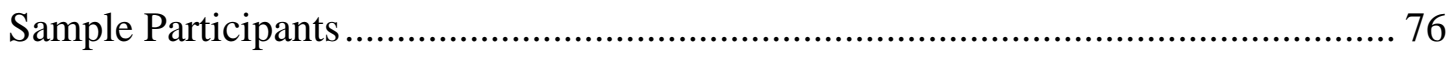

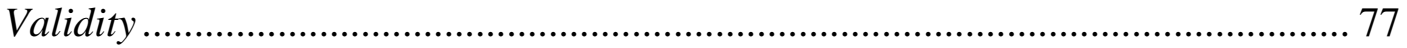

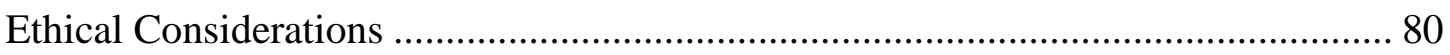

\section{Chapter 6: Results...........................................................................................82}

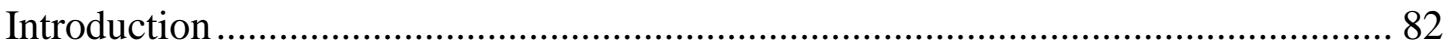

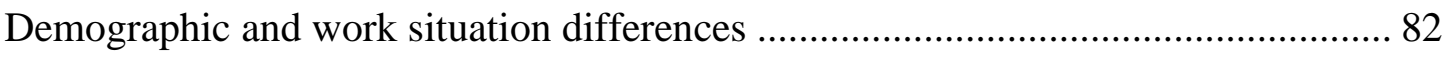

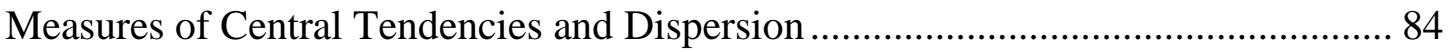

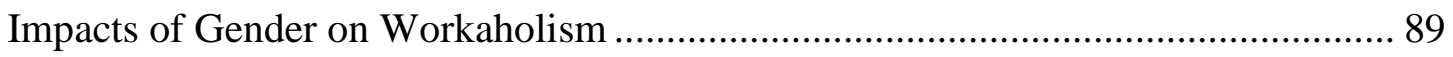

Gender and the Workaholism Composite Score ....................................................... 90

Gender and Workaholism Characteristics.............................................................. 92

Gender and Workaholism Perceptions ..................................................................... 94

Gender, Workaholism Composite Score and Workaholism Perceptions..................... 96

Gender and Overtime/Overwork ......................................................................... 98

Workaholism Composite Score and Long Hours, Overtime and Overwork ............. 101

Study Definition and Participants definition......................................................... 102

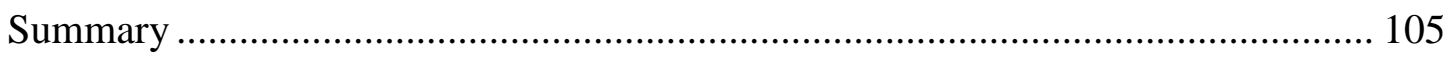

\section{Chapter 7: Discussion, Implications, Limitations and}

\section{Conclusions}

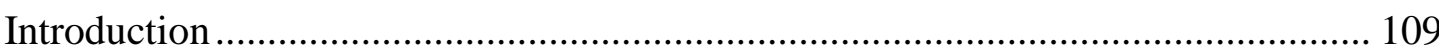

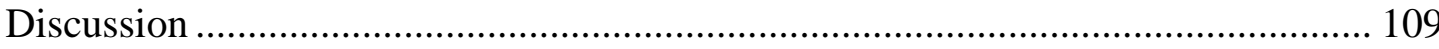

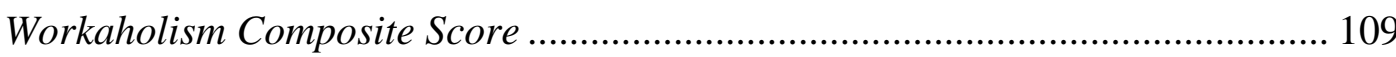

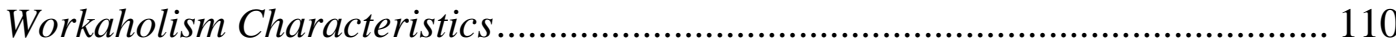

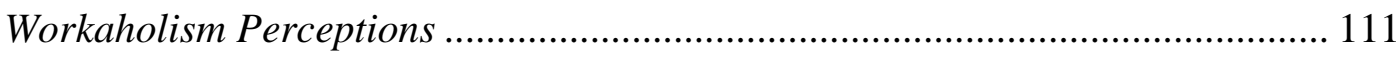

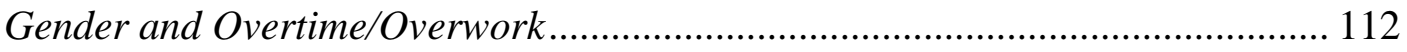

Workaholism Composite Score and Overtime/Overwork .................................... 112

Study Definition and Participants' Definition ..................................................... 113

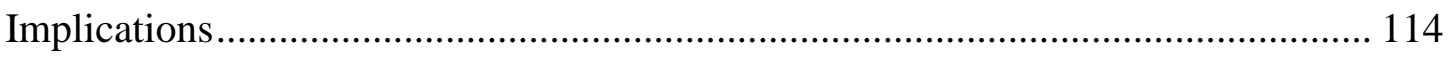

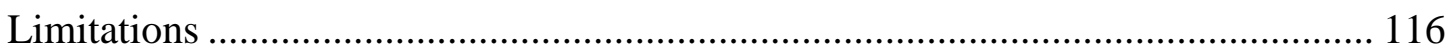

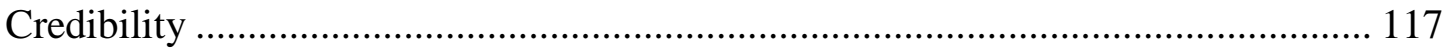

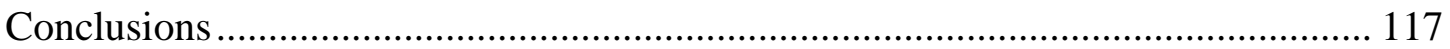

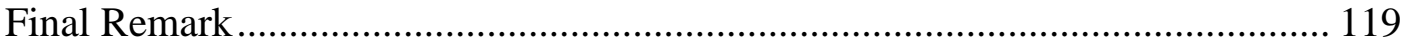


References

Appendix A: Human Ethics Committee Application....................131

Appendix B: Reliability ..........................................................................142

Appendix C: Graphs for Biographical Data Variables ................144

Appendix D: Separate-Groups Graphs for Gender Perceptions 


\section{List of Tables}

Table 1. Summary of major Workaholism definitions, 1968- 2004 ............................. 24

Table 2. Spence and Robbins' Classification of Worker Types ................................. 30

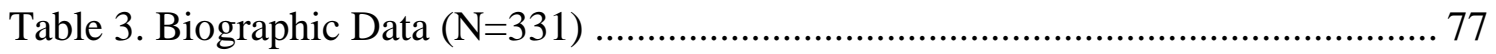

Table 4. Output of the Factor Analysis for Work Involvement .................................. 78

Table 5. Output of the Factor Analysis for Drive ...................................................... 79

Table 6. Output of the Factor Analysis for Work Enjoyment ..................................... 79

Table 7. Output of the Factor Analysis for Gender Perceptions ................................... 80

Table 8. Output of the Factor Analysis for Workaholism Perceptions .......................... 80

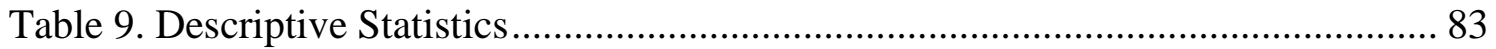

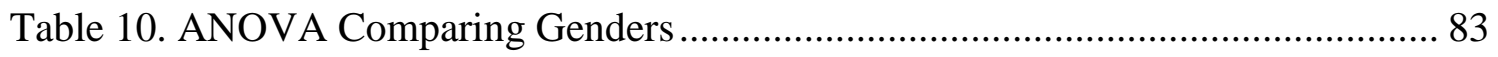

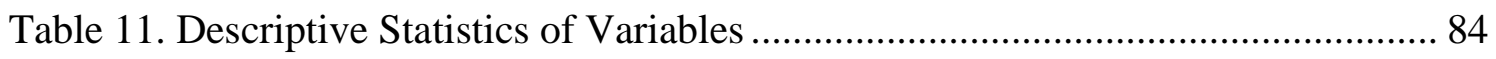

Table 12. Univariate ANOVA - Test of Equality of Group Means .............................. 86

Table 13. Box's Test of Equality of Covariance Matrices ........................................ 87

Table 14. Summary of Canonical Discriminant Functions ........................................ 87

Table 15. Independent Samples T-test between Gender and Gender Perceptions.......... 88

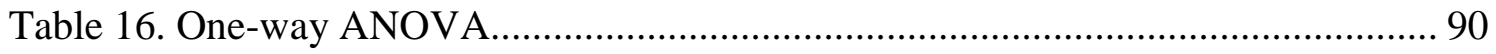

Table 17. Group Statistics for Workaholism Composite Score ................................. 91

Table 18. Independent Samples T-test between Gender and the Workaholism Composite

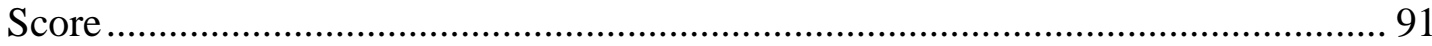

Table 19. Group Statistics between Gender and the Workaholism Characteristics....... 92

Table 20. Independent Samples T-test between Gender and the Workaholism

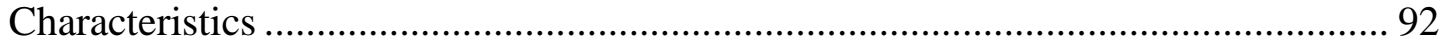

Table 21. Correlations between Measures for Males and Females .............................. 93

Table 22. Group Statistics between Gender and the Workaholism Perceptions............ 94

Table 23. Independent Samples T-test between Gender and the Workaholism

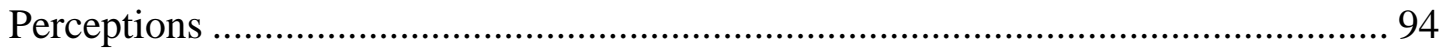

Table 24. Correlations between Workaholism Perceptions for Males and Females....... 95

Table 25. Paired Sample T-test between the two Workaholism Perceptions items for each Gender. 
Table 26. Group Statistics between Gender for the Workaholism Composite Score and

Workaholism Perceptions

Table 27. Correlations between Workaholism Composite Score and Workaholism

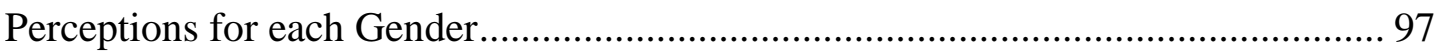

Table 28. Group Statistics between Gender and Overtime ........................................ 98

Table 29. Independent Samples T-test between Gender and Overtime ......................... 98

Table 30. Group Statistics between Gender and Overwork ....................................... 99

Table 31. Independent Samples T-test between Gender and Overwork....................... 99

Table 32. Gender and whether Participants Work more than 48 Hours ...................... 100

Table 33. Chi-Square Tests of Gender and whether Participants Work more than 48

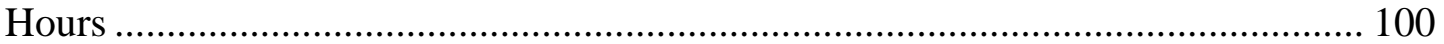

Table 34. Correlations between Workaholism Composite Score and Overtime .......... 102

Table 35. Correlations between Workaholism Composite Score and hours worked over

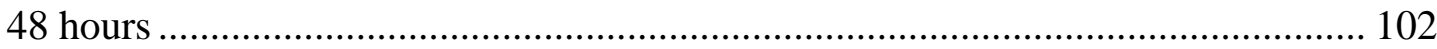

Table 36. Correlations between Workaholism Composite Score and Combine Hours

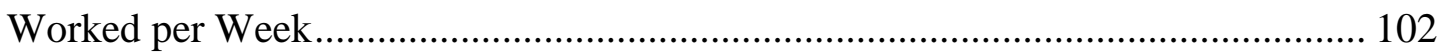

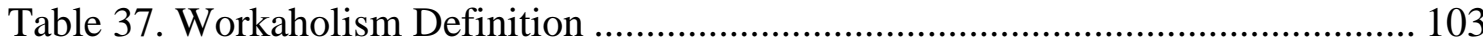

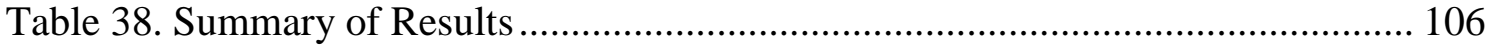

Table 39. Summary Gender Differences Found .................................................... 108

\section{List of Figures}

Figure 1. Venn diagram of overemploment, overwork (and overtime) ........................ 13

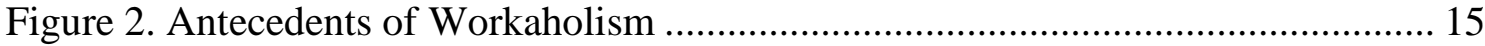

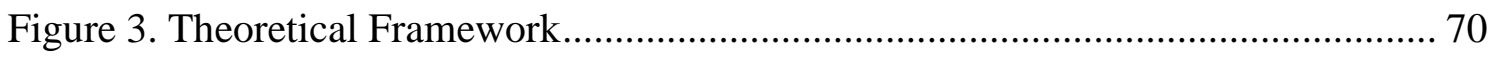

Figure 4. Results Summary Framework of Gender Differences Found...................... 108 


\section{Chapter 1: Introduction}

\section{Background}

Working long hours suggests commitment, productivity and involvement. But can one work too hard? Concerns about increasing hours worked have spurred interest in Workaholism or work addiction (Burke, 2000a). Workaholics produce worth, make money and achieve success, but Workaholism is also a cause of stress and a precursor to burnout. The effects of these appear in job performance, work relationships, family relationships and the community (McMillan et al., 2003). Workaholism in the workplace can be a major problem for both organisations and employees, and a large number of working days are lost due to stress, depression, anxiety (Worral et al., 2000), enhanced fatigue (Rosa, 1995) and burnout (Barbett et al., 1999). These are also serious health repercussions of Workaholism (McMillan and O'Driscoll, 2004). Furthermore, Workaholism can be counterproductive through a decline in either the quality of performance or quantity of productivity (Garson, 2005).

While work is a central life value and a defining characteristic shaping who we are, our self-esteem and sense of psychological well-being, it should not define us to the point where we sacrifice our health and the relationships that provide our life with meaning and value. Rather, work should be a means of providing the basic necessities and of offering satisfaction and accomplishment, not a dysfunctional addiction. Ultimately, work is an important dimension of one's life, but should not excessively spill over into the personal realm, or worse, replace one's personal life.

Taken as a whole, Workaholism is a more complicated and difficult concept than commonly thought. While most of us might assume a Workaholic is simply someone who puts a lot of time into work, this may not effectively define Workaholism. This is because it does not take into account the context in which the work is done and over what length of time. Workaholism is about a dysfunctional and compulsive behaviour with deep causes and outcomes that impact all aspects of our lives. 
It has been suggested by some scholars that Workaholism is heavily encouraged by organisations in today's society and is a socially accepted addiction (Fassel, 1990; Fassel and Schaef, 1991; McMillan and Northern, 1995). Ultimately, a price is paid for the dysfunctional addiction to work - Workaholism. It is widely accepted that the Workaholic suffers both personally and professionally, with specific risks to physical and psychological health. Often overlooked, however, is the negative impact on the organisation and even on society in general (Putnam, 2000). Workaholics have been compared to alcoholics in the sense that these two groups share some of the same symptoms, such as reality distortion, need to control, denial, anxiety, depression, withdrawal, irritability, and relationship problems with friends and family (Robinson, 1989).

Researchers posit many additional potential harmful effects of Workaholism, and have discussed numerous potential consequences of Workaholism in the literature. Overwork and Workaholism may cause physical symptoms (ulcers and chest pain) and even death (Fassel, 1990; Ishiyama and Kitayama, 1994). Research has also suggested that Workaholics may feel too busy to take care of their health (Machlowitz, 1978; Trueman, 1995). Accordingly, Spence and Robbins (1992) found that Workaholics exhibited a higher number of health complaints than some other groups of workers such as Work Enthusiasts (workers who work hard but enjoy their work, as detailed in Chapter 3). Robinson (1998) claimed that Workaholism affects individuals not only physically but, also emotionally, cutting "them off from the rest of the world ... [causing] them to be in their own cold, dark, lonely world - all alone with room only for other tasks to be completed" (p.6).

Additionally, the continued increase of females in the workforce has created a need to understand Workaholism in terms of gender differences. Although research in the area of gender differences is increasing, there is little conclusive research into how these gender differences may affect Workaholism and how such effects on Workaholism may vary between countries and cultures. As Workaholism has been found to affect health and well-being, it is important to expand knowledge in this area. Gender effects on 
Workaholism may be culturally dependent; therefore it is essential not to generalise, but rather to examine Workaholism in particular countries independently.

\section{Purpose of This Study}

The purpose of this study is to explore differences in the degree of Workaholism and Workaholism-related variables between genders in New Zealand, and particularly to provide further knowledge of the area of gender and Workaholism among academics in New Zealand. Workaholism on the whole is an under-researched subject, and as a result the effect of gender, country, culture and profession on Workaholism is as yet impossible to distinguish. There is too little information yet available to derive meaningful inferences. More research has to be generated before an understanding of gender differences surrounding Workaholism in organisations can be achieved.

Given the high social acceptance and even encouragement of Workaholism in some situations, the denial of its potential hazards and the limited amount of empirical research on the topic, it seems crucial to further investigate Workaholism and its characteristics. The more information that is compiled, the more likely it is that individuals, organisations and society as a whole may make subsequent helpful changes.

There is a strong case that working in higher education is a comparatively stressful occupation (Fisher, 1994; Kinman, 1998; Winefield, 2000). This thesis focuses specifically on the academic industry. This is done for four reasons (further information

detailed in Chapter 5). First, the advantages have faded away while salaries have also fallen and there is increasing pressure to 'publish or perish'. Second, academic staff play a vital role in the creation and development of knowledge, innovation, education and training. Third, academic staff have a greater ability to work harder and exhibit Workaholic characteristics due to work structure. Finally, likely effects on Workaholism due to the implementation of the PBRF provides further reason for research on Workaholism among academic staff in New Zealand. 
The findings of studies in this area have the potential to assist individuals, institutions and educational policy-makers in addressing the issue of stress in higher education and, ultimately, to inform policy and practice regarding working conditions. Although a limited number of small-scale studies have been conducted, as yet there has been little information available concerning the differences in the degree of Workaholism characteristics and Workaholism-related variables between genders exhibited in higher education institutions in New Zealand, or the impact upon the workforce of recent widespread changes. I therefore feel the need to explore this area further, carrying out research that can be of benefit to individuals, institutions and educational policy-makers.

\section{Research Question}

This study both replicates earlier work and extends our understanding of Workaholism by involving a different group of respondents (academics) in another country (New Zealand). The research question is:

\section{What are the Differences in the degree of Workaholism characteristics and Workaholism-related variables between genders?}

The research question is further developed in Chapter 5, breaking it down into the relationships examined in this study, and providing a framework that is based on these relationships. From this hypotheses were developed in order to answer the research question.

Considering Workaholism exclusively in terms of the number of working hours is misleading as it excludes the addictive nature. The emphasis is too often placed on the excessive working hours of these individuals, yet this is only a small aspect involved in Workaholism (often described as a symptom). This study therefore aims to break down the characteristics or aspects of Workaholism when looking at gender differences. A typical work addict is motivated by a strong internal drive that cannot be resisted. This is above any motivation due to external or contextual factors, such as financial problems, poor marriage, organisational culture, supervisory pressure, or a strong desire for career 
advancement. I define Workaholism as the tendency towards heavy work investment and involvement (the behavioural dimension) and the combination of high-drive with low-enjoyment (the cognitive dimension), which manifests itself in working compulsively and being obsessed with work. This definition corresponds with the most recent analysis of scholarly definitions which conclude that hard work at the expense of other important life roles and a strong internal drive to work are two key aspects of Workaholism (Ng et al., 2007).

\section{Summary}

Workaholism is a major cause of stress and a precursor to burnout. Workplace stress can have a widespread and negative impact on the well-being of individuals and their dayto-day performance. This is evident at a physical level, as well as at a psychological level, cognitive level, and behavioural level. Work related stress is increasingly recognised as one of the most serious occupational health hazards, resulting in factors such as job dissatisfaction, decreased productivity, absenteeism and turnover (Spielberger and Reheiser, 1995). This leads to large increases in costs faced by organisations, highlighting the importance of further study of Workaholism.

\section{Thesis structure}

The content of this research is organised into seven Chapters, arranged according to the stages of the research process. This Chapter has introduced the topic of the present research, including the background and the main issues surrounding Workaholism. Also presented is the purpose of this research and the research questions.

\section{Chapter Two: Antecedents of Workaholism}

This Chapter provides a review of the literature on antecedents of Workaholism relevant to this area of research. The Chapter starts with why people work hard and how excess is defined. Next the concepts of long hours, overemployment and overwork are discussed providing a starting point to the development of Workaholism. This is followed by a section on the development of Workaholism focussing on personality as an antecedent of Workaholism. 


\section{Chapter Three: Workaholism}

This Chapter provides a comprehensive review of the literature on Workaholism. It begins with an examination of the views of Workaholism followed by definitions developed in previous research, focussing on the widely accepted Spence and Robbins' (1992) definition. The Chapter then discusses the conceptualisation of Workaholism that has been proposed in the literature. Further, the consequences of Workaholism are introduced and discussed in terms of both personal and organisational costs. This is followed with discussion on stress and burnout as a subsequent consequence. Workaholism in today's society is also addressed.

\section{Chapter Four: Gender, Culture and Context}

This Chapter briefly delves into gender differences in the workplace and gender's effects on personality relevant to this area of research. This is then followed with a review of previous research examining gender and Workaholism which is germane to this study. Finally, this Chapter contextualises the current study by illustrating the culture and context, detailing why it is of particular interest.

\section{Chapter Five: Methodology}

This Chapter provides a discussion of the research methodology, the development of the hypotheses and theoretical framework, and the data collection techniques used in this research. The survey items corresponding to the Workaholism characteristics and the other variables examined in this study are defined and discussed. The pilot study is then detailed and the validity of the survey tested.

\section{Chapter Six: Results}

In this Chapter the data received from the surveys is analysed. A description of the statistical techniques used in analysing the data is provided. A summary of the results is supplied at the conclusion of this chapter, along with framework and an additional table summarising the gender differences found. 


\section{Chapter Seven: Discussion, Contribution, Limitations and areas for Future}

\section{Research}

This Chapter presents a summary of the research undertaken, including the contributions made by this research and its implications and areas for future research. Methods of addressing Workaholism are presented, followed by the studies limitations and credibility. 


\section{Chapter 2: Antecedents of Workaholism}

\section{Introduction}

This chapter introduces the topic of work hours and work addiction, setting the stage for the remainder of this study. Work has many benefits such as income, social contacts, opportunity to acquire and use new skills, feelings of accomplishment, and a sense of purpose and meaning (Burke, 2006). Work also has its costs. These may include fatigue, time away from friends and family, and in some cases psychological and physical health problems. Additionally, despite gains in productivity, effects by organised labour and technological advancements, contemporary society seems to be determined to maintain a heavy time investment in work. Despite having so many modern comforts most people cannot seem to take the time to enjoy what they have achieved.

This chapter looks at the antecedents of Workaholism and how these lead to Workaholism. It starts by looking specifically at why people work hard. Some of the factors under discussion include providing for families and confirming self-worth. This is followed with an examination of the discourse on work life imbalance as an antecedent of Workaholism. This discourse describes an excess of work hours as fundamental in a work life imbalance. Following this, the chapter covers how excess is defined, continuing on to discuss long hours, overemployment and overwork. Finally, the development of Workaholism is discussed in relation to psychological and sociocultural factors. Thus, this chapter is able to effectively look at the antecedents of Workaholism and how these lead to Workaholism.

\section{Why do People Work Hard?}

There are several answers to this question. These include economic necessity, organisational demands (due to greater competitive pressures, greater workload, and fewer staff as a result of downsizing and restructuring and greater job insecurity), occupational and professional norms, greater consumption and consumerism, and taking advantage of opportunities that are present. Another reason people claim to work hard is to provide a better life for their children (Burke, 2006). 
Juliet Schor (1992) suggested that increased work is driven by, and contributes to, growing consumerism. She suggests that innovation has led people into an ever accelerating work/spend cycle. As spending options and opportunities increase, individuals have to generate more earnings in order to balance the system. The driving desire to acquire things is intensified by the social costs of not having them (Porter, 2004). Another reason, as suggested by Joanne Ciulla (2000), asserted that work has become a primary source of identity, rather than the fulfilment previously derived from family, friends, and religion. Reich (2000) suggested that people lack confidence that the earnings they have today will be there tomorrow. Without assurance of a steady income, individuals feel the need to get as much as possible now, just in case. Additionally, jobs today are more indefinite in the knowledge-based economy compared to the past when one might enjoy security based on rank or seniority.

People may also work hard in order to confirm self worth as work outcomes can serve as a basis for self judgment. Work has become such an integral part of personal identity, as Reich (2000) suggested, that loss of work is believed to be a failure in an individual's personal identity. Most workers today have internalised these perceptions and fears; therefore little prompting is needed for them to feel pressurised to work hard (Porter, 2004). Individuals work more hours because organisational success supplies a sense of worth, and the organisation then pushes for higher productivity by rewarding those willing to spend more time at work. This initiates a self-reinforcing cycle in which workers confirm their self worth.

\section{Work Life Imbalance}

There is a societal obligation to distinguish between behaviour that represents a healthy work ethic and the destructive pattern of work addiction (Porter, 2004), also known as Workaholism. First, however, a definition of a healthy work relationship is necessary to compare with the maladaptive descriptions of work addiction. Quick et al. (1992)

offered the following definition: work is a central life value, and a defining characteristic shaping our identity, self-esteem and sense of psychological well-being. It is important though, that it does not define us to the point of willingness to sacrifice our 
health and well-being. "Work is an important function, among other functions, in an otherwise well-balanced life" (Holland, 2008, p. 3).

Developments in technology allow people to stay in constant contact with the workplace, making it possible for people to carry their work and the work environment with them into their homes, on vacation, and in public places that previously provided a barrier between work and other activities (Porter, 2001).

Organisations may inadvertently act as the "enabler" by encouraging Workaholic behaviour. This is most prevalent in organisations that value time on task rather than output. As a result, the organisation suffers because the Workaholic's disorder impedes innovation, creativity and critical reasoning (Holland, 2008). It is evident that the underlying causes of Workaholism, and the resulting behaviours, are varied and complex.

Kofodimos (1993) observed that career-oriented people have increasing difficulty balancing their professional and personal lives. He defines balance as:

"A satisfying, healthy, and productive life that includes work, play and love; that integrates a range of life activities with attention to self and to personal and spiritual development; and that expresses a person's unique wishes, interests, and values. It contrasts with the imbalance of a life dominated by work, focused on satisfying external requirements at the expense of inner development, and in conflict with a person's true desires." (Kofodimos, 1993. p. xiii)

Kofodimos saw imbalance as placing work before personal life. While organisational pressures contribute to imbalance, they are not the only source. Internal forces such as one's needs, wants and drive also lead to imbalance. Furthermore, Kofodimos equated work life imbalance with Workaholism. 


\section{How is excess defined?}

Before industrialisation, and the structured work of mass-producing factories, people were not drawn away from family and community involvement for the sake of paid work (Porter, 2004). Changes over time reducing the work week and adding paid holidays seemed to move towards recognising the importance of leisure. However, in recent years the average number of hours of work (and the norm) has shifted upwards (Organisation for Economic Co-operation and Development, 2011). People feel compelled to take work home, and be constantly available by email, phone or fax. The existing economic conditions have increased this trend while also lessening the perceived need for work-life balance initiatives. Porter states, "while employers will accommodate a work ethic that includes a balance of personal life, their willingness to consider it a priority may well change with economic cycles" (Porter, 2004, p. 433). This suggests that the current economic condition could bring about greater prevalence of excess work. Furthermore, this leads to difficulties in providing a consistent definition of how much is enough work and what constitutes excess.

One conclusion may be that everyone is working excessively, yet some people are more capable at achieving a balance than others, even when in identical circumstances. Moreover, some people are able to maximise their opportunities by truly leaving workplace concerns behind them when they walk out the door. In these cases it is their ability to cope that differs. This reveals that work that may be excessive for some may not be excessive for others.

\section{Long hours, Overemployment and Overwork}

Long hours are a principal component of excessive work. In North America, particularly among highly educated individuals, there has been a rise in hours worked due to increased responsibilities, heavier workloads, and technological advances, thereby leading to work-life imbalance (Aziz and Zickar, 2006). "The most common behaviour attached to any discussion of Workaholism is long hours devoted to the job" (Porter, 1996. p. 78). 
Overemployment refers to being employed beyond one's preferred work hours. It eventually leads to overwork which is considered to be an aspect of Workaholism. According to Burke (2004) any worker who is employed beyond their initially desired number of hours and is willing to sacrifice either income or imminent raises for reduced hours, but cannot, is considered to be overemployed. Overemployment may also lead to workers adjusting their number of preferred hours of work upwards. Burke (2004) suggested this triggers a dynamic process in which workers may start out working long hours involuntarily only to later begin to work the same number of hours voluntarily.

The most obvious characteristic of overwork is working beyond what is required. Consequently, overworkers devote much more time to their work than others do (Mudrack and Naughton, 2001; Scott et al., 1997). Overwork has been defined as

“Working beyond one's endurance and recuperative capacitates, [which] may be a hazard in certain personality types engaged in open-ended occupations ... which ignore the commonplace signs that inform one of the need for rest or recreation. If they are engaged in occupations that do not have a finite workday, they may at times exceed their bodies' ability to recover ... and [not be] aware of or make provision for one's physical and emotional needs." (Rhoads, 1997, taken from Burke, 2006, p. 49)

The point at which work becomes overwork varies by the demands of the job - physical and mental, the workplace, the occupation and the individual. There is much overlap of overwork and overemployment (seen in Figure 1), but also some independence as overworkers are considered to be individuals who work to excess not because of the perceived returns from the organisation, rather despite a perceived lack of returns. For example, an individual may choose to work beyond their endurance and recuperative capacitates, and are therefore overworked but not overemployed. For this reason there is much overlap between overwork and overemployent, but also some independence of the two. 
Figure 1. Venn diagram of overemploment, overwork (and overtime)

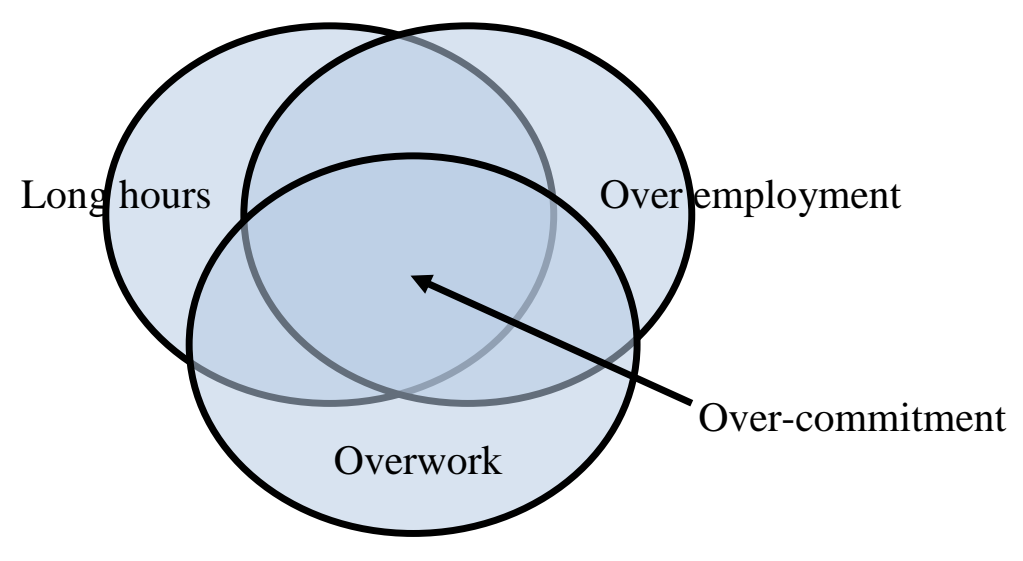

Adapted from Burke, (2006, p. 50)

Longer hours may become embedded if the risks of overwork are discounted or unrecognised and individuals eventually adjust upward their preferred hours to meet hours demanded of them by employers (Burke, 2006). It is when this occurs, in the overlap of the three, that over-commitment arises and the negative consequences surface. Such over-commitment has been used to describe the notion of Workaholism (Seybold and Salomone, 1994). The broadest consensus on the meaning of the Workaholism construct consists of a dimension with a core feature of over-commitment (Spence and Robbins, 1992). A Workaholic is highly committed to work, and devotes almost all of his or her active time to work.

\section{Development of Workaholism}

Theories and the existing empirical literature suggest that the development of Workaholism can be positioned into two areas (Chamberlin and Zhang, 2009): the development of Workaholism being influenced by internal factors (feelings of low selfworth, achievement-related values, Type A personality, obsessive compulsive personality, need for achievement, insecurities, and avoidance of painful feelings); and/or by external factors (stressful family life, vicarious learning, peer competition, and family, social, and organisational messages). Traditional views of work addiction consider the external factor of family of origin and childhood experiences as the source of the development of compulsive behaviours such as work addiction. For example, 
extreme or harsh standards, set by parents, send the message that one is never quite good enough. These harsh and rigid family structures can also lead to the development of anxiety that may be a key to the underlying dynamics leading to work addiction (Andrews and Crino, 1991). Research has demonstrated that Workaholics believe that their parents had high expectations of them (Dougherty, 1989) and that their parent's love is dependent on their success (Machlowitz, 1980). Additionally, the competitive nature of the things around us, such as the educational system, the political system and industrialised cultures further contribute to the development of Workaholism (Fassel, 1990).

Internal factors may also contribute to the development of Workaholism. Personality has been revealed to be a valid predictor of work involvement (Elloy and Terpening, 1992), total hours worked (Bozionelos, 2004) and work-related outcomes (Love and DeArmond, 2007). Personal self-esteem issues are another aspect that acts as an internal factor that may lead to the development of work addiction as the person equates selfworth to performance as part of a compulsive and endless quest of pursuing approval (Machlowitz 1980; Knetchel, 1989; Burke, 2004a). In this case work serves as a function of increasing the Workaholic's self-esteem (Porter, 1996) and provides selfvalidation (Ishiyama and Kitayama, 1994) and personal identity (Trueman, 1995).

$\mathrm{Ng}$ et al. (2007) expanded on this to suggest that Workaholism is largely derived from three sources: dispositional traits or internal factors, socio-cultural experiences or external factors, and behavioural reinforcements (e.g., rewards and punishments in organisations). It may be so that these factors have an influence on the extent of an individuals' Workaholism, but nevertheless, following the definition of Workaholism used in this study as detailed in Chapter 3, a typical work addict is motivated by a strong internal drive that cannot be resisted. This is above any motivation due to external or contextual factors, such as financial problems, poor marriage, organisational culture, supervisory pressure, or a strong desire for career advancement. Workaholics work hard because of inner pressures. Therefore, I tend to disagree that Workaholism is determined by socio-cultural experiences and behavioural reinforcements. The framework depicted 
in Figure 2 shows the development of Workaholism through dispositional or personality traits and the influence of socio-cultural experiences and behavioural reinforcements. In describing Figure 2, socio-cultural experiences and behavioural reinforcements as an influencing factor rather than a core element of Workaholism is clarified.

\section{Figure 2. Antecedents of Workaholism}

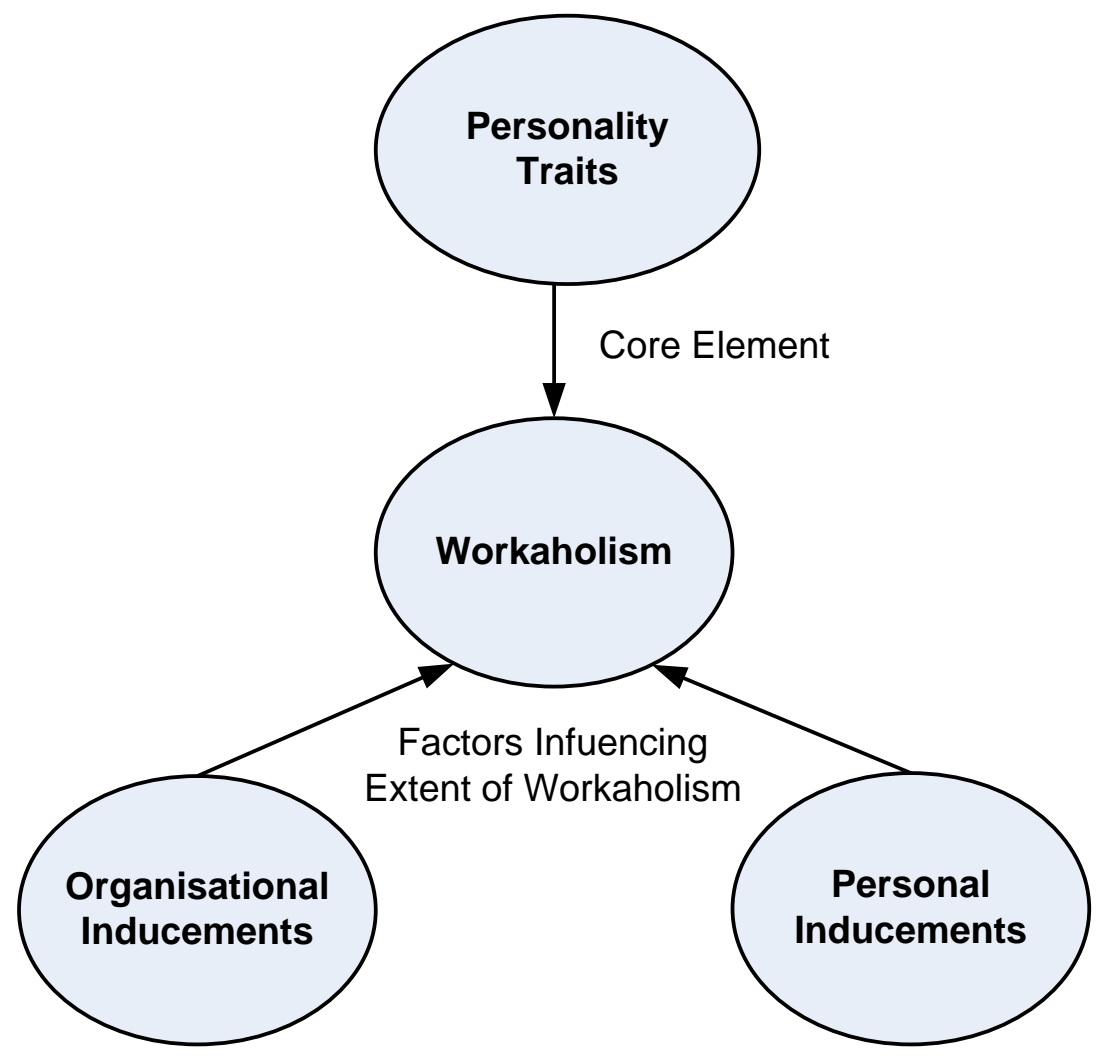

Adapted from Liang and Chu, (2009, p. 650)

Personality traits refer to cognitive and behavioural patterns that are stable over time and across situations (Cattell, 1965). This is the core element driving individuals towards Workaholism. Since personality traits can play a major role in generating addictions (Eysenck, 1997), greater dominance of certain traits promotes addiction and can make people become Workaholics (Ng et al., 2007; Scott et al., 1997). Characteristics such as perfectionism; conscientiousness; obsessive-compulsive personality; and achievementoriented traits can promote Workaholism by predisposing individuals to become more addicted to working, because working long hours is likely be considered the most reliable means of achieving important work goals ( $\mathrm{Ng}$ et al., 2007). For example, the 
type A personality is characterised by ambition, impatience and hostility (Edwards and Baglioni, 1991), and has been linked directly to Workaholism (Ersoy-Kart, 2005). Achievement-oriented workers spend a great deal of time on work activities, constantly think about work, and work beyond employer and economic requirements. This is a key part of the Workaholism definition (Work Involvement) as discussed in the next Chapter. Additionally, people who have certain personality traits - such as being rigid and a perfectionist or born achievers - are more likely to become Workaholics (Goodman, 2006).

The remaining two factors, Organisational and Personal Inducements, influence the extent of Workaholism; they induce individuals to work hard and/or work longer hours. These factors categorise a hard worker rather than a Workaholic. It is the core element of personality traits, such as drive, that differentiate the Workaholic through the addictive nature. Instead personal and organisational inducements influence the extent of Workaholism by providing additional drive. Personal inducements consist of the personal and family-related factors that influence the desire of an individual to work. Liang and Chu (2009) stated that personal inducements are catalysing elements that extend Workaholics. For example, responsible workers have a greater desire to perform well in their work. This can lead to them becoming obsessed by work and allowing their work to interfere with their personal life, which in turn leads to spending more time at work.

Organisational inducements provide the drivers that push an individual on and encourage employees to work harder. Liang and Chu (2009) asserted that the interaction of Workaholic traits and personal and/or organisational inducements will increase the degree of Workaholism. This is the case when individuals receive inducements from their families or workplaces, they become more competitive and their Workaholic traits are aroused more easily, leading to a greater degree of Workaholism. This is because an individual's Workaholism is developed not only by his/her Workaholic traits, but also by the social context in which that person interacts as seen in Figure 2. It is therefore suggested that individuals that possess Workaholism traits are more susceptible to the 
negative impacts of personal and organisational inducements, as they will amplify the individual's Workaholism. For this reason, this study aims to further the knowledge of Workaholism traits.

\section{Summary}

Work is an important function, among other functions, in an otherwise well-balanced life. There are many reasons why individuals may work hard or even work excessively. Organisations may inadvertently act as the "enabler" by encouraging Workaholic behaviour. As a result, the organisation suffers because the Workaholic's disorder impedes innovation, creativity and critical reasoning (Holland, 2008). Kofodimos sees imbalance as placing work before personal life. Organisational pressures contribute to imbalance, along with internal forces such as one's needs, wants and drive. It is evident that the underlying causes of Workaholism, and the resulting behaviours, are varied and complex. Additionally, work-life imbalance has been equated with Workaholism. Workaholics produce worth, make money and achieve success. But, Workaholism is also a cause of stress and a precursor to burnout. The effects of these appear in job performance, work relationships, family relationships and the community (McMillan et al., 2003).

In sum, the origins of work addiction are complex and multi-dimensional. Societal issues such as changing gender roles and the acceptance of work addiction as a positive personal quality create reinforcement and acceptance, especially in the workplace. Accordingly, there is a societal need to distinguish between behaviour representing a healthy work ethic and the destructive pattern of work addiction (Porter, 2004). This distinction will be explored in the next chapter through a discussion of the various definitions/facets of Workaholism. 


\section{Chapter 3: Workaholism}

\section{Introduction}

As established in Chapter 2, there are many antecedent factors to the concept of Workaholism, and this Chapter will further explore the nature of that concept.

Individuals who are continually or regularly overworked can almost be likened to alcoholics and are commonly described as "Workaholics." They invest a considerable amount of time and energy in their work (Harpaz and Snir, 2009). By the term Workaholics, Oates refers to people whose need to work has become so exaggerated that it may constitute a danger to their health, personal happiness, interpersonal relationships, and social functioning (Oates, 1971). Workaholism has become a widely used term, in both the press and everyday speech. Workaholism is known as a process addiction. A process addiction is an addiction to certain behaviours or processes that alter mood and brain chemistry by the process of engaging in an activity. It is a recurring compulsion or obsession by an individual. It is not the same as working hard or putting in long hours. In general, Workaholics are considered to be overly concerned with their work, and tend to neglect other areas of their lives, such as their families (Persuad, 2004). Mudrack and Naughton say "Workaholics work more and invest more energy in work than is absolutely required." (Mudrack and Naughton, 2001. p. 108)

Porter (2001) highlighted the importance of further knowledge of Workaholism by pointing out that there is a tendency for organisations to take high work involvement at face value - the Workaholic is generally rewarded for spending more hours on the job than those who find more efficient ways to accomplish the job - but in fact Workaholics can have a negative impact on the organisation. For example, health complaints appear to be consistently and positively related to drive in all samples and countries studied (Burke, 1999b; Spence and Robbins, 1992). Therefore, Workaholics particularly high in drive seem to suffer increased health problems, while enjoyment may be a protective factor that buffers the influence of drive. The impact on organisational productivity, 
profitability and public health are factors that need to be clearly understood and cannot be ignored.

As cited in Langan-Fox et al. (2007), Burke and McAteer (2007), pointed out that it had been assumed that advances in technology and flexible work schedules lead to a reduction in hours worked. However, developments in technology allow people to stay in constant contact with the workplace, making it possible for people to carry their work and the work environment with them into their homes, on vacation, and public places that previously provided a barrier between work and other activities (Porter, 2001). Furthermore, working time varies by gender, race, occupation, and time period. In New Zealand for example, the average hours worked is one of the highest in the World (OECD Statistics Extract). Additionally there has been a rise in hours worked and overtime due to increased responsibilities and heavier workloads, thereby leading to higher levels of stress. This suggests that the issue of Workaholism may be very important in New Zealand, providing a basis for this study to take place in this country.

This review of literature germane to Workaholism is interesting and revealing. In discussing relevant aspects identified in the literature, the foundation will be laid out for this study into the impact of gender on the Workaholism characteristics exhibited by individuals, specifically those working in academic institutions in New Zealand. This serves to highlight the value of this study.

\section{Views of Workaholism}

Literature concerning Workaholism has a common trend in that it consists of opposing views of whether Workaholism is a positive or a negative phenomenon. Some researchers portray Workaholism as a beneficial quality. For example, Furnham (1997) stated that, "unlike other forms of addiction, Workaholism is frequently spoken well of, praised, expected, and even demanded" (p. 220). Additionally, Machlowitz (1980) conducted a qualitative study of 100 Workaholics, finding them to be very satisfied and productive. It is important to note, however, that her sample was biased towards 
successful executives and not likely representative of professionals and managers in general (Burke, 2004).

The majority of literature leans toward the negative position (Fassel, 1992; Killinger, 1992; Oates, 1971). In this literature Workaholism is equated with other addictions and Workaholics are viewed as unhappy, obsessive figures, who are not performing well in their jobs and are creating difficulties for their co-workers (Naughton, 1987; Oates, 1971; Porter, 1996). Some researchers (Naughton, 1987) have speculated that Workaholic behaviours may limit job performance. For example, an employee highly involved in work, or obsessed with details, may not be productive. Rather, by creating busy work, completing simple projects, or creating crisis to provide opportunities to work harder, Workaholics are likely to hinder performance. In addition, undertaking a high volume of work may influence the quality of contributions (Burke, 2000a). Therefore, Workaholism can be viewed as both a complex and negative process that eventually affects a person's ability to function properly (Killinger, 1992).

Even with the contrary views of Workaholism, the need to better understand Workaholism is evident. Korn, Pratt, and Lambrou (1987) believed that positive Workaholic behavioural patterns may be acquired through training. It may also be possible to reduce the negative effects of Workaholism, particularly health consequences, through stress management training (Korn et al., 1987). This provides yet another reason why more information on Workaholism is essential, in order to tailor interventions to provide the best outcomes.

\section{Definition}

Workaholism has become a popular term referring to people who work hard and for many hours. However, considering Workaholism exclusively in terms of the number of working hours is misleading as it excludes the addictive nature. Despite general warnings about the potential negative consequences of long hours (Harrington, 1994; Sparks et al, 1997), the relationship between working hours and a variety of indicators of personal wellbeing remains unclear (Cooper, 1996; Sparks et al, 1997). This 
highlights the importance of not considering Workaholism exclusively in terms of the number of working hours. From a more conceptual point, Scott et al (1997) did this when claiming that work involvement, as a psychological state or attitude (discussed later in this chapter), cannot simply be expressed in terms of the number of hours worked. Another definition is that of Barbara Killinger:

"Workaholism is a soul destroying addiction that changes people's personalities and the values they live by. It distorts the reality of each family member, threatens family security and often leads to family break-up."(Burke, 2006, p. 61)

Workaholism is generally understood to involve an unwillingness to disengage from work. The most noticeable characteristics exhibited by Workaholics are tendencies to work with passion that is obvious to the observer; think about work four times more frequently than non-Workaholics; focus their conversation on work, even in social situations; strive for tangible achievements in the workplace; and work slightly more hours than others (McMillan et al., 2004). Barbara Killinger continues her definition to state that a Workaholic is:

“A work-obsessed individual who has gradually become emotionally crippled and addicted to power and control. Caught up in a compulsive drive to gain personal approval and public recognition of their success, these driven men and women live a gerbil-wheel, adrenalin-pumping existence rushing from point A to point B fixated on the next desired goal or accomplishment. Eventually, nothing or no one else really matters." (Burke, 2006, p. 61)

This definition demonstrates how a Workaholic may differ from a hard worker. A hard worker remains emotionally there for all family members and friends and manages to maintain a healthy work-life balance. Workaholics are obsessed with their job performance, bent on self-aggrandisement and are constantly moving onto more ambitious goals. They must do things their way and refuse to delegate because 'others will not do a good a job' (Burke, 2006). Additionally, it is viewed that Workaholism is 
merely one of the subtypes of heavy work investment (Harpaz and Snir, 2009). Harpaz and Snir (2009), suggested that heavy work investment has two core dimensions; time and effort. Additionally they suggest that there are various types of heavy work investment. Further, they distinguish between two major types of heavy work investment. The first is situational, stemming from external and uncontrollable predictors. External predictors such as basic financial needs (e.g., to support one's family, pay debts), and demanding supervisors or organisational culture are uncontrollable, at least in the short term. This subtype (situational work investment) is unrelated to Workaholism and is not an indication of Workaholism. The second major type of heavy work investment is dispositional. This stems from personal characteristics. Harpaz and Snir (2009) further distinguished between subtypes of dispositional heavy work investment; Workaholism, which is based on an addiction to work (an internal, negative, uncontrollable, and stable predictor); and work devotion as an expression of a passion to work (an internal, positive, controllable, and stable predictor). It can be said, therefore, that this study focuses on only a subtype of heavy work investment with low work enjoyment. This is done due to the significant negative consequences of this one subtype as detailed further in this study.

Looking back at long hours, overemployment and overwork as described in the previous chapter (Antecendents of Workaholism), the development of a Workaholic individual can be explained. Long hours is a principal component of heavy work investment. Overemployment refers to being employed beyond one's preferred work hours. It eventually leads to overwork. There is much overlap of overwork and overemployment (see Figure 3), but also some independence as overworkers are considered to be individuals who work to excess not because of the perceived returns from the organisation, rather despite a perceived lack of returns. For example, an individual may choose to work beyond their endurance and recuperative capacitates, and are therefore not overemployed. Scott, Moore, and Miceli (1997) found that these three characteristics (long hours, overemployment and overwork) are, in fact, common characteristics of Workaholism that feature across many definitions. First, Workaholics spend a great deal of time on work activities when given the discretion to do so. They are excessively hard 
workers (Long hours). Second, Workaholics are reluctant to disengage from work, and they persistently and frequently think about work when they are not at work. This suggests that Workaholics are obsessed with their work-they are compulsive workers (Overemployed). The third common feature of Workaholics is that they work beyond what is reasonably expected from them to meet requirements, organisational or economic, beyond their endurance and recuperative capacities (Overwork).

Table 1, seen below, shows a summary of the major Workaholism definitions. The majority of these definitions of Workaholism have been generated deductively and investigated using quantitative frameworks as done in this study. While there have been many definitions, Oates is credited with the first, both by his own writings and by the Oxford English Dictionary. He states that Workaholism is a word which he invented and means an addiction to work, the compulsion or the uncontrollable need to work incessantly (Oates, 1971). He referred to people whose need to work has become so exaggerated that it may constitute a danger to their health, personal happiness, interpersonal relationships, and social functioning (Oates, 1971). Oates' (1968) writing provided a basis for much of the later work in this field. His work, though, was rooted in personal conjecture rather than empirical data. In 1980, Malchlowitz published the first empirically based research on Workaholism. In this, Workaholism was conceptualised as a trait that consisted of an intrinsic desire to work long and hard, beyond job prescriptions and earned responsibility, opportunity and recognition (Malcholwitz, 1980). This work emphasised that Workaholics' attitudes towards work, rather than the actual number of hours worked, differentiated them from healthy workers. The results of this work (Workaholics reported satisfaction and no more difficulties than other workers) though, contradicted the popular stereotype of the day. For this reason Machlowitz's work remains one of the only qualitative studies in the field. 
Table 1. Summary of major Workaholism definitions, 1968- 2004

\begin{tabular}{|c|c|c|c|c|}
\hline Author & Year & Method & Criteria & $\begin{array}{l}\text { Underlying } \\
\text { Framework }\end{array}$ \\
\hline Oates & 1968 & $\begin{array}{l}\text { Qualitative } \\
\text { Anecdotal } \\
\text { Introspective } \\
\text { Generically } \\
\text { inductive }\end{array}$ & $\begin{array}{l}\text { 1. Excessive need for work } \\
\text { 2. Disrupted health, } \\
\text { happiness, relationships } \\
\text { 3. Withdrawal-takes work } \\
\text { home } \\
\text { 4. Works outside work time } \\
\text { and conceals it } \\
\text { 5. Starts early and needs less } \\
\text { sleep than others } \\
\text { 6. Works weekends or } 2 \text { jobs }\end{array}$ & $\begin{array}{l}\text { Pathological } \\
\text { Addiction } \\
\text { theory }\end{array}$ \\
\hline Machlowitz & 1980 & $\begin{array}{l}\text { Qualitative } \\
\text { Inductive }\end{array}$ & $\begin{array}{l}\text { 1. Intrinsic desire to work } \\
\text { long and hard } \\
\text { 2. Work exceeds others' } \\
\text { expectations } \\
\text { 3. Intense, energetic, } \\
\text { competitive, driven } \\
\text { 4. Strong self-doubts, needs } \\
\text { reassurance } \\
\text { 5. Prefers labour to leisure } \\
\text { 6. Works anywhere, anytime } \\
\text { 7. Maximises time usage } \\
\text { 8. Blurs business and } \\
\text { pleasure }\end{array}$ & $\begin{array}{l}\text { Strengths- } \\
\text { based }\end{array}$ \\
\hline Robinson & 1989 & $\begin{array}{l}\text { Qualitative } \\
\text { Deductive } \\
\text { Anecdotal }\end{array}$ & $\begin{array}{l}\text { 1. Overdoing/hurrying/binges } \\
\text { 2. Low self-worth/ignore } \\
\text { personal needs } \\
\text { 3. Control/perfectionism } \\
\text { 4. Intimacy difficulties } \\
\text { 5. } \text { Mental preoccupation }\end{array}$ & $\begin{array}{l}\text { Pathological } \\
\text { Addiction } \\
\text { theory }\end{array}$ \\
\hline Fassel & 1992 & $\begin{array}{l}\text { Qualitative } \\
\text { Anecdotal } \\
\text { Clinical } \\
\text { interviews }\end{array}$ & $\begin{array}{ll}\text { 1. } & \text { Multiple addictions } \\
\text { 2. } & \text { Denial } \\
\text { 3. } & \text { Self-esteem problems } \\
\text { 4. } & \text { External referencing } \\
\text { 5. } & \text { Ability to relax } \\
\text { 6. } & \text { Obsessiveness } \\
\end{array}$ & $\begin{array}{l}\text { Pathological } \\
\text { Addiction } \\
\text { theory }\end{array}$ \\
\hline $\begin{array}{l}\text { Spence and } \\
\text { Robbins }\end{array}$ & 1992 & $\begin{array}{c}\text { Qualitative } \\
\text { Deductive } \\
\text { Cluster analyses } \\
\end{array}$ & $\begin{array}{ll}\text { 1. } & \text { Work involvement } \\
\text { 2. } & \text { Drive } \\
\text { 3. } & \text { Enjoyment } \\
\end{array}$ & $\begin{array}{l}\text { Observable } \\
\text { Behavioural }\end{array}$ \\
\hline Clark et al. & 1993 & $\begin{array}{l}\text { Qualitative } \\
\text { Deductive } \\
\text { Conceptual } \\
\text { sorting }\end{array}$ & $\begin{array}{l}\text { 1. } \begin{array}{l}\text { Personality factor }= \\
\text { conscientiousness }\end{array} \\
\text { 2. } \begin{array}{l}\text { Personality trait }= \\
\text { obsessive-compulsive }\end{array} \\
\text { 3. } \begin{array}{l}\text { Style = perfectionism, } \\
\text { compulsion, energy }\end{array}\end{array}$ & $\begin{array}{l}\text { Personality } \\
\text { theory Clinical } \\
\text { psycho- } \\
\text { pathology }\end{array}$ \\
\hline
\end{tabular}


Table 1. (Continued)

\begin{tabular}{|c|c|c|c|c|}
\hline Scott et al. & 1997 & $\begin{array}{l}\text { Qualitative } \\
\text { Deductive }\end{array}$ & $\begin{array}{l}\text { 1. Discretionary time } \\
\text { spent working } \\
\text { 2. Thinking about wok } \\
\text { when not at work } \\
\text { 3. Working beyond } \\
\text { requirements }\end{array}$ & $\begin{array}{l}\text { Observable } \\
\text { Behavioural }\end{array}$ \\
\hline McMillan et al. & 2002 & $\begin{array}{c}\text { Qualitative } \\
\text { Deductive } \\
\text { Confirmatory } \\
\text { factor analyses }\end{array}$ & $\begin{array}{ll}\text { 1. } & \text { Reluctance to } \\
\text { disengaged from work } \\
\text { 2. Enjoyment } \\
\text { 3. Drive } \\
\text { 4. Work or think about } \\
\text { work } \\
\text { 5. Work anytime or } \\
\text { anywhere }\end{array}$ & $\begin{array}{l}\text { Observable } \\
\text { Behavioural }\end{array}$ \\
\hline Snir and Harpaz & 2004 & Deductive & $\begin{array}{ll}\text { 1. } & \text { Behavioural and } \\
\text { cognitive elements } \\
\text { 2. Steady/stable trait } \\
\text { 3. Not externally } \\
\text { imposed } \\
\text { 4. Not solely } \\
\text { attitudes/values/beliefs }\end{array}$ & $\begin{array}{l}\text { Observable } \\
\text { Behavioural }\end{array}$ \\
\hline
\end{tabular}

(Burke, R.J. (2006), Research Companion to Working Time and Work Addiction, Great Britain, Edward Elgar Publishing, p. 93)

Robinson provided the next influential study of Workaholism. His definition was developed using an addiction paradigm, where the symptoms of addiction were overlaid onto work specific behaviour. The Robinson definition comprises of five aspects; overdoing (hurrying/binges); self-worth (productivity at expense of personal needs); control (perfectionism); intimacy (relationship difficulties/impatience); and mental preoccupation (difficulty relaxing). Robinson (2007, p. 7) defined Workaholism as "an obsessive-compulsive disorder that manifests itself through self-imposed demands, an inability to regulate work habits, and an overindulgence in work to the exclusion of most other life activities."

Fassel (1992) approached Workaholism from an organisational consulting perspective. Fassel defined Workaholism as comprising of six characteristics; multiple addictions; denial; self-esteem problems; external referencing; inability to relax; and obsessiveness. This was based on anecdotal data from organisational clients and Workaholic 
Anonymous groups, although no formal research or data analysis was undertaken. The lack of scientific analysis means that this definition remains speculative.

Spence and Robbins' (1992) provided the next definition. Their deductively based framework was based on a review of theory and literature that was used to produce a model of Workaholism. This was subsequently tested on homogenous samples of students and social workers. Workaholism was defined as a stable trait that involves; a high degree of commitment to work; a good deal of time spent working; and a compulsion to work even when it is not necessary (Spence and Robbins, 1992). Their writings and definition are covered in more detail later in his Chapter as they provide a basis for the definition used in this study which was developed through this review of theory and literature. Clark et al. (1993) used a deductive method based on personality theory and psychometric paradigms to develop and test a model of Non-adaptive and Adaptive personality. Workaholism was classified as most closely associated to the "big five' personality trait of conscientiousness, and fell into the subcategory of obsessive compulsiveness, involving perfectionism, compulsion and high energy (Burke, 2006). Scott et al. (1997) suggested a definition of Workaholism that consists of three components; discretionary time spent working; thinking about work when not at work; and working beyond requirements.

At the turn of the century, McMillan et al. (2002) concurrently tested the Spence and Robbins (1992) and the Clark et al. (1996) definitions of Workaholism. In 2004 they then defined Workaholism, on the basis of several deductive, data based studies, as comprising of five elements; reluctance to disengage from work; enjoyment; drive; work or think about work; and work anytime or anywhere. This is believed to contribute/lead to a number of health problems (McMillan et al., 2004). The authors note that it might be that low enjoyment in work is the critical factor that leads to poor health outcomes, as many studies reporting poor health outcomes for Workaholics conceptualised Workaholism as comprising low enjoyment. Around the same time Mudrack and Naughton (2001) developed a behaviour based definition of Workaholism comprising of two elements; non-required work; and attempts to control others. This later criterion is a 
new concept in Workaholism research and still at the preliminary stages of testing. For this reason it has been excluded from the definition used in this study. Mudrack and Naughton (2001) also suggested that the tendency to work or think about work is actually the essence of Workaholism, while Enjoyment and Drive are merely antecedents that trigger the Workaholic behaviour.

More recently Snir and Harpaz (2004) proposed that any definition of Workaholism should reflect that it is a steady state that involves considerable allocation of time to work-related activities and work-related thoughts that are not derived from external necessity. This definition shares a considerable overlap with the McMillan et al. and the Scott et al. definitions. This also underpins the Spence and Robbins (1992) definition and, in view of that fact, the definition used in this study as discussed in Chapter 5.

\section{Conceptualisation}

Various conceptualisations and definitions of Workaholism have been proposed. At the heart of these definitions lies the idea that Workaholics are people who work excessively hard. This agrees with the popular definition of Workaholism (Burke, 2001a). Regardless, there is still little accord on an operational definition concerning Workaholism (Porter, 1996). Spence and Robbins (1992) pointed out that, even though this is the case, there is little consensus on the definition of the term beyond its core feature of heavy investment in work. Until 1990, the majority of the research on Workaholism was anecdotal, atheoretical, and non-empirical (Burke, 2004). Without having an operationally sound definition, there is no way of truly classifying Workaholism.

Spence and Robbins (1992) noted that the motivation for working long and hard may differ across persons; it might result from a strong inner drive — which is considered the root cause of Workaholism - but also from external, contextual factors such as financial problems, a poor marriage, the organisational culture, or a strong desire for career advancement (Holland, 2008). Thus, simple measures of Workaholism in terms of the number of hours people spend on their work are conceptually flawed. Current 
conceptualisations therefore also include the motivation for working excessively hard and long. A typical work addict is motivated by a strong internal drive that cannot be resisted. This is above any motivation due to external or contextual factors, such as financial problems, poor marriage, organisational culture, supervisory pressure, or a strong desire for career advancement. Workaholics work hard because of inner pressures, very often with an aspect of perfectionism. Not responding to these addictive pressures makes the Workaholic feel guilty about not working (McMillan et al, 2002). As overcommitment is considered one dimension of Workaholism, most authors emphasise the addictive aspect of Workaholism as a second dimension. These authors describe Workaholics as feeling an internal drive (Spence and Robbins, 1992).

Scott et al.'s (1997) conceptualisation suggested that Workaholism is an all encompassing phenomenon that has implications for both the work and the non work domain. Previous research has shown that Workaholics spend more time on their work than others (McMillan, Brady, O’Driscoll, and Marsh, 2002; Scott et al., 1997). Workaholics may even create more work for themselves by making simple projects more complicated than necessary, or by causing crises for the fun of working on the problems resulting from these (Machlowitz, 1980). This suggests that Workaholics work longer and harder than others not because their jobs require them to do so, but because they tend to create high job demands for themselves.

Porter (1996) defined Workaholism as excessive Work Involvement while neglecting other areas of life due to an internal motivation. Scott, Moore, and Miceli (1997) supported this. They asserted that Workaholics spend a great deal of time on work activities (even at the cost of sacrificing time for non-work activities), constantly think about work when they are not working, and work beyond organisational requirements. However, even with the recent attempts to define Workaholism, there is still little consistency found in the different typologies ( $\mathrm{Ng}$, Sorensen, and Feldman, 2006).

Other definitions include that of Robinson and Post (1994), who defined Workaholism as the "overindulgence in and preoccupation with work, often to the exclusion and 
detriment of the Workaholic's health, intimate relationships, and participation in child rearing" (p. 517). Using this definition Robinson and colleagues developed the Work Addiction Risk Test (WART). It consists of 25 items drawn from a list of symptoms reported by clinicians who diagnose Workaholism (Taris, Schaufeli, and Verhoeven, 2005). These items cover five dimensions: Compulsive Tendencies (working hard and having difficulties relaxing after work); Control (referring to annoyance when having to wait for something/someone, or when things to do not go their way); Impaired Communication and Self-Absorption (putting more energy into one's work than into relationships with others); Inability to Delegate; and Self-Worth (concerned with the degree to which one is interested in the results of one's work rather than the work process itself).

Flowers and Robinson (2002) found that the WART's five dimensions were not fully supported. It was the Spence and Robbins (1992) definition that was the first empirically-based definition of Workaholism and their measure was described in sufficient detail to assess reliability and validity issues. They suggested the topic needs more systematic investigation and so created the Workaholism typology and proposed an explicit definition of Workaholism. This definition has now become widely accepted among researchers in this field (Porter, 1996; Burke, 1999b; Burke et al., 2008). For this reason, I will use the Spence and Robbins (1992) definition of Workaholism - the 'Workaholism triad' as detailed below.

Spence and Robbins (1992) defined a Workaholic as "a person who exhibits three properties: In comparison to others, the Workaholic is highly work involved, feels compelled or driven to work because of inner pressures, and is low in work enjoyment" (p. 162). Work Involvement is the degree to which a person is constructive in using his or her time (both on and off the job), and how committed the individual is to being productive at work. It is a generalised attitude of psychological environment with work. Work drive is a reflection of the person's internal motivation to work. It is the inner pressure to work maintained by internal fulfilment rather than external pressure (Spence 
and Robbins, 1992). Work Enjoyment is the extent to which the person gains a sense of emotional satisfaction or pleasure derived from work.

Further, Spence and Robins identified and labelled six respondent types based on the Workaholism triad. These worker types are based upon various combinations, using medians, on three scales (see Table 2). Each of the six types are characterised by different levels of perfectionism, delegation, job stress, time allocation at work, job involvement, working hours, physical problems, sickness, and performance at work.

Table 2. Spence and Robbins' Classification of Worker Types

\begin{tabular}{llll}
\hline Worker Type & Driven to Work & Work Involvement & Work Enjoyment \\
\hline Positively Engaged Worker & High & High & High \\
Workaholic & High & High & Low \\
Unengaged Worker & Low & Low & Low \\
Work Enthusiast & Low & High & High \\
Relaxed Worker & Low & Low & High \\
Disenchanted Worker & Low & High & Low
\end{tabular}

(Aziz, S. and Zickar, M.J. (2006), "A cluster analysis investigation of Workaholism as a syndrome", Journal of Occupational Health Psychology, Vol. 11, p. 53)

Positively Engaged Workers score high on each of the components and are considered to be healthy in their working behaviour. Work Engagement refers to a positive, fulfilling, work-related attitude that is characterised by vigour, dedication, and absorption (Schaufeli, Salanova, Roma, and Bakker, 2002). They propose that vigour is characterised by high levels of energy, the willingness to invest effort in one's work, and persistence in the face of difficulties. Dedication refers to being strongly involved in one's work, while experiencing the feeling of significance, enthusiasm, inspiration, pride, and challenge. Absorption refers to the state of being fully concentrated and engrossed in one's work, whereby time passes quickly and it becomes difficult to detach from work. Thus engaged employees work hard, feel strong and vigorous at work, are enthusiastic and optimistic about the work they do and are involved in their work, feeling engrossed. 
Workaholics score high on Work Involvement and Drive to work and low on Work Enjoyment. Alternatively, scoring low on all three worker types describes the Unengaged Worker, who is unmotivated by money, uncommitted to work, lacking in loyalty, unhappy with the work challenge, but not dissatisfied and without a high intention to leave (Buelens and Poelmans, 2004).

Work Enthusiasts score high on Work Involvement and Work Enjoyment, while scoring low on Drive to work. A Work Enthusiast is a person who is highly involved in work, but, unlike the Workaholic, highly enjoys their work rather than being driven to work. This is to say they lack the typical compulsive drive of Workaholics. Work enthusiasts find work fun rather than addictive. They work hard because they have the intrinsic motivation from liking their job instead of the obsessive inner drive of a Workaholic. Therefore their motivation to work is fundamentally different. This agreed with Harpaz and Snir's (2009) theory that work devotion is a separate subtype of worker to a Workaholic where individuals express a passion to work (are Work Involved but also have high Work Enjoyment).

The Relaxed Worker type score low on Work Involvement and Drive to work, while scoring high on Work Enjoyment. They do not perceive much pressure at work; they enjoy the challenges presented, but are not highly involved. They are also found to report the greatest amount of time devoted to non-work activities (Buelens and Poelmans, 2004). Finally, the Disenchanted Worker, scoring low on Work Enjoyment and Drive to work, while scoring high on Work Involvement, has been found to be completely alienated, completely dissatisfied, and has a strong intention to leave (Buelens and Poelmans, 2004).

I agree with this definition in that it excludes "positive Workaholism." "Positive Workaholism" constitutes a distinct psychological phenomenon: Work Engagement, which I believe to be separate and distinct in itself. In my view, Workaholism and Work Engagement share the behavioural component (working excessively hard), but the underlying motivation differs fundamentally. Workaholics are propelled by an obsessive 
inner drive they cannot resist, whereas engaged workers are intrinsically motivated (Schaufeli et al., 2009). The latter work hard because of the pleasure they get from the work itself - work is fun. In other words, Workaholics are being pushed toward work, whereas engaged workers are being pulled toward it (Schaufeli et al., 2009). For this reason Workaholics have low Work Enjoyment as opposed to Engaged Workers who have high enjoyment as defined by Spence and Robbins (1992). Additionally, I agree with Porter (2001, p. 151), "Joy in work is not a part of Workaholism viewed as an addiction." Thus, Work Engagement is considered as a distinct psychological phenomenon separate from Workaholism. Moreover, it seems that the drive component makes the difference as it is negatively related to work outcomes, quality of social relationships, and perceived health (Schaufeli, Taris, and Van Rhenen, 2008). Conversely Work Engagement is positively related with these variables (Schaufeli, Taris, and Van Rhenen, 2008). Hence, for the sake of conceptual clarity, instead of discriminating between "good" and "bad" forms of Workaholism, this study differentiates Workaholism (being intrinsically bad) and Work Engagement (being intrinsically good). Work Engagement is a notion that has developed as the equivalent of a "good" Workaholic (Maslach et al., 2001; Schaufeli et al., 2002a), a hyperperforming Workaholic (Korn et al., 1987), happy Workaholics (Keichel, 1989), happy hard workers (Buelens and Poelmans, 2004) and Work Enthusiasts (Spence and Robbins, 1992). In doing this the conflicting views in the literature concerning whether Workaholism is a positive or a negative phenomenon are addressed. For example, where Machlowitz (1980) found Workaholics to be very satisfied and productive, participants would be considered to be Work Enthusiasts rather than Workaholics. I believe it is important not to consider different psychological phenomenon under the sample rubric so to prevent obscuring differences, creating conceptual confusion and obstruction of empirical research, as suggested by Schaufeli et al. (in Burke, 2006).

A syndrome is defined by the Oxford English Dictionary as "a concurrence of several symptoms in a disease; a set of such concurrent symptoms." As Aziz and Zickar noted, if Workaholism is a syndrome, each of the three components (high work involvement, high drive, and low work enjoyment) as defined by Spence and Robbins would be 
necessary. The authors also showed that Workaholics experience more work-life imbalance and less life satisfaction than non-Workaholics (Aziz and Zickar, 2006).

It is a combination of high-drive/low-enjoyment that is problematic (the Workaholic respondent type) rather than being high or low on either individual aspect (Spence and Robbins, 1992). It is therefore important that there are more comprehensive studies of Workaholism in organisations. This study addresses the characteristics of Workaholism exhibited by employees and will provide information on gender tendencies, which has the potential to assist individuals, institutions and educational policy-makers in addressing the issue of Workaholism in academics. It is important to know which characteristics are exhibited as, particular characteristics can lead to the negative side affects whereas others lead to positive outcomes. Since the development of this widely accepted definition, the importance of the study of Workaholism has been highlighted by many researchers. Hence, as mentioned in the introduction, I define Workaholism as the tendency towards heavy work investment and involvement (the behavioural dimension) and the combination of high-drive with low-enjoyment (the cognitive dimension), which manifests itself in working compulsively; being obsessed with work. Again, this definition corresponds with the most recent analysis of scholarly definitions which conclude that hard work at the expense of other important life roles and a strong internal drive to work are two key aspects of Workaholism (Ng et al., 2007).

\section{Consequences of Workaholism in the Workplace}

"On the surface, this person might be identified as having a very strong work ethic and as being of great value to the company. Below the surface impression, this is not a person enjoying optimal mental-health (well-being on and off the job), and the addictive pattern has repercussions that must be considered." (Porter, 2004. p. 435)

Many studies have shown the detrimental effects of Workaholism (Burke, 2000c; Kanai et al., 1996; McMillan et al., 2001; Spence and Robbins, 1992) - not only to the Workaholic individual, but also to the organisation as a whole. 


\section{Personal Costs}

It has been shown that it is not uncommon for Workaholics to have major health problems, including stress-induced illnesses, chronic fatigue, and increased anxiety levels (Caproni, 1997). According to Greenberg (1987), this is in part because work addicts are notorious for missing sleep and failing to obtain proper nutrition leading to intermittent and chronic insomnia and fatigue. Aziz and Zickar's (2006) findings supported this notion, stating that Workaholism is a health-related syndrome as it was found to correlate with such variables as work stress and work life imbalance.

Workaholics spend an excess amount of time on their work, suggesting that they have insufficient opportunity to recover from their excessive efforts (Schaufeli et al., 2009), leaving them emotionally or cognitively exhausted over time (Taris et al., 2005). Porter (1996) reflected that work addicts rarely notice their complete immersion in work. They therefore ignore the effects on personal health. Consequently, Workaholics report comparatively high levels of psychological distress and physical complaints (Schaufeli et al., 2008; Taris et al., 2005; Burke 1999a; 2000a; Burke et al., 2004; Kanai et al., 1996; McMillan et al., 2003). McMillan and O’Driscoll (2004) supported this in reporting poorer social and role functioning among Workaholics.

Robinson (1989) stated that additional emotional costs include lack of self-esteem, frustration, feeling trapped, a negative life view, a lack of humour, social isolation or withdrawal, self-absorption and mood swings. The results of Workaholism are a negative impact on relationships, health damage and financial problems (Hanson, 1985). The toll of work addiction on interpersonal relationships can be considerable. Divorce, social life disruption and family alienation are some of the potential risks. Unfortunately, too often the people who live with work addicts pay the highest price for this compulsive lifestyle (Machlowitz, 1980). Moreover, according to Greenberg (1987), the Workaholic rarely notices the harm to the family and continues to disappoint them time and time again. Not surprisingly, the divorce rate for work addicts is approximately $40 \%$ higher than the rest of the population (Reeves, 2005). 


\section{Organisational Costs}

Besides ill-health and life satisfaction, another relevant outcome associated with Workaholism is job performance. Schaufeli et al., (2006) argued that Workaholics work hard rather than smart; they create difficulties for themselves and their co-workers, suffer from perfectionism, are rigid and inflexible, and do not delegate. This can have negative consequences for the organisation. It has been stated that the Workaholic suffers from an ever-decreasing level of self-management that not only harms individual careers but eventually also harms the organisation. Hanson (1985) asserted that this is due to several features associated with the Workaholic. These are; reduced actual productivity; poor morale (of the Workaholic and its effect on co-workers); poor judgment; increased errors (including safety risks); increased medical costs; absenteeism; lost productivity; and the impact of eventual burnout. Moreover, given that Workaholics often suffer from insomnia, fatigue, and even sleep deprivation (Greenberg, 1987) the potential harm to the individual and organisation can be significant. Harrison and Horne (2000) detailed that decision-making, critical thinking and creative abilities are significantly impacted by fatigue. Other areas negatively affected include memory, communication skills, judgment and the ability to work collegially with others. These effects are often overlooked but are significant side effects of Workaholism.

Additionally, since Workaholics work hard due to an obsessive inner drive, rather than because they like the job, they tend to report low levels of job satisfaction (Burke 1999a). As previous studies have revealed (Taris et al., 2005; Burke, 1999c; Bakker et al., 2009; Robinson et al., 2001), the tendency of Workaholics to invest much time and effort in their work leads to Workaholics reporting low family satisfaction, poor relationship quality with partners, and high work-family conflict. Workaholism therefore comes at the expense of other important life roles and is also likely to lead to impaired family functioning (Ng et al., 2007).

Workaholics are prone to rigid thinking; they are not able to be flexible in their ideas (Porter, 2004). This results in perfectionist attitudes that exceed simple upholding of high standards. Employees who report to a Workaholic will be persistently frustrated by 
the unfeasible tasks set before them. The Workaholic then interprets this as indication that no one else is able or willing to do the job the right way. This provides the Workaholic a convenient excuse to reassume all responsibility, increasing their workload (Porter, 2004). The inability to delegate is contrary to developing others in the organisation, limiting the potential for future organisational success. The Workaholic is also a poor team contributor as they take on more work, inhibiting team interaction to the extent that several other people are only able to do half of what they would like. This leads to the net team accomplishment being lower than it could otherwise be. Although this occurs, the Workaholic is still viewed as and rewarded for being the star performer. (Porter, 2004).

Workaholics are driven to be in control. This may include control of the work, control of the flow of work, or control of other people. Additionally, by taking over critical job tasks, the Workaholic can be in control of information that others need (Porter, 2004). This contrived centrality feeds the Workaholic's self-esteem, but it hinders others and may allow problems to develop that would otherwise have been avoided. An atmosphere of distrust can form around a Workaholic because of information hoarding and other control tactics. This damages both efficiency and the responsiveness needed today to remain competitive.

The Workaholic may also artificially create crises which need them to step in to resolve. Resolution provides another opportunity for the Workaholic to feed their esteem (Porter, 2004). The levels of stress are higher than they would otherwise be due to the crisis creation and impossible standards. Other workers often face a choice between joining in the Workaholic pattern and expending extra effort to circumvent the Workaholic individual (Porter, 2004). This can lead to entire organisations assuming the addictive pattern (Schaef and Fassel, 1988).

Furthermore, Workaholics tend to trade off the organisation's goal to support their addiction. They meet specified objectives when those outcomes support their addiction as well as serve the organisation's goal. When deadlines are missed or goals not met, 
Workaholics are especially adept at providing reasons why, in spite of their efforts, other people or conditions impeded their achievement. It is always clear that the Workaholic is putting in more hours than others, so these excuses may be acknowledged as truth, further harming morale among other co-workers (Porter, 2004).

Additionally, a study by Burke (2001b) revealed no evidence that Workaholics perform especially well, in that there was no relationship between salary increases and career satisfaction on the one hand and Workaholic behaviours on the other hand. Thus, it appears that Workaholics might be working harder than others without receiving more "rewards" for their efforts. This is contingent with the idea that Workaholics are motivated by a strong inner drive rather than by external motivators.

There may also be indirect effects on the organisation. A Workaholic's interactions with fellow employees influence the workplace environment, which in turn has immediate as well as long-term effects (Porter, 1996). Co-workers may learn of the Workaholic's less productive work style and then actively decrease working with the Workaholic. As a result, Workaholics tend to work more independently, which leads them to believe they are indispensable to the organisation. This Workaholic behaviour could cause the deterioration of gains from collaborative work, diminishing the effectiveness of the overall organisation (Porter, 1996). In terms of other consequences to the organisation, stress reactions and possible burnout may be imminent through a decline in individual performance, increases in health related expenses, or higher turnover rates (Homer, 1985; Maslach and Jackson, 1981).

In sum, the Workaholics add costs to the organisation such as higher health costs, more sick leave and a lower work ability rate than co-workers (Salmela-Aro and Nurmi, 2004). Furthermore, the work addict may also create a negative workplace atmosphere that results in increased stress on co-workers, largely by minimising the co-workers' sense of control (Porter, 2004). In short, Workaholics often end up creating inefficiencies for employers by spending excessive time on projects while attempting to achieve perfection. Additionally, the resulting and/or underlying psychological and physical 
symptoms often result in absenteeism and other hindrances to productivity (Reeves, 2005). It is therefore important to consider the effects or stress reactions and possible burnout when examining the consequences of Workaholism.

\section{Stress Reactions and Possible Burnout}

Stress in the workplace is a major problem for both organisations and employees, and a large number of working days are lost due to stress, depression or anxiety (Glyllensten and Palme, 2005). Stress is defined as the adverse reaction people have to excessive pressures or other types of demand placed on them. Individuals and their organisations face a growing problem of managing stress at work but are hampered by a lack of understanding of the nature of occupational stress. The continued increase of women in the workforce has created a need to understand workplace stress in terms of gender differences as well as its potential influence on coping methods. Gender differences have been found to affect health and well-being and serve as a buffer to the outcomes of job stress. It is therefore important to know the extent of these gender differences on antecedents of stress (such as Workaholism as investigated in this study) in New Zealand.

Workplace stress can have a widespread and negative impact on the well-being of individuals and their day-to-day performance. This is evident at a physical level (exhaustion, headaches and high blood pressure), as well as at a psychological level (depression, anxiety and low self-esteem), a cognitive level (absent-mindedness and a failure of attention and memory), and a behavioural level (absenteeism, substance abuse and aggressive behaviour). Work related stress is increasingly recognised as one of the most serious occupational health hazards, resulting in factors such as job dissatisfaction, decreased productivity, absenteeism and turnover (Spielberger and Reheiser, 1995). This leads to large increases in costs faced by organisations. In accordance with Karasek's (1979) job strain model, work related stress is a result of high job demands and low job decision latitude exceeding the employees' coping resources. It is therefore important to gather large amounts of information on the causes of stress. The effects of factors such as gender, among others, on stress in the workplace are also important if we want to do 
anything about the widespread and negative impact on the well-being of individuals and their day-to-day performance that stress has. Landy, Quick, and Kasl (1994, as cited in Speilberger and Vagg, 1998) observed that "work-related stress in the 21st century will be quite exacerbated by international competitive challenges and corporate restructuring activities [that] will place workers at risk of psychological stress in addition to traditional health risks in the workplace" (p. 65). Conceptualising and measuring occupational stress has therefore become increasingly important in this millennium.

A variable accounting for differences in stress levels is gender. In general, female faculty members have reported higher levels of stress than their male counterparts (Blackburn and Bently, 1993; Blix et al., 1994; Sax et al., 1999; Smith et al., 1995; Thompson and Dey, 1998). Effects of stress are detrimental to the well-being of tertiary faculty. This study focuses on academic staff for several reasons as detailed in Chapter 4 (for example, the increasing workload and pressure placed on academics). In a study by Blix et al. (1994), 48\% of participants reported health problems related to stress, and $84 \%$ reported a decrease in productivity due to stress. Furthermore, tertiary faculty who have reported high levels of stress have been found to be more likely to report intent to leave academia than faculty with low levels of stress (Barnes et al., 1998). By exploring gender differences in antecedents of job stress, such as Workaholism, among academics in New Zealand information that is of great consequence to tertiary institutions in New Zealand can be provided.

Jick and Mitz (1985) provided a view on how stress is manifested in different ways by men and women. Specifically, they suggest that women experience psychological stress (depression, emotional discomfort) more frequently than men, whereas men experience physiological stress (coronary heart disease, cirrhosis of the liver) more frequently than women. This suggests that a focus on gender should not only be considered when addressing stress, but also antecedents of stress such as Workaholism.

Having discussed the consequences of Workaholism I will now turn to the current methods of addressing Workaholism, as I believe this study may provide a basis for 
useful information on how these methods could be developed further in the future. This draws on the literature providing information on reducing Workaholism levels through individual and family therapy and organisational and managerial interventions.

\section{Current Methods of Addressing Workaholism}

There is a large speculative body of literature suggesting ways to reduce Workaholism levels. This literature can be divided into two parts (Burke, 2006) focussing on: individual and family therapy (Robinson, 1992, 1997); and organisational and managerial interventions. These methods are designed as blanket policies designed to promote work life balance without targeting specific types on individuals such as genders.

\section{Individual Therapy}

It has been suggested that Workaholics must examine their feelings (Minirth et al., 1981) as well as their thought patterns (Burke 2006). Other authors have advocated the use of self-help programs for Workaholics (Kietchel, 1989; Oates, 1968) such as Workaholics Anonymous. Workaholics' Anonymous chapters have sprung up in some New Zealand cities. These are self help groups that endorse a twelve-step approach common to the treatment of a variety of addictions. Self-help programs include identifying alternatives to work, exploring new hobbies and outside interests and enjoying doing nothing (Burke, 2006). Low self-esteem and low-image is one of the causes of Workaholism. It is important to tackle irrational beliefs, such as the belief in the need to impress others through accomplishments and outperform them due to low self-esteem and low-image. Self-help requires using cognitive reframing, practicing unconditional self-acceptance and behaving in ways that are opposite to previously held beliefs. This is done through delegating tasks to others, setting boundaries between work and home, attempting to balance work and life, and engaging in more leisure activities (Burke, 2006). The difficulty in treating Workaholism is compounded by the societal acceptance of Workaholism. 


\section{Family Therapy}

Denial is common among Workaholics and their families. Family members are reluctant to complain (Burke, 2006). Workaholics define their behaviour and symptoms in a favourable light (Porter, 1996). Parental expectations on children also need to be addressed. In order to change this spiralling negative behaviour family member need to express their negative feeling towards the Workaholic and families need to learn to set boundaries around the amount they work and talk about their work. Goals can be set to improve family dynamics. Additionally, families need to develop an understanding of the intergenerational transmission of addictions. These initiatives may make spending time with families more satisfying, and create rewards for Workaholics for their family participation. Furthermore, family counselling may also foster improved communication within the family.

\section{Workplace Interventions}

The employer or organisation is often the 'pusher' of Workaholic behaviour. This occurs when a culture exists that tends to value time on a task more than actual output. Such organisations need to reassess their culture and determine whether their culture values well balanced employees who are competent and creative or burnt out Workaholics. Employers can also help Workaholics. So what can organisations realistically do about Workaholism? The organisation needs to address the excessive work behaviours and restrain from rewarding those who create unnecessary work to fuel their addiction unquestionably (Porter, 2004). Schaef and Fassel (1988) suggested that employers should pay attention to the performance and work habits of employees and be alert to the signs of Workaholism. Managing a balanced workforce requires determination of whether a culture rewarding actual productive and creative output is more important than simple 'face time' or the appearance of productivity. The organisation must reduce rewards for dysfunctional and compulsive work related behaviours. Too often the Workaholic views work addiction as a sign of success because the organisation often rewards the dysfunctional behaviour (Korn and Pratl, 1986). Instead, the organisation should seek ways to assist its employees to get work done more efficiently, such as positive feedback for efficiencies like more productive time 
management and by rewarding the more realistic control and use of time. It is important not to reward Workaholics for their Workaholic behaviour, but rather to reward those who are productive while leading balanced lives. According to Porter (2001) organisations should care why people work so many hours. As such, the development of workplace values which promote more balanced priorities and healthier life-styles will support Workaholics to change their behaviours (Burke, 2006). It is important to create and support an overall healthy culture in the workplace. Health and mental health promotion are key components to developing a balanced, productive and cost-effective work force.

It is also necessary to ensure employees take their vacation away from work. The organisation can also play a role in assisting Workaholic employees to change their behaviour. Managers can help and encourage delegation of Workaholics' work. Another role Haas (1991) suggested managers take to change Workaholic behaviours is to meet with employees daily to discuss what has been accomplished during the day and plan for the following day. This should include specific times to take breaks. It is also vital to provide accessibility to a comprehensive Employee Assistance Program and a network of mentors or coaches to help design and maintain personal health and career enhancement programs in order to reduce the incidence of Workaholism.

Finally, as well as decreasing Workaholism, improving work engagement is a way to improve employees' well-being. A focus on increasing work engagement may therefore also provide a means to reducing Workaholism. It has been established that job resources (such as autonomy, performance feedback, social support and supervisory coaching) and personal resources (such as self-efficacy, resilience, self-esteem and optimism) are antecedents of work engagement (Bakker, 2008; Schaufeli and Bakker, 2004). Increasing these resources may result in a positive impact on work engagement and therefore on Workaholism too.

Although these methods of addressing Workaholism are already in practice, it may be beneficial to target particular practices to better suit employees. By examining how 
different factors affect the exhibition of Workaholism characteristics this may be possible. For example, a better working knowledge on the differences in the degree of Workaholism characteristics and Workaholism-related variables between genders may provide insights on how to target specific practices for certain employees or groups of employees to better manage Workaholism.

\section{Workaholism in Today's Society}

To date, most studies have shown that individuals in the medical profession are among the most likely to be Workaholics (Killinger, 1992). There have also been suggestions of Workaholism increasing in North America (Schor, 1991), among other countries. There could be many reasons, both inside and outside the organisation, for this rise in Workaholism. Changes continue to occur in the work/life structure, resulting in ambiguity in terms of the differences between work and personal life (Fletcher and Bailyn, 1996; Sullivan, 1999). Inside the organisation, the increasing complexity of professions, constant pressure to be more efficient (to do more with less), and the advancement of technology (Griffiths, 2005) are possible causes for this rise in Workaholism. Additionally, it has been noted that the changing nature of careers over time and continued organisational change further accentuate the need to understand Workaholism (Arthur and Rousseau, 1996). This is the case in the site of this study, academia in New Zealand, where there has recently been significant organisational change, as discussed in the following chapter.

Another notion is whether or not gender plays a role in Workaholism. Until recently, the vast majority of Workaholics were assumed to be men (Burke, 2000a). Keane (1998) supposed that in a "male dominated and macho culture," women must be seen to work harder and longer than men in order to be viewed as equals, thus causing women to be more likely to exhibit Workaholic behaviours.

\section{Summary}

In sum, Workaholics work long hours not because of joy in the work but instead because they are driven to achieve and posses an internal need to work. They react to criticism with hostility and resentment, as with any addiction. They experience frustration from 
failing to meet superhuman standards and express competition with colleagues in the workplace. Workaholics are addicted to the process of work to the extent that outcomes are only important when they supply external rewards to temporarily enhance selfesteem and self-image. Workaholics behave in this way in order to achieve self-worth through striving for ever increasing accomplishments. They are given to rigid thinking and perfectionism. Additionally, they have difficulty delegating, which limits the development of colleagues. Furthermore, they are not likely to be effective team contributors; instead they are striving to be in control (in control of their work activities and other people around them). As a consequence they increase their chances of poor health, poor relationships and diminished leadership contribution. The old saying that "hard work never killed anybody" may not be the case when it comes to Workaholism. This is evident in the case of Karoshi. According to Iwasaki, Takahashi and Nakata (2006), "Karoshi is usually thought to indicate death or permanent disability from cerebrovascular diseases and ischemic heart diseases caused by overwork" (p. 44).

The key indicator of Workaholism is the choice to neglect other areas of life (Porter, 1996). This most often comes to light in complaints from family or friends. These complaints typically go unheeded. By securing promotions and raises the Workaholic is being a good provider. The organisation, whose reward system too often relies on "facetime" as the indicator of who is the best, most devoted worker, does not respond to suggestions of family problems. Society supports or even encourages Workaholism, as it does no other addiction. One might question to what extent Workaholism has become the new norm (Porter, 2004).

When carrying out research in this area, it is important to note that there are three distinct concepts that are often mistakenly 'lumped' together and considered as Workaholism. These are: Working hard for external reasons; Working hard for enjoyment (Work Enthusiasm); and working hard because of an addiction (Workaholism). It is this final concept, Workaholism, which has the vast array of negative effects discussed in this Chapter, therefore necessitating further research. 
In the next Chapter literature on gender in the workplace, gender and personality, and Workaholism and gender are discussed, showing how gender differences may lead to differences in how Workaholism is exhibited. Additionally, Workaholism and culture and the university context will be reviewed, developing a deeper understanding of the context of this study and the importance of further research in this area. 


\section{Chapter 4: Gender, Culture and Context}

\section{Introduction}

In order to make a comparison between Workaholism in males and females in the workplace, gender differences within the workplace need to be considered. This includes examining New Zealand as a specific context. This is then followed by examining gender and Workaholism mutually, which is particularly important due to the increase of women in the workforce and in management. Delving into the nature of personality and how it is gender dependent is also important to note as personality traits influence the development of Workaholism. It can therefore be purposed that gender has an influence Workaholism.

Additionally, Workaholism may reflect specific cultural traits and meanings and therefore differences in the degree of Workaholism characteristics and Workaholismrelated variables between genders may vary between countries and cultures. Previous research (Burke et al., 2008) has concluded that future research of Workaholism needs to consider country and cultural factors, highlighting the importance of considering country culture and values when studying Workaholism, rather than generalising. This emphasises the importance of considering the demographic characteristic of gender in different countries, such as this study does in New Zealand and the need for this context to be made apparent. The culture and context of this study are examined in the final sections of this Chapter; the University context; and the New Zealand University context. These sections describe in detail the context specific to this study.

\section{Gender and the Workplace}

Firstly, bias due to gender differences within the workplace need to be considered. Women have not only joined the workforce in historically high numbers, but they have also shown a growing commitment to steady long term workplace attachment (Gerson, 1986). Gender differences in the workplace are often due to the stereotypes given to each of the genders and their place in the workplace. There is no doubt that organisational cultures are essentially gender biased (Herr Van Nostrand, 1993). The 
reason for this male embodiment of managerial culture is that when organisations and management systems were first formed only males were in the workforce (Herr Van Nostrand, 1993; Still, 1994). Despite the increase of women in the workforce and management, and the introduction of laws such as anti-discrimination, equal opportunity and affirmative action, there has been little fundamental change to this underlying culture. There are several ways in which the organisational culture works against the inclusion of women into senior ranks. These include: (Still, 1994)

- The "boys' club". The inner circle of male senior level professionals has many shared experiences such as school, sporting activities and community and professional associations. Due to this background, a certain amount of "bonding" and trust builds up, forming a "club". Women do not easily fit into this atmosphere other than in roles such as wife, secretary or personal assistant.

- The male managerial cultural model. This is the only model that exists in organisations. For women who are attempting to climb the managerial ladder, there are no assimilation or transition models. Women have to submerge their own natural instincts and conform to the prevailing paradigm.

- The masculine model is considered to be the professional model. This applies to communication, standards of behaviour, processes and practices in organisations (Wood, 1994). This view suggests that men's ways of doing things are the standard or norm, which in turn affects notions of leadership which are typically linked with masculine modes of communication - for example, assertion, independence, competitiveness and confidence. Alternatively, the qualities of inclusivity, collaboration and cooperation, which feature highly in women's speech, are linked with subordinate roles rather than with leadership.

This situation is highlighted by the inclination of successful women to become progressively more masculine in their gender-role orientation (Sachs, Chrisler and Devlin, 1992 as cited in Fielden and Cooper, 2001). This not only leads to the 
marginalisation of women but, for those who are not prepared to change their genderrole orientation, results in increased frustration from the loss of opportunities for advancement (Marshall, 1993; Gottieb, Kelloway and Barham, 1998 as cited in Fielden and Cooper, 2001). When women are not prepared to change their gender-role orientation it is frequently viewed as a lack of desire and commitment, rather than a reflection of the masculine culture still so prevalent in organisations. Research shows that women who work in these masculine cultures often feel isolated and alone, being unable to relate to either male or female colleagues (Marshall, 1995). This provides a base for differing levels of stress in the workplace between genders.

New Zealand women have made significant progress in terms of employment and education; they are considered pioneers of equal rights having been the first in a selfgoverning nation to win the right to vote in the general elections. New Zealand is also a country that unlike many others is noted for women having held the top four public posts - Prime Minister, Governor General, Attorney General and Chief Justice. Having women in such high profile, public positions raises the question of whether the global phenomenon identified by Schein et al. (1996) and Schein and Muller (1992) as "think management - think male" holds true in New Zealand. Although, there is a range of studies on the representation of women in senior management positions and on pay equity (McPherson, 2011; Morley, 2005; McGregor in Davidson and Burke, 2004), which suggests New Zealand is less advanced on issues of gender discrimination. This contradictory evidence highlights the further need for gender studies particularly in New Zealand. Additionally, this makes New Zealand a particularly interesting country to study gender comparisons and prevents generalisation across countries when it comes to gender differences. The aim of the present study is to empirically examine several propositions on this intriguing issue, as outlined in the Methodology Chapter of this study.

\section{Gender and Personality}

Gender differences in personality have been acknowledged in many empirical studies. Maccoby and Jacklin (1974) carried out the first major review of research on sex-related 
differences in personality (in particular, cognition, temperament, and social behaviour) in children and adults. They found that men are more assertive and less anxious than women. Feingold (1994) used meta-analysis to confirm these gender differences in adult personality traits as reported by Maccoby and Jacklin (1974) as well as exploring other gender differences in normative data from the most widely used personality inventories. He concluded that females showed lower assertiveness and higher gregariousness (extraversion), anxiety, trust, and tender-mindedness than males. Wiggins suggests that gender differences in personality appear to be associated with neuroticism (1979). Gender differences on traits related to neuroticism have been consistently reported with females exhibiting higher levels of neuroticism than males (Lynn and Martin, 1997). Neuroticism is understood to consist of a broad sphere of negative effects, including predispositions to experience anxiety, anger, depression, shame, and other distressing emotions. As mentioned above, Feingold (1994) found females to exhibit higher anxiety than males. In addition, Nolen-Hoeksema (1987) reported that women scored higher in symptoms of depression while Kling, Hyde, Showers, and Buswell (1999) found that women scored lower than men on measures of self-esteem. As previously discussed low self-esteem and low-image is one of the causes of Workaholism. This illustrates how personality affects Workaholism, and in particular gender differences in personality lead to differences in the degree of Workaholism characteristics and Workaholism-related variables between genders. It is a case of work serving as a function of increasing the Workaholic's self-esteem (Porter, 1996) which may be more necessary for females as they were found to have lower self-esteem.

One area of neuroticism that females were not found to exhibit more than males is anger. Some studies examining anger found males to exhibit more anger (Scherwitz, Perkins, Chesney, and Hughes, 1991), however, others reported that females exhibit more anger (Ross and Van Willigen, 1996), or that there is no difference (Averill, 1982). Bem (1974) offered an influential approach to the study of gender differences using scales measuring masculinity and femininity. The masculinity scale is essentially a measure of dominance, whereas the femininity scale is strongly related to the dimension of love. Feingold's 
(1994) conclusion that men are high in assertiveness and women are high in nurturance was consistent with this distinction (Wiggins and Broughton, 1985).

Another area in which males and females are reported to differ is in cognitive styles. Winstead, Derlega, and Unger (1999) observed that Western philosophers regularly characterise males as “guided by 'reason' and females by reason's opposites - including emotion" (p. 264). This is supported by considerable empirical evidence for the view that females are more sensitive to emotions (Eisenberg, Fabes, Schaller, and Miller 1989; McClure, 2000; Fujita, Diener, and Sandvik, 1991; Grossman and Wood, 1993). As these personality traits influence the development of Workaholism it can be supposed that gender influences Workaholism. In their study of personality correlates of Workaholism, Burke, Matthiesen and Pallensen found that both self-efficacy and some of the Big Five factors (Neuroticism, Extraversion, Openness to experience, Agreeableness and Conscientiousness) were related to important work behaviours such as the three Workaholism Characteristics (Work Involvement, Drive and Work Enjoyment). Others have also addressed the personality-Workaholism link (Clark et al., 1996; McMillan et al., 2001) suggesting that there is a relationship. This provides a source for differences in the degree of Workaholism characteristics and Workaholismrelated variables between genders.

\section{Gender and Workaholism}

It is essential to study Workaholism among women, and to examine possible gender differences, as more women move into managerial and professional roles (Burke and Mattis, 2005; Davidson and Burke, 2004). According to Bielby and Bielby (1989) centuries of gender discrimination and cultural learning have shaped role identifications (men closely relate to work and women to family) and therefore, men might be more likely to work more hours and engage in Workaholism. Recent research suggests that it is important to explore potential gender differences in future studies of Workaholism (Harpaz and Snir, 2003), and that the importance of gender roles in shaping work patterns and behaviours has been underestimated. 
This investigation examines differences in the degree of Workaholism characteristics and Workaholism-related variables between genders, seeking to determine whether gender impacts the type of Workaholism characteristics exhibited. At least seven previous studies have addressed gender differences in Workaholism and Workaholismrelated variables (Doerfler and Kammer, 1986; Machlowitz, 1980; Spence and Robbins, 1992; Elder and Spence, n.d.; Burke, 1999a; Koyuncu et al., 2006; Burgess et al., 2006). In one of the earliest, Doerfler and Kammer (1986) examined the relationship between levels of Workaholism and both gender and sex role orientation (masculine, feminine, androgynous). They collected data from attorneys, physicians and psychologists. Workaholism was measured by the ten characteristics proposed by Machlowitz (1980). They reported that 23 percent of their respondents were Workaholics, consistent across the two genders and three professional groups. Interestingly, a majority of single Workaholics were female and female Workaholics reported more masculine and androgynous characteristics than feminine characteristics.

Spence and Robbins (1992) made gender comparisons in social workers in academic positions using their Workaholism triad (Work Involvement, Drive to work, and Work Enjoyment), behavioural correlates (e.g. perfectionism, non-delegation) and health complaints. In this sample, women scored significantly higher than men on Drive to work, Work Enjoyment, job stress, job involvement and time commitment scales; no differences were found on Work Involvement, perfectionism and non-delegation scales. Women also reported more health complaints. Their findings suggest that women have a greater tendency to show at least some characteristics of Workaholism and suggest that this may be due to the more competitive work environment and the higher expectations placed upon them in order to succeed in the workplace.

Elder and Spence (unpublished manuscript) reported comparisons of male and female MBA graduates on these same measures along with measures of job satisfaction and psychological well-being. Few differences were found. Men scored significantly higher than women on job involvement. The three Workaholism triad measures were 
significantly correlated for men; Drive to work and Work Enjoyment scales were uncorrelated for women.

Burke (1999a), again using measures developed by Spence and Robbins (1992), examined gender differences on the three Workaholism characteristics and behavioural correlates in a predominantly white managerial sample. Although males and females were found to differ on many personal and situational demographic characteristics, they were similar on the three Workaholism components: Work Involvement, Drive to work and Work Enjoyment. Females reported higher levels of particular behavioural correlates (e.g. perfectionism, job stress) which are likely associated with lower levels of satisfaction and well-being, while males reported more time devoted to work and worked longer hours per week, which is likely associated with females' 'family responsibilities'. Koyuncu et al. (2006) also compared scores on the three Spence and Robbins Workaholism components among male and female professors in Turkey. Males scored significantly higher than females on both Work Involvement and Drive to work but the two groups were similar on Work Enjoyment.

Burgess et al. (2006) examined gender differences in the same three Workaholism characteristics, Workaholic behavioural correlates and work and well-being outcomes among 324 female and 134 male MA and PhD level Australian psychologists. Males and females were found to differ on many personal and situational demographic characters. They also found differences in two of the three Workaholism components (Work Involvement, and Drive to work) with males scoring higher on both. Consistent with Burke (1999a), females reported higher levels of particular behavioural correlates (e.g. perfectionism, job stress) again likely to be associated with lower levels of satisfaction and well-being. This study though, produced results that conflicted with the results in previous studies (Burke, 1999a; Spence and Robbins, 1992; Elder and Spence, n.d; Koyuncu et al., 2006) in regards to the Workaholism components exhibited by the genders while being consistent in the behavioural correlates of the genders. This suggests that the effects of gender on the Workaholism components exhibited may be culturally dependent while job behaviours are universally consistent. This suggests that 
future studies should focus on differences in the degree of Workaholism components between genders rather that behavioural correlates such as perfectionism, job stress, non-delegation, as done in the current study.

This study both replicates earlier work and extends our understanding of Workaholism by involving a different group of respondents (academics) in another country (New Zealand) independently. Workaholism is once again measured by the scales of Spence and Robbins (1992), the most widely used measure of Workaholism (Aziz and Zickar, 2006; Burke, 2008). As discussed in Chapter 3, Spence and Robbins (1992) defined a Workaholic or work addict as an individual that is highly work involved, feels driven to work because of inner pressures not organisational requirements, and derives little joy from their work. Burgess et al. (2006) concluded that females and males typically exhibit similar levels of Workaholism, rather the difference is the ways in which Workaholism components are enacted in the workplace that may be different between females and males. For this reason this study looks at the Workaholism characteristics exhibited rather than levels of Workaholism.

In sum, the results of the few empirical studies into gender and Workaholism have been mixed. Some research has indicated that gender is independent of Workaholism, while other studies suggest that gender is related to Workaholism, in which it is uncertain if men or women have more Workaholic characteristics, if either. This raises the issue over gender's affect on Workaholism requiring further investigation to resolve. As detailed below, it has been suggested that Workaholism may be culturally dependent and therefore this issue may be better explored by examining it in an individual country.

\section{Workaholism and Culture}

Finally, it should be noted that Workaholism may reflect specific cultural traits and meanings, and therefore differences in the degree of Workaholism characteristics and Workaholism-related variables between genders may vary between countries and cultures. Authors such as Burke, Koyuncu and Fiksenbaum (2008) suggested that future research should consider both country and cultural factors as they may impact on 
Workaholism. They examined the potential antecedents of the Workaholism components and the relationship of these components to work and 'extra-work' satisfactions, and psychological well-being among professors in Turkey using Spence and Robbin's (1992) definition of Workaholism. Burke et al. (2008) found that both individual difference characteristics and organisational factors serve as antecedents. These results suggest the need to consider both country and cultural factors in future research of Workaholism. Burke et al. (2008) highlighted the importance of considering country culture and values when studying Workaholism. This emphasises the importance of considering the demographic characteristic of gender in different countries, such as this study does in New Zealand.

Additionally, Snir and Harpaz (2004) found that religious Jews in Israel viewed work as far less important than religion and a potential interference with religious practice. On the other hand, in Western culture the Protestant work ethic considers hard work as a reflection of one's salvation while 'idleness' suggests damnation (Porter, 2004). Accordingly, cultural context is an important consideration when defining, diagnosing and treating behaviours related to work excesses. This emphasises the importance of considering the demographic characteristic of gender in different countries. The purpose of this study is, therefore, to explore differences in the degree of Workaholism characteristics and Workaholism-related variables between genders in New Zealand to provide further knowledge of the area of gender and Workaholism within organisations in New Zealand.

\section{University Context}

While not highly paid in comparison to professionals in other sectors, such as the commercial sector, academics have been envied for their tenure, light workloads, flexibility and the freedom to pursue their own research interests. These advantages though have faded away during the past three decades. Academic salaries have fallen in real terms in countries such as the USA, the UK, and Australia, (Gillespie et al., 2001). Increasingly, academic positions are becoming untenured, workloads have increased, academics are under increasing pressure to attract external funds, and 'publish or perish' 
(Fisher, 1994). Kinman (1998) suggests that Workaholism characteristics will ensue from the organisational climate and wider educational policy, as well as those that could be viewed as intrinsic to the job. In general, university academic staff perceives increasing levels of demand and decreasing levels of support from their institutions.

Blix et al. (1994) found men were more likely to be full professors than assistant professors or lecturers, have doctoral degrees, have higher salaries, and to be tenured. Men were more likely to have supportive home networks than women and to spend more time on scholarly endeavours of the kind to be rewarded in the promotion process and to have more publications of all types. Kinman (1998) found, in her study into the causes and consequences of occupational stress in UK academic and related staff, that in response to the statement 'I find my job stressful', 70 per cent of respondents either agreed or strongly agreed. Only 11 per cent indicated that job-related stress was not an issue for them.

"One respondent remarked: 'I find that my constant experience is of trying to run up the down escalator, an escalator that is moving ever faster. I think this is also the experience of most of my colleagues.' This sentiment is echoed by another lecturer who observed: 'Stress is practically endemic in my institution."' (Kinman, 1998)

At the conclusion of this study Kinman (1998) suggested that stress-related factors are derived from the organisational climate and wider educational policy, as well as those that could be viewed as intrinsic to the individual such as Workaholism. In general, university academic and academic-related staff perceives increasing levels of demand and decreasing levels of support from their institutions. Recent research on stress among academic and general staff of universities from across the globe indicates that the occurrence of workplace stress in universities is alarmingly common and increasing (Winefield, 2000). In addition to this, Winefield (2000) reported that USA, UK and New Zealand universities are also experiencing increasing student to staff ratios and levels of work pressure. 
Academic staff play a vital role in the creation and development of knowledge and innovation, as well as to education and training. It has been well documented that high levels of workplace stress, which occurs through Workaholism, undermine the quality, productivity and creativity of employees' work, in addition to employees' health, wellbeing, and morale. Research has also established that high levels of occupational stress result in substantial costs to organisations and the community. It is clearly important that universities manage and protect their staff from increasing levels of stress in order to preserve staff well-being, organisational performance and the intellectual health of the nation (Gillespie et al., 2001). In order to do this, we first need to understand the Workaholism within the university sector and how factors like gender affect this.

\section{New Zealand University Context}

In a study of seven New Zealand universities, Boyd, and Wylie (1994) reported that 80 percent of the academics believed that their workload had increased and become more stressful in recent years. In addition, 54\% of academics expected further increases in workload in the future. The high percentage of academics expecting further increases in workload is likely to increase the pressure, suggesting that in the future Workaholism is likely to increase. This study was then followed up in 1998 by Chambers, who found that half of the academics in their sample 'often' or 'almost always' found their work to be stressful. Academics were significantly more likely to say that they 'often' or 'almost always' found their work to be stressful compared with the other groups. Seventy nine percent of academics stated that their jobs had become much more, or more stressful. Academics were significantly more likely to say that their stress levels had increased recently compared with the other groups. In addition, fifty nine percent of academics expected further increases in workload in the future. Further study therefore needs to be conducted in the present to assess Workaholism among academic staff in New Zealand.

Chambers (1998) found that for academics there were four work-content areas which were rated as often or always stressful by more than 25 percent of respondents. These were; lack of time for reading/research (61 percent), marking students' work (37 percent), research writing and publishing (37 percent), and internal 
administration/meetings ( 29 percent). Additionally, she found that more than 40 percent of academics rated 5 work-related factors as often or always stressful. These were university climate/morale (46 percent), deadlines/demands (44 percent), university management (42 percent), interruptions to work (42 percent), and continual change (41 percent). It appears that for academic staff both work-content issues and work-related factors such as organisational systems and environment cause workplace stress. This shows that in the previous decade stress was a problem among University Professors in New Zealand. Additionally, a high percentage of academics expected further increases in workload in the future, as a result workplace stress is likely to increase. Further study therefore needs to be conducted to assess stress antecedents among academics in New Zealand. This study looks specifically at Workaholism as an antecedent of stress.

Additionally, it has long been recognised that organisational change can be a significant cause of workplace stress. Change in the workplace is likely to compound existing sources of job stress; the process of change can also have powerful negative effects on employees' psychological well-being. Individuals undergoing periods of change have commonly reported feelings of anxiety and insecurity, a lack of confidence in their abilities and uncertainty about their future in their organisations. At the beginning of the last decade the Performance-Based Research Fund (PBRF) was implemented, with ongoing changes still occurring. The purpose of this fund is to ensure that excellent research in the tertiary education sector is encouraged and rewarded. This entails assessing the research performance of Tertiary Education Organisations (TEOs) and then funding them on the basis of their performance. The PBRF is designed to:

- Increase the average quality of research

- Ensure research continues to support degree and postgraduate teaching

- Enable that funding is available for postgraduate students and new researchers

- Improve the quality of public information on research outputs

- Prevent undue concentration of funding that would undermine research support for all degrees or prevent access to the system by new researchers 
- Underpin the existing research strengths in the tertiary education sector.

(Tertiary Education Commission, 2009)

In order to meet these aims, the prime focus of the PBRF is on rewarding and encouraging excellence. Excellence in this respect is not just about the production of high-quality research articles, books, exhibitions and other forms of research output. It also includes all of the following:

- The production and creation of leading-edge knowledge

- The application of that knowledge

- The dissemination of that knowledge to students and the wider community

- Supporting current and potential researchers (eg. postgraduate students) in the creation, application and dissemination of knowledge

(Tertiary Education Commission, 2009)

The implementation of the PBRF is therefore likely to affect Workaholism among academic staff in New Zealand as funding is based on performance. The PBRF funding formula is based on three elements or 'measures':

- Quality Evaluation: the assessment of the research quality of TEO staff members, based on peer review

- A Postgraduate Research Degree Completions (RDC) measure: the number of postgraduate research-based degrees completed in the TEO

- An External Research Income (ERI) measure: the amount of income for research purposes received by the TEO from external sources

This provides further reason for research on Workaholism among academic staff in New Zealand. There are also other recent policy changes in relation to tertiary education and research funding that may have the same effect. 
The changing research environment in New Zealand includes the following changes:

- The changes to the regulatory framework for tertiary education, including the changes to TEO Charters and the introduction of Profiles

- The changes to the tertiary funding framework, including the establishment of Centres of Research Excellence and the introduction of the fee-maxima policy

- The degree of competition both within and outside the tertiary sector

- Changes in relation to TEO-industry linkages

- Changes in the wider academic labour market

- Changes to research funding, especially to the funding allocated by the Foundation for Research, Science and Technology, the Health Research Council and the Royal Society of New Zealand.

(Tertiary Education Commission, 2003)

\section{Summary}

In this review of international management literature, relating to Workaholism, Workaholism and gender, and Workaholism and culture, no studies which fully explored gender differences in the Workaholism characteristics exhibited among academics in New Zealand were identified. Given the importance of knowledge in this area, as Workaholism has many negative impacts on the organisation and the health and well-being of individuals, it seems a greater understanding would be beneficial. The university context, as well as the New Zealand university context, has also been addressed above as this study concentrates on academics in New Zealand.

In sum, after an examination of the literature, as done in the previous three Chapters, several questions remain unanswered; what are the affects of gender on Workaholism; and what are the affects of gender on the Workaholism characteristics? As the affects of gender on the Workaholism characteristics exhibited may be culturally dependent another questions remains; what are the effects of gender on the Workaholism characteristics exhibited in/by particular cultures? As New Zealand is a particular area 
of interest, as it may have a unique gender culture the question, 'What are the affects of gender on the Workaholism characteristics exhibited in New Zealand?' is of particular interest. The following research endeavours to answer this question focussing on differences in the degree of Workaholism characteristics and Workaholism-related variables between genders characteristics rather that behavioural correlates such as perfectionism, job stress, non-delegation, as suggested by burgess et al. (2006). In the next chapter, the methodology of this thesis is outlined. 


\section{Chapter 5: Methodology}

\section{Introduction}

This chapter describes the methodology used in this thesis. It begins with outlining the research questions, the theoretical framework and the developed hypotheses. The first section, in outlining the research question, covers why study in this area is important and how this has led to the research question. This draws on the literature from the previous Chapter. The reason for the choosing the population the question targets is then explained. And finally, the definition of Workaholism used in this study is reiterated as this is pertinent to the research questions. In the second section the hypotheses are developed in order to answer the research questions and the theoretical framework is developed highlighting the relationships involved in answering the research questions, basing the theoretical framework of this thesis on the research questions. This was followed with the type of approach used in this study.

The third section of this Chapter discusses the research design, the survey participants, the data collection methods and the instruments used. The pilot is then presented along with the analysis of the pilot in order to achieve both content and construct validity. Following this, the Chapter discusses the sampling methods used to achieve the sample population. This Chapter concludes with a final section covering ethical considerations.

\section{Purpose of Study}

This study provides evidence as to the differences in the degree of Workaholism characteristics and Workaholism-related variables between genders within New Zealand, which may be significantly different from elsewhere due to the specific nature of New Zealand culture. As established in the previous chapter, Workaholism on the whole is an under-researched subject - for example, the differences in Workaholism characteristics between genders have not yet been studied in New Zealand. As a result the relationship between Workaholism and gender in different countries, cultures and professions is as yet impossible to distinguish. There is too little information, specific to individual contexts, available to derive meaningful inferences. In this respect, the 
findings of studies examining specific contexts have the potential to assist individuals, institutions and in the case of this study (examining the academic context) educational policy-makers in addressing the issue of Workaholism in higher education and, ultimately, to inform policy and practice regarding working conditions. Workaholism is real, and it has real implications for the individual, co-workers, supervisors, family, and society.

To address the aforementioned unresolved issue of the gender differences in Workaholism, this study uses the suggestions of other authors that Workaholism may be culturally dependent and therefore takes the approach of examining this issue in an individual country. This study also looks at a single industry - academia, where Workaholism characteristics ensue from the organisational climate and wider educational policy, as well as being intrinsic to the job. This was done as it makes the results particularly informative when developing interventions to address Workaholism within a specific industry - academia, an industry where Workaholism is ripe. This is important as it is essential not to generalise, but rather to examine Workaholism in particular in specific countries and industries. By researching the antecedents of the Workaholism characteristics exhibited at a higher level by each of the genders, information on how to tailor interventions for both genders may be established.

This study both replicates earlier work and extends the understanding of Workaholism by involving a different group of respondents (academics) in another country (New Zealand). As this study is relevant to the current interest in issues of work-life balance and stress-related studies, the benefits of this undertaking include a greater knowledge about, and an understanding of, the differences in the degree of Workaholism characteristics and Workaholism-related variables between genders. Therefore, a research in this area has the potential to provide policy makers, higher education institution leaders and university educators, valuable information and insights into the policy and practice of dealing with issues of work stress and enhancing productivity in a sustainable way. There are several areas in which this research has implications. These include providing valuable information that may be helpful when designing 
interventions to promote work-life balance, as each of the genders may require different support mechanisms in order to achieve greater work-life balance.

\section{Research Question:}

What is the differences in the degree of Workaholism (and related issues) between genders?

The key to understanding Workaholism is to fully appreciate the characteristics of an individual's behaviour that depict Workaholism. Workaholism has become a popular term referring to people who work hard and for many hours. However, considering Workaholism exclusively in terms of the number of working hours is misleading as it excludes the addictive nature. A typical work addict is motivated by a strong internal drive that cannot be resisted. This is above any motivation due to external or contextual factors, such as financial problems, poor marriage, organisational culture, supervisory pressure, or a strong desire for career advancement. The emphasis is too often placed on the excessive working hours of these individuals, yet this is only a small aspect involved in Workaholism (often described as a symptom). This study therefore aims to break down the characteristics, or aspects, of Workaholism when looking at gender differences. For this reason the research question was further developed as below.

1. What is the impact of gender on the Workaholism characteristics (Work Involvement, Drive and Work Enjoyment) combined in the Workaholism Composite Score?

\section{What is the impact of gender on the Workaholism characteristics} (Work Involvement, Drive and Work Enjoyment) individually?

In order to get a more all-encompassing picture of the differences in the degree of Workaholism (and related issues) between genders supplementary questions were developed. 
3. What is the impact of gender on the perceptions of participants' Workaholism?

4. What is the impact of gender on whether there is a correlation between the Workaholism Composite Score and perceptions of participants' Workaholism?

As factors such as overtime and overwork do play a part in Workaholism a further question was developed.

\section{What is the impact of gender on overwork and overtime?}

As stated in the previous chapter, it is essential to study Workaholism among women, examining possible gender differences, as more women move into managerial and professional roles (Burke and Mattis, 2005; Davidson and Burke, 2004). Researchers have suggested that it important to explore potential gender differences in future studies of Workaholism (Harpaz and Snir, 2003). This provides insight into the development of the research questions for this thesis. This study examines the differences in the degree of Workaholism and Workaholism-related variables between genders, seeking to determine whether gender impacts the type of Workaholism characteristics exhibited. Given the importance of knowledge in this area (as Workaholism has many negative impacts on the organisation and the health and well-being of individuals) it seems a greater understanding would be beneficial. The university context, as well as the New Zealand university context, has also been addressed in the previous chapter as this study concentrates on academics in New Zealand. The choice of the population selection is explained in further detail below.

\section{Definition utilised in study}

Workaholism is a concept that seems intuitively easy to understand, and a term used in everyday conversation. Although this is the case, the preceding discussion demonstrates that Workaholism is perhaps not as straightforward as it might seem at first glance. Workaholics work more and invest more energy in work than is absolutely required. The 
definition utilised in this study therefore is not based on hours worked. If hours worked are not sufficient by themselves as a behavioural indicator of Workaholism, then what behaviours might qualify? Implicit in Workaholism is the element of free choice (Burke, 2006).

A decision was made to use the definition of Workaholism put forward by Spence and Robbins (1992) in combination with Snir and Harpaz (2004). Snir and Harpaz (2004) suggested that Workaholism is a steady state that involves considerable allocation of time to work-related activities and work-related thoughts that are not derived from external necessity. This definition shares a considerable overlap with the McMillan et al. and the Scott et al. definitions. This also underpins the Spence and Robbins (1992) definition and therefore is used as a foundation for the definition of Workaholism used in this study. In addition, Spence and Robbins' (1992) definition was the first academic/research definition and has been widely accepted by academics in this area. They refer to the three characteristics of strong drive to work, high work involvement, and low work enjoyment, as the Workaholic triad. Hence, for this thesis I define Workaholism as the tendency towards heavy work investment and involvement (the behavioural dimension) with considerable allocation of time to work-related activities and work-related thoughts and the combination of high-drive with low-enjoyment (the cognitive dimension), which manifests itself in working compulsively; being obsessed with work for reasons that are not derived from external necessity. As previously mentioned, this agrees with the most recent analysis of scholarly definitions which conclude that hard work at the expense of other important life roles and a strong internal drive to work are two key aspects of Workaholism ( $\mathrm{Ng}$ et al., 2007).

However, as Mudrack and Naughton (2001) also suggested that Enjoyment and Drive are merely antecedents that trigger the Workaholic behaviour, discussed in Chapter 3, there is some contention with the definition used in this study. It is certainly feasible that Work Enjoyment and Drive are constructs that are related to Workaholism, but whether they merely describe Workaholic behaviour, as opposed to explaining its origins and causes remains unknown (Burke, 2006). In order to address this area of contention this 
study focuses on studying Work Involvement, Drive, Work Enjoyment, and hours worked as separate constructs, albeit inter-related along with the unitary Workaholism construct. In any event, it is apparent that the nature of Workaholism remains unclear and that future research is required in many areas of this field.

Additionally, there is debate about whether Workaholism implies high or low Work Enjoyment (Spence and Robbins, 1992 and McMillan et al., 2002 respectively) or whether Work Enjoyment should be excluded from the definition entirely (Burke 2006) Determining whether individuals enjoy their work is undoubtedly meaningful on many levels. Although this may be the case, there have been no definitive studies that found Work Enjoyment to have no obvious connections or correlation to Workaholism. This provides one reason why this study includes low Work Enjoyment in the definition of Workaholism. Other reasons include the fact that the Spence and Robbins (1992) definition, as mentioned above, has been widely accepted by academics in this area and the significant negative consequences of having low Work Enjoyment. A final reason for including 'low' Work Enjoyment in the definition of Workaholism utilised in this study is for the sake of conceptual clarity instead of discriminating between "good" and "bad" forms of Workaholism. The definition utilised in this study discriminates between Workaholism (being intrinsically bad) and work engagement (being intrinsically good).

\section{Choice of population}

This research specifically addresses whether there are gender differences among academics in New Zealand in the Workaholism triad characteristics as defined by Spence and Robbins (1992) (high work involvement, drive to work, and low work enjoyment). New Zealand is a particularly interesting country in which to study gender comparisons, as it is uniquely different in that it is a pioneer of equal rights. Because of this unique culture I believe it is important to consider New Zealand individually.

The literature has led me to believe that the results of this study carried out in New Zealand will result in contradictory findings to those in previous studies around the world. In particular the gender culture in New Zealand as described above may lead to 
females not possessing significantly more drive than their male counterparts as they do not need to prove themselves to be equals.

I have chosen academic institutions for three reasons. First, the advantages of tenure, light workloads, flexibility and the freedom to pursue their own research interests have faded away during the past three decades. Academic salaries have fallen in real terms (Gillespie et al., 2001). Increasingly, academic positions are becoming untenured, workloads have increased and academics are under increasing pressure to attract external funds and 'publish or perish' (Fisher, 1994). Second, academic staff play a vital role in the creation and development of knowledge and innovation, as well as for education and training, as discussed in the previous Chapter. It is clearly important that universities manage and protect their staff from increasing levels of stress in order to preserve staff well-being, organisational performance and the intellectual health of the nation (Gillespie et al., 2001). In order to do this, we first need to understand the extent of Workaholism within the university sector and how factors like gender may affect this.

Third, academic staff's work is not managed. This means they have a greater ability to work harder and exhibit Workaholic characteristics. They are not restricted by nine to five office hours or to particular tasks. Additionally, it can be a matter of pride to exhibit Workaholic characteristics. Finally, likely effects on Workaholism due to the implementation of the PBRF provide further reason for research on Workaholism among academic staff in New Zealand. There are also other recent policy changes in relation to tertiary education and research funding that may have the same effect, again as discussed in the previous Chapter.

\section{Hypotheses}

As the first research question of this study is deductive, testable statements or hypotheses were developed. Relationships were conjectured between variables on the basis of the network of associations established in the theoretical framework formulated for this study (seen below in Figure 3). These hypotheses were then tested in order to confirm or refute the conjectured relationships. 
Spence and Robbins (1992) made gender comparisons using their Workaholism triad (Work Involvement, Drive to work, Work Enjoyment) and found women scored significantly higher than men on feeling driven to work, work enjoyment, job stress, job involvement and time commitment scales. This suggests that women have a greater tendency to show at least some characteristics of Workaholism. Burgess et al. (2006) examined gender differences in the same three Workaholism components. They also found differences in two of the three Workaholism components (work involvement and feeling driven to work) with males scoring higher on both. This suggests there are differences in the degree of Workaholism and Workaholism-related variables between genders although the exact nature of the relationship is unknown and as mentioned in the previous Chapter may be culturally dependent. I propose that there is an impact on Workaholoism due to gender. Accordingly, the following hypothesis was made:

\section{H1: There is a difference between the Workaholism Composite Score of males and females.}

In response to whether these differences are seen specifically in the different characteristics of Workaholism as defined by Spence and Robbins, (high work involvement, drive to work, and low work enjoyment) the following hypotheses were developed:

\section{H2: There is a difference between the Work Involvement of males and females.}

\section{H3: There is a difference between the Drive of males and females.}

\section{H4: There is a difference between the Work Enjoyment of males and females.}

According to Bielby and Bielby (1989) centuries of gender discrimination and cultural learning have shaped role identifications (men closely relate to work and women to family) and therefore, men might be more likely to identify themselves as Workaholics. On the other hand, females may feel the need to prove themselves as equals and therefore identify themselves as Workaholics to even their status. Overcompensation (women believing that they need to overcompensate to prove their capability to male co- 
workers and supervisors) has been shown in studies by Goldenhar, et al. (1998) and Johnson (1991). This suggests there are differences in the degree of Workaholism perceptions, although the exact nature of the relationship is unknown. Accordingly, the following hypothesis was developed:

H5: There is a difference between the perceptions of being a Workaholic of males and females.

H6: There is a difference between correlations between the Workaholism Composite Score and perceptions of participants' Workaholism of males and females.

Once again, according to Bielby and Bielby (1989) centuries of gender discrimination and cultural learning have shaped role identifications and therefore, men might be more likely to work more hours as well as engage in Workaholism. Accordingly, the following hypothesis was made:

\section{H7: There is a difference between the overtime and overwork of males and females.}

The above hypotheses represent two-sided alternative hypotheses $(\neq)$.

Based on these variables and relationships, hypotheses and a theoretical framework, seen below, were developed to show the network among the variables involved in this study. The theoretical framework of this thesis is based on the research questions. In order to answer these research questions several hypotheses were established. 
Figure 3. Theoretical Framework

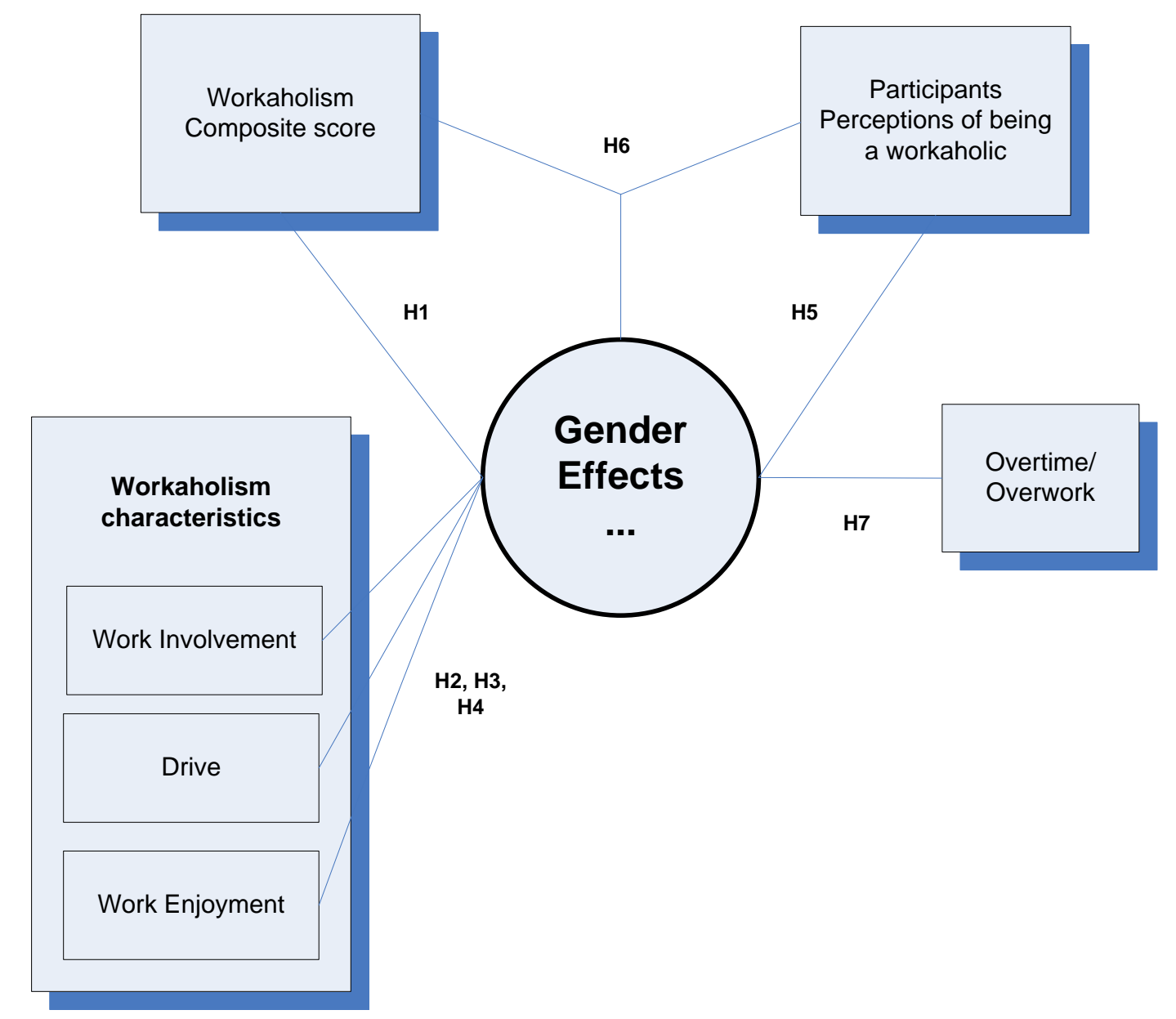

\section{Type of Approach}

Workaholism research is predominantly conducted within a social science paradigm in which social scientists formally define a theory as a system of logical statements that explain the relationship between two or more phenomena (Berg, 1995). This study takes a quantitative positivist approach with the aim of making gender comparisons. This type of research is considered appropriate as it seeks to build on the limited knowledge of Workaholism. This approach has also traditionally been used when considering Workaholism. 


\section{Survey Participants}

Participants consisted of a sample of academic staff from each of the eight New Zealand Universities. In order to ensure validity I needed to ensure that each sex was sufficiently represented, allowing claims about gender and its impact on the Workaholism characteristics exhibited to be made. It was expected that a proportion of the surveys would not be returned. Before the surveys were disseminated ethical approval was obtained by the ethics review board of Victoria University of Wellington to ensure the integrity of the knowledge produced and to promote the practice of ethical responsibilities towards the participants. Before participating, all academics were informed about the objectives of the study through an information sheet that was provided in the form of an email, explaining that participation implied consent.

\section{Sampling}

The surveyed population consisted of all academics listed on the universities staff directories $(\mathrm{N}=3174)$. It is collectively exhaustive - no population element is excluded from the survey population. The process used is seen above the section on survey population. I required that any participant that had not spent their whole career in New Zealand had worked in New Zealand for a minimum of five years in order to be included in the study. It was felt that only after at least this length of employment in New Zealand would a person be sufficiently exposed and adapted to the New Zealand culture to contribute to this study. Once the completed surveys were received the sample population was selected by excluding any participants that had not worked in New Zealand for a minimum period of five years and those working part time. It was intended, if necessary, to improve the representativeness of the sample by reducing sampling error in order to ensure equal representatives from each gender. This was not necessary as the responses provided equal representation in themselves.

\section{Method of Data Collection}

The research involves academics at the eight New Zealand Universities. Surveys were administered online through a Qualtrics link provided by e-mail. The survey information was sent through the e-mail. Contact information was provided to each individual through the e-mail invitation in order for respondents to ask questions about the study. 
The surveys were sent to all academic staff listed in each University's Staff Directory on their website. The survey took approximately 10 minutes to complete. Once all of the data were collected, data analysis began. This study used a survey for data collection as it is relatively easy to reach a large population as well as allowing for the responses to be objectively analysed. The issue to be examined can be targeted very specifically and easily summarised and reported.

\section{Tools for Data Collection}

The survey instrument used in this study has taken the three characteristics defined by Spence and Robbins (1992) as the Workaholism scales for the survey. The existing measure developed by Spence and Robbins (1992) was not used. This was done in order to exclude behavioural correlates and examine only the Workaholism characteristics since, as discussed in the previous Chapter, behavioural correlates appear to be consistent across populations. Instead it is the Workaholism characteristics that need to be examined for various populations (Burgess et al., 2006). Therefore, personally developed statements were used that correspond with high Work Involvement, strong Drive and low Work Enjoyment. Additionally the survey addresses the aspects of the New Zealand gender culture as defined in the literature and the definition of Workaholism and Workaholism Perceptions. A final section of the Survey was developed to examine how participants define Workaholism in order to compare this with the definition used in this study and developed from the literature. Although participants' definitions of Workaholism would not impact their responses to the items on the Workaholism characteristics, this was included in the survey as I felt it would provide additional insight on the topic of Workaholism from the target population and may provide a view for future research.

The Workaholism survey developed for this study consists of eleven demographic questions. Among these questions hours worked and hours contracted to work were addressed in order to calculate overtime and overwork. Overtime, the actual working hours relative to the contracted working hours, was measured with three questions: respondents were asked how many hours per week they worked according to their 
labour contract $(M=36.1 ; S D=6)$ and how many hours they actually worked in an average work week and weekend $(M=51.5 ; S D=13.8)$. Overwork (excess working time) was, for the purpose of this study, defined as working at least 48 weekly hours. Many researchers seem to use this cut off point, in line with the 1993 European Directive on working time (White and Beswick, 2003).

Following this 24 items were used to assess the three Workaholism scales (Work Involvement, Drive and Work Enjoyment). Each item was assessed on a five point Likert response format ranging from "strongly agree" to "strongly disagree". When responding to questions regarding Workaholism, Workaholics may rationalise and claim that their work behaviour is not really optional (Scott et al. 1997; Schaef and Fassel, 1988). Given the mere possibility of denial this study sought to minimise its potential impact on responses. I did this by having asked about specific work activities (without suggesting Workaholism). Moreover, I endeavoured not to use items that were contextspecific; instead the items referred to activities that seemed discretionary across multiple contexts. For example, all academics are obligated to do their jobs and execute assigned work.

Perceptions of being a Workaholic were addressed in a fourth scale (Workaholism Perceptions) through two questions asking whether they consider themselves to be Workaholics and whether other people consider them to be so. I placed these questions after those addressing the Workaholism scales so as to not impact the responses to items in the three Workaholism scales (Work Involvement, Drive and Work Enjoyment), thus avoiding bias. If they were at the beginning of the survey participants may try to match their other responses to what they had responded on these questions. These were used to compare with the Workaholism Composite Score in order to develop a better understanding of Workaholism, help determine the reliability of the Workaholism scales, and also to provide some interesting comparisons against participants' results on the three scales. Again, each item is assessed on a five point response format ranging from "strongly agree" to "strongly disagree". The survey then addresses the aspects of the New Zealand gender culture in the workplace in a fifth scale (Gender perceptions) 
through five items developed using the literature covered in Chapter 2. Once again each item is assessed on a five point response format ranging from "strongly agree" to "strongly disagree".

The final item requires respondents to define Workaholism. This item provides respondents with options to select. These options consist of each aspect of the definition used in this study as well as some contradictory options. It also allows for an "other" response in which respondents can provide an open ended response where their definition may differ from the one used in this study. This is done in order to provide part of the answer to the second research question, "How does participants' definition of Workaholism compare to the widely accepted definition used in this study?"

This survey, consisting of scale items, will produce quantitative data which will then be statistically analysed, allowing for comparisons to be made. This follows an objective approach searching for contributory relationships where gender is the independent variable, while the dependent variables are the scales of the survey (Work Involvement, Drive and Work Enjoyment), as well as the Workaholic composite score, perceptions of being a Workaholic and overwork (where each variable is used to answer different parts of the research question and laid out in the theoretical framework). I also included marital status, whether the respondent has children and their employment position as independent variables. It is through the statistical analysis of the survey results that the research question will be answered.

\section{Pilot Study}

As the survey was developed for this study it was necessary to carry out a pilot study in order to pre test the instrument (Baker 1994: 182-3). Other procedures used to improve the internal validity of the study included the following (Edwin, et al., 2001):

- Recording the time taken to complete the questionnaire and deciding whether it is reasonable.

- Discarding all unnecessary, difficult or ambiguous questions 
- Assessing whether each question gives an adequate range of responses

- Establishing that replies can be interpreted in terms of the information that is required

- Re-wording any questions that are not answered as expected

- Revise

It is important to administer the survey to pilot subjects in exactly the same way as it was intended to be administered in the main study. The pilot therefore followed the method mentioned above.

\section{Participants}

Participants for the pilot consisted a small fraction $(\mathrm{N}=77)$ of the same population as the full study. They were selected from the Staff Directory from Victoria University of Wellington. The same population was used as this survey is specifically targeted at academics in New Zealand and would therefore not be suitable to pilot on another population. It is assumed that academic staff from Victoria University of Wellington are a good proxy for the population of interest.

\section{Pilot Study Outcomes}

The pilot study revealed that the time taken to complete the survey varied between around four minutes and nine minutes. This fell within the time required to complete the survey as stated in the information sheet. I believe this is a reasonable length. The next part of the pilot required looking at any questions that may have been unnecessary, difficult or ambiguous. The following two questions had a particularly low response rates, "How many years have you worked in New Zealand?" and "How many years have you worked outside New Zealand?" The first question is of particular importance in this study as it is used in the selection of the population sample. This is necessary as this is a New Zealand case study, and it is therefore felt that participants need to have worked in and experienced the New Zealand culture for a minimum number of years. In order to ensure a higher response rate on this question it was rephrased to ask "Have you worked in New Zealand for five or more years?" The second question was removed as it was found to be unnecessary, and may mislead participants on the New Zealand focus of 
this study. Instead at the beginning of the survey a note was added to inform participants that the survey was focused on their work behaviours while working in New Zealand. Additionally, in order to calculate overwork, an additional question was added. This asked participants their work hours as stated in their employment contract. The pilot confirmed that along with these changes respondents found the wording of the items clear and understandable. Through this the instruments have achieved content validity.

Following this, Cronbach's alphas were used as a measure of internal consistency, that is, how closely related a set of items are as a group. This was done for the sets of questions using Likert scales. One item in particular, "I get bored and restless when I don't have anything to do at work" had a low response rate and was therefore excluded from the scale for analysis. Cronbach's alpha is a function of the number of test items and the average inter-correlation among the items. The Work Enjoyment, Drive, Gender Culture and Perceptions of being a Workaholic Scales were found to be reliable (see Appendix 1). Work Involvement was found not to be reliable. Two items in this scale were found to have low correlation with their cluster of items and were therefore excluded. These were "Consider job important to who I am" and "Feel it's difficult to separate myself from my work". This helps ensure the measure is valid by ensuring it consistently captures what is being explored.

\section{Sample Participants}

Biographical details such as gender, ethnicity, marital status, institution of employment and employment position are provided in Table 3. The detailed graphs of these variables can be found in Appendix $C$. Half the participants were female. A large majority of participants $(66.8 \%)$ were married, followed by $15.7 \%$ in a de facto relationship. Only $28.4 \%$ of the participants had no children. Sixty five percent of the sample was comprised of New Zealand Europeans. $43.5 \%$ of the participants held senior lecturing positions, followed by lecturer positions (16.6\%), Professors (15.4\%), and Associate/Assistant Professors (13.6\%). 
Table 3. Biographic Data $(\mathrm{N}=331)$

\begin{tabular}{|c|c|c|}
\hline \multicolumn{2}{|l|}{ Variable } & Percentage $(\%)$ \\
\hline \multirow[t]{2}{*}{ Gender } & Male & 50.5 \\
\hline & Female & 49.5 \\
\hline \multirow[t]{5}{*}{ Marital Status } & Married & 66.8 \\
\hline & Divorced/Separated & 6.6 \\
\hline & Widowed & 0.3 \\
\hline & Never Married & 10.3 \\
\hline & De Facto Relationship & 15.7 \\
\hline \multirow[t]{2}{*}{ Children } & Yes & 70.7 \\
\hline & No & 28.4 \\
\hline \multirow[t]{8}{*}{ Ethnicity } & Maori & 3.3 \\
\hline & NZ European & 65.3 \\
\hline & European & 20.2 \\
\hline & Pacific Islander & 0.6 \\
\hline & Asian & 1.8 \\
\hline & Middle Eastern & 0.3 \\
\hline & African & 0.3 \\
\hline & Other & 7.3 \\
\hline \multirow{8}{*}{$\begin{array}{l}\text { Institution Of } \\
\text { Employment }\end{array}$} & Otago University & 13.6 \\
\hline & University of Canterbury & 3.3 \\
\hline & Victoria University of Wellington & 15.1 \\
\hline & Waikato University & 14.5 \\
\hline & Massey University & 9.4 \\
\hline & University of Auckland & 24.5 \\
\hline & Auckland University of Technology & 10.9 \\
\hline & Lincoln University & 8.5 \\
\hline \multirow{5}{*}{$\begin{array}{l}\text { Employment } \\
\text { Position }\end{array}$} & Lecturer & 16.6 \\
\hline & Senior Lecturer & 43.5 \\
\hline & Associate/Assistant Professor & 13.6 \\
\hline & Professor & 15.4 \\
\hline & Other & 10.6 \\
\hline
\end{tabular}

\section{Validity}

Factor analysis was carried out to test the factorial validity of the data. This helps determine whether the items are measuring the same concepts or variables. Initial communalities are estimates of the variance in each variable accounted for by all 
components or factors. Extraction communalities are estimates of the variance in each variable accounted for by the factors (or components) in the factor solution. Small values indicate variables that do not fit well with the factor solution, and should possibly be dropped from the analysis. This thesis followed the strategy of excluding items with loadings below 0.50 (Carver and Nash, 2006).

The survey was originally intended to measure three dimensions of Workaholism: Work Involvement (five items), reflecting the need to spend time efficiently both at work and when off work, blurred boundaries between work and private life and the inability to relax. Drive (seven items) reflecting internal motivation for work and the frequency of thinking about work. Enjoyment of Work, (ten items) assessing satisfaction from work. The survey was also intended to measure Workaholism Perceptions (two items) and Gender Perceptions (five items).

Table 4. Output of the Factor Analysis for Work Involvement

\begin{tabular}{|l|r|r|}
\hline & Initial & Extraction \\
\hline I use my time constructively while on the job & 1.000 & .615 \\
I use my time constructively while off the job & 1.000 & .837 \\
get bored and restless when I don't have anything to do at & 1.000 & .623 \\
Work & & 1.000 \\
I fully dedicate myself to everything I do while on the job & 1.000 & .650 \\
\hline
\end{tabular}

Extraction Method: Principal Component Analysis.

Table 4 shows that Work Involvement has good construct validity and that the five items all measure the same variable. 
Table 5. Output of the Factor Analysis for Drive

\begin{tabular}{|l|r|r|}
\hline & Initial & Extraction \\
\hline I feel obligated to work hard, even if I don't enjoy the work & 1.000 & .770 \\
I often feel there's something inside me that drives me to work & 1.000 & .861 \\
hard & & 1.000 \\
I often find myself thinking about work, even when I want to & .610 \\
get away from it for awhile & 1.000 & .415 \\
I feel I have high standards for all things I do & 1.000 & .469 \\
I often find it difficult to justify taking a vacation & 1.000 & .924 \\
It's important to me to work to my best abilities at all times & 1.000 & .676 \\
\hline
\end{tabular}

Extraction Method: Principal Component Analysis.

The instrument to measure Drive did not achieve good construct validity. For this reason the red items seen above in Table 5 were excluded from further data analysis.

\section{Table 6. Output of the Factor Analysis for Work Enjoyment}

\begin{tabular}{|l|r|r|}
\hline & Initial & Extraction \\
\hline I often try to pinpoint what I need to do for ongoing success & 1.000 & .964 \\
I like to be challenged by my work & 1.000 & .393 \\
After attaining a goal, I look for a new and more challenging & 1.000 & .939 \\
one & & 1.000 \\
Most of the time I find my work very enjoyable & 1.000 & .574 \\
Sometimes I enjoy my work so much I don't want to stop & 1.000 & .657 \\
I enjoy my work so much I lose track of time when engaged in & & .599 \\
a project & 1.000 & .639 \\
I frequently look forward to going to work & 1.000 & .616 \\
Most of the time I am interested in the work I do & 1.000 & .521 \\
I tend to be proud of the work I do & 1.000 & .526 \\
\hline
\end{tabular}

Extraction Method: Principal Component Analysis.

The instrument to measure Work Enjoyment did not achieve good construct validity either. For this reason the red item seen above in Table 6 were excluded from further data analysis. 


\section{Table 7. Output of the Factor Analysis for Gender Perceptions}

\begin{tabular}{|l|r|r|}
\hline & Initial & Extraction \\
\hline Males and female academics are not considered as equals & 1.000 & .064 \\
Females need to prove themselves to be equal to males & 1.000 & .722 \\
Females need to work longer and harder than their male & 1.000 & .107 \\
colleagues to be accepted & & .756 \\
The academic industry has a male dominated, macho culture & 1.000 & .764 \\
\hline $\begin{array}{l}\text { The organisational culture works against the inclusion of } \\
\text { females in senior ranks }\end{array}$ & 1.000 & \\
\hline
\end{tabular}

Extraction Method: Principal Component Analysis.

Two items in the measure of Gender Perceptions in the workplace prevented this measure from achieving construct validity. These items, seen above in red in Table 7, were therefore excluded.

Table 8. Output of the Factor Analysis for Workaholism Perceptions

\begin{tabular}{|l|r|r|}
\hline & \multicolumn{1}{|c|}{ Initial } & Extraction \\
\hline Would other people describe you as a Workaholic & 1.000 & .914 \\
Would you describe yourself as a Workaholic & 1.000 & .914 \\
\hline
\end{tabular}

Extraction Method: Principal Component Analysis.

Table 8 shows that Workaholism Perceptions has good construct validity and that the two items both measure the same variable.

Given the factor analytic results subsequent analyses therefore focus on the shortened version of this survey. Thus, when the subscales hereafter are mentioned, they refer to the shortened versions of the original subscales.

\section{Ethical Considerations}

As the data collected can be considered sensitive, precautions were made to ensure this research was anonymous. Prior to distributing the surveys, Human Ethics Committee approval was obtained from Victoria University of Wellington. Each participant was supplied with an information sheet assuring participants of the confidentiality of their responses and that reporting would be in non-attributable form, and that consent was 
implied by voluntary participation in filling out the survey. A copy of the information sheet is in Appendix B. In order to ensure anonymity research data will be restricted to me and my supervisor, and all opinions and data are reported in aggregated form in such a way that individual people are not identifiable.

The next Chapter reports the results of this thesis in order to answer the research question - what is the differences in the degree of Workaholism and Workaholismrelated variables between genders? The chapter is broken down into sections that cover each of the sub-questions detailed in this Chapter. 


\section{Chapter 6: Results}

\section{Introduction}

This chapter reports on the results of this study. The first section presents demographic and work situation differences between genders. These are presented as this study is intended to specifically investigate the effect of gender. The second section presents the central tendencies and the dispersion among the variables. The third part of this Chapter looks into the effects of gender in order to answer the first research question for this study - What are the differences in the degree of Workaholism and Workaholismrelated variables between genders? The extent to which this is examined can been seen in theoretical framework (Figure 3) in the previous Chapter. This is done through examining statistics, initially carrying out discriminant analysis and ANOVAs followed by carrying out T-tests and Pearson correlations. The fourth part of this Chapter shows some additional analysis of the results by comparing the Workaholism Composite Score and Overtime and well as comparing the definition of Workaholism used in this study and how participants define Workaholism. Finally, a summary of the results found in

this study can also be found at the end of this Chapter, along with a post research framework showing the differences in the degree of Workaholism and Workaholismrelated variables between genders.

A total of 414 completed questionnaires were returned from a total of 3174, representing a response rate of $13 \%$. Missing data for one or more key study variables and removing respondents working part time reduced this number to 381. Of these, 50 were excluded as the respondents had not worked in New Zealand for the minimum period of five years, leaving a remainder of 331 responses. The gender composition of the remaining sample was $50.5 \%$ male $(\mathrm{N}=167), 49.5 \%$ female $(\mathrm{N}=164)$.

\section{Demographic and work situation differences}

Previous Comparisons of demographic and work situation characteristics of male and female participants have shown considerable and predictable differences. The findings of this study are no exception. Table 9 and Table 10 show the male and female 
comparisons on a number of personal demographic and work situation characteristics. There were no significant differences between genders for marital status, or having children. There were significant differences between genders for ethnicity and employment position.

Table 9. Descriptive Statistics

\begin{tabular}{|ll|r|r|r|r|}
\hline Gender & & $\mathrm{N}$ & \multicolumn{1}{|c|}{ Mean } & Std. Deviation & Variance \\
\hline Male & Marital Status & 166 & 1.81 & 1.505 & 2.266 \\
& Children & 165 & 1.20 & .401 & .161 \\
& Ethnicity & 166 & 2.90 & 1.945 & 3.785 \\
& Employment Position & 167 & 2.65 & 1.152 & 1.326 \\
& Valid N (listwise) & 127 & & & \\
\hline Female & Marital Status & 164 & 2.22 & 1.639 & 2.688 \\
& Children & 163 & 1.37 & .485 & .236 \\
& Ethnicity & 162 & 2.65 & 1.829 & 3.346 \\
Employment Position & 164 & 2.56 & 1.326 & 1.757 \\
Valid N (listwise) & 143 & & & \\
\hline
\end{tabular}

Table 10. ANOVA Comparing Genders

\begin{tabular}{|ll|r|r|r|r|r|}
\hline & & \multicolumn{1}{c|}{$\begin{array}{c}\text { Sum of } \\
\text { Squares }\end{array}$} & df & $\begin{array}{c}\text { Mean } \\
\text { Square }\end{array}$ & \multicolumn{1}{c|}{$\mathrm{F}$} & Sig. \\
\hline Marital Status & Between Groups & 14.023 & 1 & 14.023 & 5.665 & .018 \\
& Within Groups & 811.929 & 328 & 2.475 & & \\
& Total & 825.952 & 329 & & & \\
\hline Children & Between Groups & 2.489 & 1 & 2.489 & 12.567 & .000 \\
& Within Groups & 64.572 & 326 & .198 & & \\
& Total & 67.061 & 327 & & & \\
\hline Ethnicity & Between Groups & 5.095 & 1 & 5.095 & 1.428 & .233 \\
& Within Groups & 1163.100 & 326 & 3.568 & & \\
& Total & 1168.195 & 327 & & & \\
\hline Employment & Between Groups & .608 & 1 & .608 & .395 & .530 \\
Position & Within Groups & 506.546 & 329 & 1.540 & & \\
& Total & 507.154 & 330 & & & \\
\hline
\end{tabular}




\section{Measures of Central Tendencies and Dispersion}

The mean, standard deviation and variance provide a general indication of how the respondents have reacted to the survey. As this study is intended to investigate gender differences, therefore the following statistics have been split in order to compare the two groups.

Table 11. Descriptive Statistics of Variables

\begin{tabular}{|c|c|c|c|c|c|}
\hline \multicolumn{3}{|c|}{ Variables - Items } & Mean & Std. & Variance \\
\hline \multirow{5}{*}{$\begin{array}{l}\text { Work } \\
\text { Involvement }\end{array}$} & $\begin{array}{l}\text { I use my time constructively } \\
\text { while on the job }\end{array}$ & $\begin{array}{l}\text { Male } \\
\text { Female }\end{array}$ & $\begin{array}{l}4.10 \\
3.30 \\
\end{array}$ & $\begin{array}{l}.709 \\
.720 \\
\end{array}$ & $\begin{array}{l}.503 \\
.518 \\
\end{array}$ \\
\hline & $\begin{array}{l}\text { I use my time constructively } \\
\text { while off the job }\end{array}$ & $\begin{array}{l}\text { Male } \\
\text { Female }\end{array}$ & $\begin{array}{l}3.91 \\
4.02\end{array}$ & $\begin{array}{l}.724 \\
.812\end{array}$ & $\begin{array}{l}.524 \\
.659\end{array}$ \\
\hline & $\begin{array}{l}\text { I get bored and restless when I } \\
\text { don't have anything to do at } \\
\text { work }\end{array}$ & $\begin{array}{l}\text { Male } \\
\text { Female }\end{array}$ & $\begin{array}{l}3.25 \\
3.32\end{array}$ & $\begin{array}{l}1.285 \\
1.257\end{array}$ & $\begin{array}{l}1.651 \\
1.579\end{array}$ \\
\hline & $\begin{array}{l}\text { I fully dedicate myself to } \\
\text { everything I do while on the job }\end{array}$ & $\begin{array}{l}\text { Male } \\
\text { Female }\end{array}$ & $\begin{array}{l}4.00 \\
4.19\end{array}$ & $\begin{array}{l}.821 \\
.840\end{array}$ & $\begin{array}{l}.674 \\
.705\end{array}$ \\
\hline & $\begin{array}{l}\text { I like to devote myself to } \\
\text { productive projects }\end{array}$ & $\begin{array}{l}\text { Male } \\
\text { Female }\end{array}$ & $\begin{array}{l}4.44 \\
4.52\end{array}$ & $\begin{array}{l}.670 \\
.632\end{array}$ & $\begin{array}{l}.448 \\
.399\end{array}$ \\
\hline \multirow{5}{*}{ Drive } & $\begin{array}{l}\text { I feel obligated to work hard, } \\
\text { even if I don't enjoy the work }\end{array}$ & $\begin{array}{l}\text { Male } \\
\text { Female }\end{array}$ & $\begin{array}{l}3.50 \\
4.89 \\
\end{array}$ & $\begin{array}{r}1.038 \\
.905 \\
\end{array}$ & $\begin{array}{r}1.077 \\
.819 \\
\end{array}$ \\
\hline & $\begin{array}{l}\text { I often feel there's something } \\
\text { inside me that drives me to work } \\
\text { hard }\end{array}$ & $\begin{array}{l}\text { Male } \\
\text { Female }\end{array}$ & $\begin{array}{l}4.07 \\
4.09\end{array}$ & $\begin{array}{l}.836 \\
.761\end{array}$ & $\begin{array}{l}.699 \\
.579\end{array}$ \\
\hline & $\begin{array}{l}\text { I often find myself thinking } \\
\text { about work, even when I want to } \\
\text { get away from it for awhile }\end{array}$ & $\begin{array}{l}\text { Male } \\
\text { Female }\end{array}$ & $\begin{array}{l}4.08 \\
4.18\end{array}$ & $\begin{array}{l}.914 \\
.854\end{array}$ & $\begin{array}{l}.835 \\
.730\end{array}$ \\
\hline & $\begin{array}{l}\text { It's important to me to work to } \\
\text { my best abilities at all times }\end{array}$ & $\begin{array}{l}\text { Male } \\
\text { Female }\end{array}$ & $\begin{array}{l}4.28 \\
4.39 \\
\end{array}$ & $\begin{array}{l}.682 \\
.597 \\
\end{array}$ & $\begin{array}{l}.465 \\
.357 \\
\end{array}$ \\
\hline & $\begin{array}{l}\text { I often work until I'm too tired } \\
\text { to do more }\end{array}$ & $\begin{array}{l}\text { Male } \\
\text { Female }\end{array}$ & $\begin{array}{l}3.59 \\
3.64\end{array}$ & $\begin{array}{l}1.052 \\
1.159\end{array}$ & $\begin{array}{l}1.107 \\
1.342\end{array}$ \\
\hline
\end{tabular}


Table 11 continued.

\begin{tabular}{|c|c|c|c|c|c|}
\hline \multicolumn{3}{|c|}{ Variables - Items } & Mean & & Variance \\
\hline \multirow{16}{*}{$\begin{array}{l}\text { Work } \\
\text { Enjoyment }\end{array}$} & $\begin{array}{l}\text { I often try to pinpoint what I } \\
\text { need to do for ongoing success }\end{array}$ & $\begin{array}{l}\text { Male } \\
\text { Female }\end{array}$ & $\begin{array}{l}3.53 \\
3.78 \\
\end{array}$ & $\begin{array}{r}1.001 \\
.851 \\
\end{array}$ & $\begin{array}{r}1.002 \\
.723 \\
\end{array}$ \\
\hline & $\begin{array}{l}\text { After attaining a goal, I look for } \\
\text { a new and more challenging one }\end{array}$ & $\begin{array}{l}\text { Male } \\
\text { Female }\end{array}$ & 3.99 & .818 & .668 \\
\hline & \multirow{2}{*}{$\begin{array}{l}\text { Most of the time I find my work } \\
\text { very enjoyable }\end{array}$} & \multirow{2}{*}{$\begin{array}{l}\text { Male } \\
\text { Female }\end{array}$} & 3.99 & .812 & .659 \\
\hline & & & $\begin{array}{l}4.10 \\
4.05\end{array}$ & $\begin{array}{l}.744 \\
.765\end{array}$ & $\begin{array}{l}.553 \\
.585\end{array}$ \\
\hline & \multirow{2}{*}{$\begin{array}{l}\text { Sometimes I enjoy my work so } \\
\text { much I don't want to stop }\end{array}$} & \multirow{2}{*}{$\begin{array}{l}\text { Male } \\
\text { Female }\end{array}$} & 3.63 & 1.001 & 1.002 \\
\hline & & & 3.26 & 1.060 & 1.124 \\
\hline & \multirow{2}{*}{$\begin{array}{l}\text { I enjoy my work so much I lose } \\
\text { track of time when engaged in a } \\
\text { project }\end{array}$} & \multirow{2}{*}{$\begin{array}{l}\text { Male } \\
\text { Female }\end{array}$} & 3.71 & .934 & .871 \\
\hline & & & 3.60 & .930 & .866 \\
\hline & \multirow{2}{*}{$\begin{array}{l}\text { I frequently look forward to } \\
\text { going to work }\end{array}$} & \multirow{2}{*}{$\begin{array}{l}\text { Male } \\
\text { Female }\end{array}$} & 3.63 & .902 & .814 \\
\hline & & & 3.49 & .964 & .928 \\
\hline & \multirow{2}{*}{$\begin{array}{l}\text { Most of the time I am interested } \\
\text { in the work I do }\end{array}$} & \multirow{2}{*}{$\begin{array}{l}\text { Male } \\
\text { Female }\end{array}$} & 4.22 & .556 & .309 \\
\hline & & & 4.23 & .580 & .336 \\
\hline & \multirow{2}{*}{$\begin{array}{l}\text { I tend to be proud of the work I } \\
\text { do }\end{array}$} & \multirow{2}{*}{$\begin{array}{l}\text { Male } \\
\text { Female }\end{array}$} & 4.29 & .639 & .408 \\
\hline & & & 4.22 & .612 & .374 \\
\hline & \multirow{2}{*}{$\begin{array}{l}\text { I look at overcoming obstacles } \\
\text { as positive experiences }\end{array}$} & \multirow{2}{*}{$\begin{array}{l}\text { Male } \\
\text { Female }\end{array}$} & 4.06 & .796 & .634 \\
\hline & & & 3.76 & .869 & .756 \\
\hline \multirow{6}{*}{$\begin{array}{l}\text { Gender } \\
\text { Perceptions }\end{array}$} & \multirow{2}{*}{$\begin{array}{l}\text { Females need to prove } \\
\text { themselves to be equal to males }\end{array}$} & \multirow{2}{*}{$\begin{array}{l}\text { Male } \\
\text { Female }\end{array}$} & 2.29 & 1.069 & 1.143 \\
\hline & & & 3.66 & 1.177 & 1.386 \\
\hline & \multirow{2}{*}{$\begin{array}{l}\text { The academic industry has a } \\
\text { male dominated, macho culture }\end{array}$} & \multirow{2}{*}{$\begin{array}{l}\text { Male } \\
\text { Female }\end{array}$} & 2.34 & 1.125 & 1.266 \\
\hline & & & 3.55 & 1.182 & 1.398 \\
\hline & \multirow{2}{*}{$\begin{array}{l}\text { The organisational culture } \\
\text { works against the inclusion of } \\
\text { females in senior ranks }\end{array}$} & \multirow{2}{*}{$\begin{array}{l}\text { Male } \\
\text { Female }\end{array}$} & 2.32 & 1.118 & 1.250 \\
\hline & & & 3.57 & 1.140 & 1.299 \\
\hline \multirow{4}{*}{$\begin{array}{l}\text { Workaholism } \\
\text { Perceptions }\end{array}$} & \multirow{2}{*}{$\begin{array}{l}\text { Would other people describe } \\
\text { you as a Workaholic }\end{array}$} & \multirow{2}{*}{$\begin{array}{l}\text { Male } \\
\text { Female }\end{array}$} & 3.26 & 1.010 & 1.020 \\
\hline & & & 3.20 & 1.142 & 1.303 \\
\hline & \multirow{2}{*}{$\begin{array}{l}\text { Would you describe yourself as } \\
\text { a Workaholic }\end{array}$} & \multirow{2}{*}{$\begin{array}{l}\text { Male } \\
\text { Female }\end{array}$} & 2.89 & .980 & .960 \\
\hline & & & 2.81 & 1.042 & 1.086 \\
\hline
\end{tabular}

In summary, all variables are widely clustered around the mean, slightly skewed towards agreeing with the statements. The variance for most of the items was quite high indicating that respondents widely spread their responses from the minimum of 1 to the maximum of 5 . The standard deviations demonstrate that the variables are closely clustered. 
The next part of this study looks into the effects of gender. The extent to which this is done can been seen in theoretical framework (Figure 3). This is done through examining statistics, and carrying out ANOVA's, T-tests and Pearson correlations. Two-sided P value and two-tailed Sig values were used as the hypotheses in this study did not specify the direction of any differences hypothesised.

However, before this is done the gender perception in academia needs to be examined. Table 11 shows the mean, standard deviation and variance for the gender perceptions for each gender. The differences between the genders in the mean scores for each items as depicted in Table 11 suggest that these may be good discriminators as there are separations. Further analysis can be seen below in Table 12.

Discriminant Analysis was carried out to investigate differences between genders on the basis of gender perceptions. The aim of the statistical analysis in discriminant analysis is to combine the variable scores in some way so that a single new composite variable, the discriminant score, is produced. The degree of overlap between the discriminant score distributions can then be used as a measure whether there is a significant difference between the groups.

Table 12. Univariate ANOVA - Test of Equality of Group Means

\begin{tabular}{|c|c|c|c|c|c|}
\hline & Wilks' Lambda & $\mathrm{F}$ & df1 & df2 & Sig. \\
\hline $\begin{array}{l}\text { Females need to prove } \\
\text { themselves to be equal to } \\
\text { males }\end{array}$ & .729 & 140.670 & 1 & 378 & .000 \\
\hline $\begin{array}{l}\text { The academic industry has a } \\
\text { male dominated, macho } \\
\text { culture }\end{array}$ & .782 & 105.351 & 1 & 378 & .000 \\
\hline $\begin{array}{l}\text { The organisational culture } \\
\text { works against the inclusion of } \\
\text { females in senior ranks }\end{array}$ & .764 & 116.837 & 1 & 378 & .000 \\
\hline
\end{tabular}

Table 12 provides strong statistical evidence of significant differences between means for each gender, producing very high value F's. 
Table 13. Box's Test of Equality of Covariance Matrices

\begin{tabular}{|l|r|r|}
\hline \multicolumn{2}{|c|}{ Log Determinants } \\
\hline Gender & Rank & $\begin{array}{c}\text { Log } \\
\text { Determinant }\end{array}$ \\
\hline Male & 3 & -.161 \\
Female & 3 & -.159 \\
Pooled within-groups & 3 & -.147 \\
\hline
\end{tabular}

The ranks and natural logarithms of determinants printed are those of the group covariance matrices.
Test Results

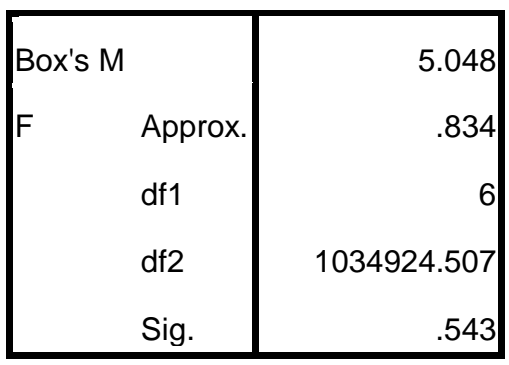

Tests null hypothesis of equal population covariance matrices.

The significance value of 0.543 indicates that the data does not differ significantly from multivariate normal. This means one can proceed with the analysis.

\section{Table 14. Summary of Canonical Discriminant Functions}

Eigenvalues

\begin{tabular}{|l|r|r|r|r|}
\hline $\begin{array}{l}\text { Functio } \\
\mathrm{n}\end{array}$ & Eigenvalue & \% of Variance & Cumulative \% & $\begin{array}{l}\text { Canonical } \\
\text { Correlation }\end{array}$ \\
\hline 1 & $.471^{\mathrm{a}}$ & 100.0 & 100.0 & .566 \\
\hline
\end{tabular}

a. First 1 canonical discriminant functions were used in the analysis.

\section{Wilks' Lambda}

\begin{tabular}{|l|r|r|r|r|}
\hline $\begin{array}{l}\text { Test of } \\
\text { Functio } \\
\mathrm{n}(\mathrm{s})\end{array}$ & Wilks' Lambda & Chi-square & df & \multicolumn{1}{c|}{ Sig. } \\
\hline 1 & .680 & 145.364 & 3 & .000 \\
\hline
\end{tabular}

An eigenvalue indicates the proportion of variance explained. A large eigenvalue is associated with a strong function. The canonical relation is a correlation between the discriminant scores and the levels of the dependent variable. A high correlation indicates a function that discriminates well. The present correlation of 0.566 is not extremely high. This suggests there is moderate discrimination between the genders.

Wilks' Lambda is the ratio of within-groups sums of squares to the total sums of squares. This is the proportion of the total variance in the discriminant scores not explained by 
differences among groups. A lambda of 1.00 occurs when observed group means are equal (all the variance is explained by factors other than difference between those means), while a small lambda occurs when within-groups variability is small compared to the total variability. A small lambda indicates that group means appear to differ. The associated significance value indicates whether the difference is significant. Here, the Lambda of 0.680 has a significant value of 0.000 , thus, the group means appear to differ.

As a difference was found further analysis was carried out in the means of a T-test, as seen below in Table 15.

Table 15. Independent Samples T-test between Gender and Gender Perceptions

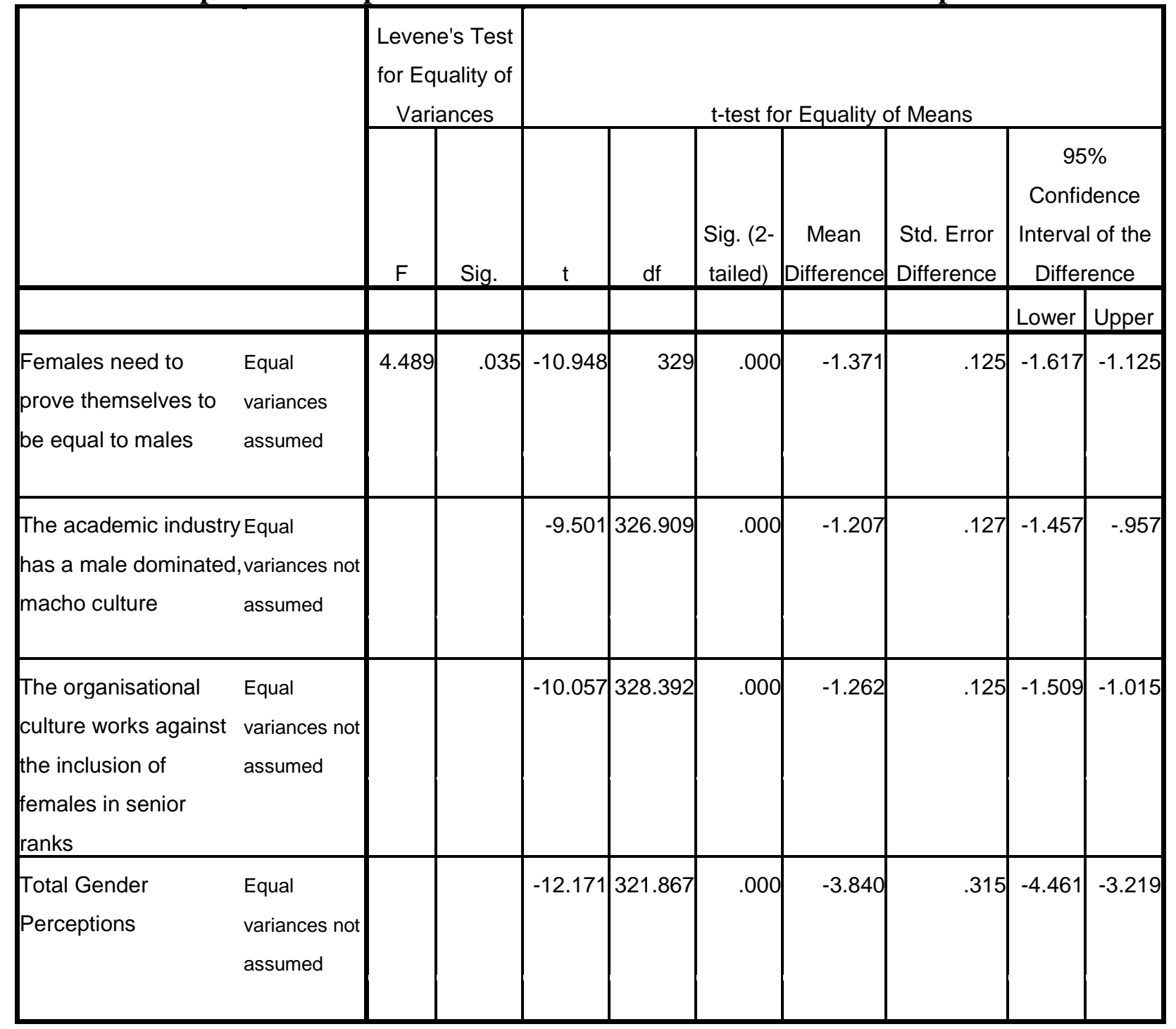


Levene's Test for Equality of Variances determines if the items have about the same or different variability between scores. A value greater than $.05(\alpha)$ means that the variability in the two conditions is not significantly different. In this instance equal variances were not assumed only for the first item. The Sig (2-Tailed) value shows if means for each gender are statistically different. If the Sig (2-Tailed) value is greater than .05 it can be concluded that there is no statistically significant difference between genders. If the Sig (2-Tailed) value is less than or equal to .05 it can be concluded that there is a statistically significant difference between genders. As seen below, in this test the Sig (2-Tailed) is .000 , as this is below .05 it can be concluded that there is a statistically significant difference between genders in the mean for gender perceptions in the workplace. The test statistic $t$ for the three variables respectively is -10.948, -9.507, 10.06 and -12.186 . The sign of the test statistic is what is expected if the alternative hypothesis is true. Therefore the null hypothesis is rejected in favour of the alternative hypothesis. Since our Group Statistics seen above revealed that the mean response for females was greater than the mean for males, we can conclude that females tend towards agreeing with the statements whereas males tend towards disagreeing with the statements. This in itself suggests there are gender differences in the workplace.

\section{Impacts of Gender on Workaholism}

Having examined participants' perceptions on the gender culture in the workplace, this study moves on to look into the differences in degrees of the Workaholism exhibited between genders. First, one-way analysis of variance (ANOVA) was carried out to determine whether there are any significant differences between the means of the independent groups (males and females) on the basis of the Workaholism Composite Score. The Workaholism Composite Score was used as it was composed using all the items from the three Workaholism characteristics scales. The one-way ANOVA compares the means between the groups (in this case gender) and determines whether those means are significantly different from each other. Specifically, it tests the null hypothesis. If, however, the one-way ANOVA returns a significant result then we accept the alternative hypothesis, which is that each genders means are significantly different from each other. 
Table 16. One-way ANOVA

Workaholism Composite Score
\begin{tabular}{|l|r|r|r|r|r|}
\hline & \multicolumn{1}{|c|}{$\begin{array}{c}\text { Sum of } \\
\text { Squares }\end{array}$} & \multicolumn{1}{c|}{ df } & $\begin{array}{r}\text { Mean } \\
\text { Square }\end{array}$ & \multicolumn{1}{c|}{ F } & Sig. \\
\hline Between Groups & 2.913 & 1 & 2.913 & 13.313 & .000 \\
Within Groups & 82.919 & 379 & .219 & & \\
Total & 85.832 & 380 & & & \\
\hline
\end{tabular}

This is the table that shows the output of the ANOVA analysis and whether there is a statistically significant difference between each gender's means. The significance level is 0.000 , which is below 0.05 and, therefore, there is a statistically significant difference in the mean Workaholism Composite Score between the different genders.

As a significant difference between the genders was found through the ANOVA test further anaylsis on the differences in the degree of Workaholism and Workaholismrelated variables between genders was examined. This was does by analyzing the relationships involved in each of the subquestions individually using T-tests and Pearson correlations.

\section{Gender and the Workaholism Composite Score}

A composite score for Workaholism was computed by adding standardised work involvement scores to standardised work drive scores and the reversed standardised work enjoyment scores (Workaholism Composite Score $=($ work involvement + work drive + reversed work enjoyment)/3). Work enjoyment was reversed because the definition of Workaholism requires low work enjoyment, so where participants chose five, one was used for the calculation; where participants chose four, two was used for the calculation and vice versa. The composite score for Workaholism is then on a scale on one to five and therefore easily comparable to the responses on the same scale. High scores represent being a Workaholic. Note that work enjoyment should not be construed as the opposite of Workaholism; work enjoyment is still a dimension of Workaholism, but now it is treated as a continuous variable. 
A $\mathrm{T}$ test was carried out in order to examine whether there was a significant difference in the Workaholism Composite Score due to gender. The results of t-test comparing the means of men and women are shown in Table 17.

Table 17. Group Statistics for Workaholism Composite Score

\begin{tabular}{|ll|r|r|r|r|}
\hline & Gender & \multicolumn{1}{|c|}{$\mathrm{N}$} & \multicolumn{1}{c|}{ Mean } & Std. Deviation & Std. Error Mean \\
\hline Workaholism Composite & Male & 167 & 3.22 & .431 & .033 \\
Score & Female & 164 & 3.41 & .506 & .040 \\
\hline
\end{tabular}

Table 18. Independent Samples T-test between Gender and the Workaholism Composite Score

\begin{tabular}{|c|c|c|c|c|c|c|c|c|c|}
\hline & \multicolumn{2}{|c|}{$\begin{array}{c}\text { Levene's Test } \\
\text { for Equality of } \\
\text { Variances }\end{array}$} & \multicolumn{7}{|c|}{ t-test for Equality of Means } \\
\hline & $\mathrm{F}$ & Sig. & $\mathrm{t}$ & $\mathrm{df}$ & \begin{tabular}{|l} 
Sig. (2-- \\
tailed)
\end{tabular} & $\begin{array}{c}\text { Mean } \\
\text { Difference }\end{array}$ & $\begin{array}{l}\text { Std. Error } \\
\text { Difference }\end{array}$ & $\begin{array}{r}95^{\circ} \\
\text { Confid } \\
\text { Interval } \\
\text { Differe }\end{array}$ & $\begin{array}{l}\% \\
\text { lence } \\
\text { of the } \\
\text { ence }\end{array}$ \\
\hline Equal variances not assumed & & & & & & & & Lower & Upper \\
\hline $\begin{array}{l}\text { Workaholism Composite } \\
\text { Score }\end{array}$ & 43.908 & .000 & -3.733 & 318.855 & .000 & -.193 & .052 & -.295 & -.091 \\
\hline
\end{tabular}

Levene's Test shows that equal variances cannot be assumed for the Workaholism composite score. As the Sig (2-Tailed) value is less than or equal to .05 it can be concluded that there is a statistically significant difference between genders. Therefore, the null hypothesis is rejected in favour of the alternative hypothesis H1. Since our Group Statistics seen above revealed that the mean response for females was greater than the mean for males, we can conclude that females tend to have a higher Workaholism Composite Score than males. In order to further explore these gender differences the relationship between gender and each of the Workaholism characteristics was examined. 


\section{Gender and Workaholism Characteristics}

An independent sample $\mathrm{T}$ test was carried out. This indicates whether each of the Workaholism characteristics significantly differ among genders. The results of the t tests comparing the means of men and women are shown in Table 19.

Table 19. Group Statistics between Gender and the Workaholism Characteristics

\begin{tabular}{|ll|r|r|r|r|}
\hline & Gender & $\mathrm{N}$ & \multicolumn{1}{|c|}{ Mean } & Std. Deviation & Std. Error Mean \\
\hline Average Work Involvement & Male & 167 & 3.93 & .593 & .046 \\
& Female & 164 & 4.11 & .597 & .047 \\
\hline Average Drive & Male & 167 & 3.90 & .613 & .047 \\
& Female & 164 & 4.07 & .661 & .052 \\
\hline \multirow{2}{*}{ Average work Enjoyment } & Male & 167 & 3.92 & .630 & .049 \\
& Female & 164 & 3.84 & .629 & .049 \\
\hline
\end{tabular}

Table 20. Independent Samples T-test between Gender and the Workaholism Characteristics

\begin{tabular}{|c|c|c|c|c|c|c|c|c|c|}
\hline & \multicolumn{2}{|c|}{$\begin{array}{l}\text { Levene's } \\
\text { Test for } \\
\text { Equality of } \\
\text { Variances }\end{array}$} & \multicolumn{7}{|c|}{ t-test for Equality of Means } \\
\hline & $\mathrm{F}$ & Sig. & $\mathrm{t}$ & df & $\begin{array}{l}\text { Sig. (2- } \\
\text { tailed) }\end{array}$ & $\begin{array}{c}\text { Mean } \\
\text { Difference }\end{array}$ & $\begin{array}{l}\text { Std. Error } \\
\text { Difference }\end{array}$ & $\begin{array}{r}95 \% \text { Co } \\
\text { Intervo } \\
\text { Diffe }\end{array}$ & $\begin{array}{l}\text { nfidence } \\
\text { lof the } \\
\text { rence }\end{array}$ \\
\hline Equal variances assumed & & & & & & & & Lower & Upper \\
\hline Average Work Involvement & 1.144 & .286 & -2.687 & 329 & .008 & -.176 & .065 & -.304 & -.047 \\
\hline Average Drive & .635 & .426 & -2.412 & 329 & .016 & -.169 & .070 & -.307 & -.031 \\
\hline Average work Enjoyment & 1.070 & .302 & 1.253 & 329 & .211 & .087 & .069 & -.049 & .223 \\
\hline
\end{tabular}

The Levene's Test for Equality of Variances shows that equal variances can be assumed each of the characteristics as the P-value is higher than $\alpha$. The Sig. (2-Tailed) value for Work Involvement and Drive is below .05 enabling the conclusion that there is a significant difference between genders for each of these characteristics. Therefore these tables suggest that the alternative hypothesis $\mathbf{H 2}$ and $\mathbf{H 3}$ can both be accepted. However, 
the Sig. (2-Tailed) value for Work Enjoyment is above .05. The alternative hypothesis H4 cannot be accepted as there is no significant difference in Work enjoyment between genders. Females displayed significantly higher than males on the Work Involvement and Drive scales, while males and females indicated similar levels of Work Enjoyment.

The mean differences between the sexes are the relationships among the measures within each sex were also examined. The correlation matrix is displayed in Table 21, with males in the top half and females in the bottom half. These results demonstrate a difference between the sexes with respect to the relationships among the variables.

Table 21. Correlations between Measures for Males and Females

\begin{tabular}{|c|c|c|c|c|}
\hline & & $\begin{array}{c}\text { Average Work } \\
\text { Involvement }\end{array}$ & $\begin{array}{c}\text { Average } \\
\text { Drive }\end{array}$ & $\begin{array}{c}\text { Average Work } \\
\text { Enjoyment }\end{array}$ \\
\hline $\begin{array}{l}\text { Average Work } \\
\text { Involvement }\end{array}$ & $\begin{array}{l}\text { Pearson Correlation } \\
\text { Sig. (2-tailed) } \\
\mathrm{N}\end{array}$ & - & $\begin{array}{r}.215^{\star} \\
.005 \\
167 \\
\end{array}$ & $\begin{array}{l}.276^{\star \star} \\
.000 \\
167 \\
\end{array}$ \\
\hline Average Drive & $\begin{array}{l}\text { Pearson Correlation } \\
\text { Sig. (2-tailed) } \\
\mathrm{N}\end{array}$ & $\begin{array}{r}.213^{* *} \\
.006 \\
164 \\
\end{array}$ & - & $\begin{array}{r}.199 \\
.010 \\
167 \\
\end{array}$ \\
\hline $\begin{array}{l}\text { Average work } \\
\text { Enjoyment }\end{array}$ & $\begin{array}{l}\text { Pearson Correlation } \\
\text { Sig. (2-tailed) } \\
\mathrm{N}\end{array}$ & $\begin{array}{r}.359^{\star *} \\
.000 \\
164\end{array}$ & $\begin{array}{r}.206^{\star *} \\
.008 \\
164\end{array}$ & - \\
\hline
\end{tabular}

${ }^{* *}$. Correlation is significant at the 0.01 level (2-tailed).

*. Correlation is significant at the 0.05 level (2-tailed).

Note. The correlation for Females appear below the diagonal

As seen above in Table 21 both males and females reported a substantial positive correlation between Work Involvement and Work Enjoyment and between Work Involvement and Drive. Although both males and females reported a substantial positive correlation between Work Involvement and Work Enjoyment, the correlation for females was significantly higher. Females also reported a substantial positive correlation between Drive and Work Enjoyment, whereas males only reported a modest but still significant correlation between these two scales. An examination of the relationships 
among the three scales defining Workaholism reveals a substantial positive correlation between each of the characteristics.

\section{Gender and Workaholism Perceptions}

An independent sample $\mathrm{T}$ test was carried out. This indicates whether Workaholism perceptions significantly differ among gender. The results of $t$ tests comparing the means of men and women are shown in Table 22.

Table 22. Group Statistics between Gender and the Workaholism Perceptions

\begin{tabular}{|ll|r|r|r|r|}
\hline & Gender & \multicolumn{1}{|c|}{$\mathrm{N}$} & \multicolumn{1}{c|}{ Mean } & \multicolumn{1}{|c|}{ Std. Deviation } & Std. Error Mean \\
\hline Others describe you as a & Male & 163 & 3.29 & 1.017 & .080 \\
Workaholic & Female & 162 & 3.19 & 1.150 & .090 \\
\hline You describe yourself as a & Male & 163 & 2.89 & .988 & .077 \\
Workaholic & Female & 162 & 2.78 & 1.038 & .082 \\
\hline
\end{tabular}

Table 23. Independent Samples T-test between Gender and the Workaholism Perceptions

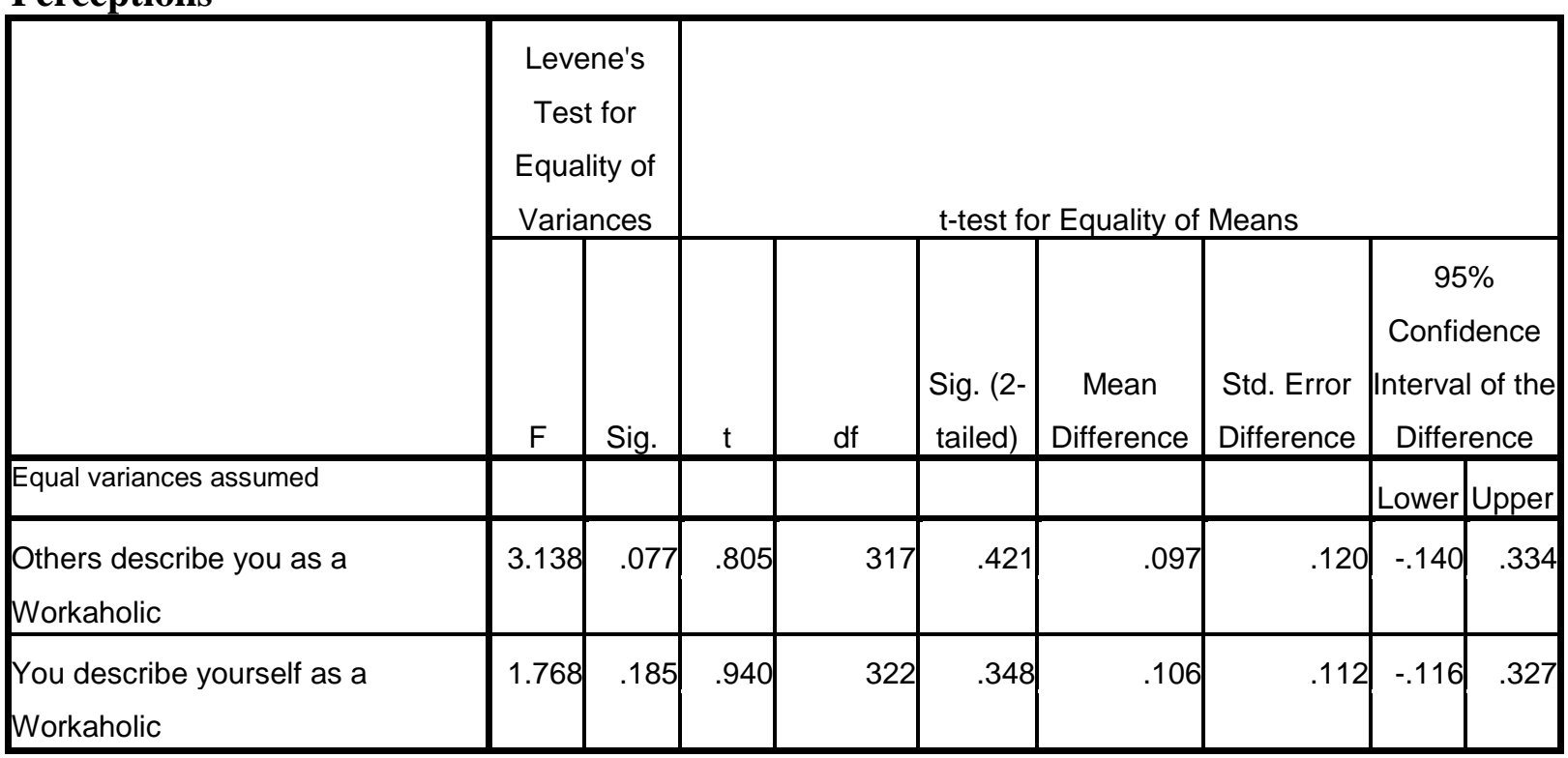

The Levene's Test for Equality of Variances shows that equal variances can be assumed each of the items as the P-value is higher than $\alpha$. The Sig. (2-Tailed) value for each of the items is above .05 , it can be concluded that there is no significant difference between genders for each of the two items. Therefore, Table 23 suggests that alternative hypothesis $\mathbf{H 5}$ cannot be accepted. 
Table 24. Correlations between Workaholism Perceptions for Males and Females

\begin{tabular}{|c|c|c|c|}
\hline & & $\begin{array}{c}\text { Would other people } \\
\text { describe you as a } \\
\text { Workaholic }\end{array}$ & $\begin{array}{c}\text { Would you describe } \\
\text { yourself as a } \\
\text { Workaholic }\end{array}$ \\
\hline $\begin{array}{l}\text { Others describe you as a } \\
\text { Workaholic }\end{array}$ & $\begin{array}{l}\text { Pearson Correlation } \\
\text { Sig. (2-tailed) } \\
\mathrm{N}\end{array}$ & - & $\begin{array}{r}.801 \\
.000 \\
162 \\
\end{array}$ \\
\hline $\begin{array}{l}\text { You describe yourself as } \\
\text { a Workaholic }\end{array}$ & $\begin{array}{l}\text { Pearson Correlation } \\
\text { Sig. (2-tailed) } \\
\mathrm{N}\end{array}$ & $\begin{array}{r}.779 \\
.000 \\
162\end{array}$ & - \\
\hline
\end{tabular}

**. Correlation is significant at the 0.01 level (2-tailed).

Note. The correlation for Females appear below the diagonal

As seen above in Table 24, an examination of the relationships between the two items show that both males and females reported a substantial positive correlation between the two items revealing a substantial positive correlation between the items.

The next step in examining gender and Workaholism perceptions consisted of carrying out a paired sample t-test to see if the means of the two items differ from one another for each gender. This was done using split populations (by gender). As seen below in Table 25, "Paired Differences" show the descriptive statistics for the difference between the two items. The mean difference between the two items is higher for females. Also seen in the above table, the significance value is less than .05 , it can therefore be concluded that there is a significant difference between genders in the difference between the two items. 
Table 25. Paired Sample T-test between the two Workaholism Perceptions items for each Gender

\begin{tabular}{|c|c|c|c|c|c|c|c|c|c|c|}
\hline \multirow[b]{3}{*}{ Gender } & & & \multicolumn{5}{|c|}{ Paired Differences } & \multirow[b]{3}{*}{$\mathrm{t}$} & \multirow[b]{3}{*}{ df } & \multirow[b]{3}{*}{$\begin{array}{l}\text { Sig. (2- } \\
\text { tailed) }\end{array}$} \\
\hline & & & & & & \multicolumn{2}{|c|}{$\begin{array}{c}95 \% \\
\text { Confidence } \\
\text { Interval of the } \\
\text { Difference }\end{array}$} & & & \\
\hline & & & Mean & $\begin{array}{c}\text { Std. } \\
\text { Deviation }\end{array}$ & $\begin{array}{c}\text { Std. Error } \\
\text { Mean }\end{array}$ & Lower & Upper & & & \\
\hline Male & Pair 1 & $\begin{array}{l}\text { Others describe you as a } \\
\text { Workaholic - You describe } \\
\text { yourself as a Workaholic }\end{array}$ & .395 & .634 & .050 & .297 & .493 & 7.931 & 161 & .000 \\
\hline Female & Pair 1 & $\begin{array}{l}\text { Others describe you as a } \\
\text { Workaholic - You describe } \\
\text { yourself as a Workaholic }\end{array}$ & .407 & .736 & .058 & .293 & .522 & 7.050 & 161 & .000 \\
\hline
\end{tabular}

\section{Gender, Workaholism Composite Score and Workaholism Perceptions}

A comparison between the composite score for Workaholism and responses on the statements and "You describe yourself as a Workaholic" was carried out to address the relationship between the Workaholism Composite Score and "Others describe you as a Workaholic" participants Workaholism Perceptions. The means for each gender are displayed in Table 26 and the correlation matrix is displayed in Table 27, with males in the top half and females in the bottom half. These results again demonstrate a difference between the sexes. As seen below in Table 27 females reported a substantial positive correlation between the Workaholism Composite Score and "Others describe you as a Workaholic" and a modest but still significant correlation between the Workaholism Composite Score and "You describe yourself as a Workaholic". Males, however, did not show any significant correlations between the composite score for Workaholism and each of the statements. An examination of these relationships reveals a substantial positive correlation only in the case of females. Although as seen above a substantial positive correlation was seen between the statements for both genders. Therefore this suggests that the alternative hypothesis $\mathbf{H 6}$ can be accepted. 
Table 26. Group Statistics between Gender for the Workaholism Composite Score and Workaholism Perceptions

\begin{tabular}{|ll|r|r|r|}
\hline Gender & N & Mean & Std. Deviation & Std. Error Mean \\
\hline Male $\quad \begin{array}{l}\text { Workaholism Composite } \\
\text { Score }\end{array}$ & 167 & 3.22 & .431 & .033 \\
$\begin{array}{l}\text { Others describe you as a } \\
\text { Workaholic }\end{array}$ & 163 & 3.29 & 1.017 & .080 \\
$\begin{array}{l}\text { You describe yourself as a } \\
\text { Workaholic }\end{array}$ & 163 & 2.89 & .988 & .077 \\
\hline $\begin{array}{l}\text { Workaholism Composite } \\
\text { Score }\end{array}$ & 164 & 3.41 & .506 & .040 \\
$\begin{array}{l}\text { Would other people describe } \\
\text { you as a Workaholic }\end{array}$ & 162 & 3.19 & 1.150 & \\
\hline $\begin{array}{l}\text { Would you describe yourself } \\
\text { as a Workaholic }\end{array}$ & 162 & 2.78 & & \\
\hline
\end{tabular}

Table 27. Correlations between Workaholism Composite Score and Workaholism Perceptions for each Gender

\begin{tabular}{|c|c|c|c|c|}
\hline & & $\begin{array}{c}\text { Workaholism } \\
\text { Composite } \\
\text { Score }\end{array}$ & $\begin{array}{c}\text { Others describe you } \\
\text { as a Workaholic }\end{array}$ & $\begin{array}{l}\text { You describe } \\
\text { yourself as a } \\
\text { Workaholic }\end{array}$ \\
\hline $\begin{array}{l}\text { Workaholism Composite } \\
\text { Score }\end{array}$ & $\begin{array}{l}\text { Pearson Correlation } \\
\text { Sig. (2-tailed) } \\
\mathrm{N}\end{array}$ & - & $\begin{array}{r}-.034 \\
.671 \\
163 \\
\end{array}$ & $\begin{array}{r}-.046 \\
.560 \\
163 \\
\end{array}$ \\
\hline $\begin{array}{l}\text { Others describe you as a } \\
\text { Workaholic }\end{array}$ & $\begin{array}{l}\text { Pearson Correlation } \\
\text { Sig. (2-tailed) } \\
\mathrm{N}\end{array}$ & $\begin{array}{r}.204^{* *} \\
.009 \\
162 \\
\end{array}$ & - & - \\
\hline $\begin{array}{l}\text { You describe yourself as } \\
\text { a Workaholic }\end{array}$ & $\begin{array}{l}\text { Pearson Correlation } \\
\text { Sig. (2-tailed) } \\
\text { N }\end{array}$ & $\begin{array}{l}.159^{*} \\
.043 \\
162\end{array}$ & - & - \\
\hline
\end{tabular}

**. Correlation is significant at the 0.01 level (2-tailed).

*. Correlation is significant at the 0.05 level (2-tailed).

Note. The correlation for Females appear below the diagonal 


\section{Gender and Overtime/Overwork}

Overtime was calculated by subtracting hours per week of work according to participants labour contract from the actual hours worked per week. For the purpose of this study overwork was defined as working at least 48 weekly hours. Many researchers seem to use this cut off point, in line with the 1993 European Directive on working time (White and Beswick, 2003).

Table 28. Group Statistics between Gender and Overtime

\begin{tabular}{|rl|r|r|r|r|}
\hline & Gender & \multicolumn{1}{|c|}{$\mathrm{N}$} & \multicolumn{1}{c|}{ Mean } & Std. Deviation & Std. Error Mean \\
\hline \multirow{2}{*}{ Overtime } & Male & 134 & 15.216 & 10.6805 & .9227 \\
& Female & 146 & 14.719 & 10.3109 & .8533 \\
\hline
\end{tabular}

Table 29. Independent Samples T-test between Gender and Overtime

\begin{tabular}{|c|c|c|c|c|c|c|c|c|c|}
\hline & \multicolumn{2}{|c|}{$\begin{array}{c}\text { Levene's } \\
\text { Test for } \\
\text { Equality of } \\
\text { Variances } \\
\end{array}$} & \multicolumn{7}{|c|}{ t-test for Equality of Means } \\
\hline & $\mathrm{F}$ & Sig. & $\mathrm{t}$ & $d f$ & $\begin{array}{l}\text { Sig. (2- } \\
\text { tailed) }\end{array}$ & $\begin{array}{c}\text { Mean } \\
\text { Difference }\end{array}$ & $\begin{array}{l}\text { Std. Error } \\
\text { Difference }\end{array}$ & $\begin{array}{r}95 \% \text { Con } \\
\text { Interval } \\
\text { Differ }\end{array}$ & $\begin{array}{l}\text { fidence } \\
\text { of the } \\
\text { ence }\end{array}$ \\
\hline Equal variances assumed & & 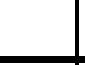 & & & & & & Lower & Upper \\
\hline Overtime & .056 & .812 & .396 & 278 & .692 & .4972 & 1.2549 & -1.9730 & 2.9675 \\
\hline
\end{tabular}

The Levene's Test for Equality of Variances shows that equal variances can be assumed for overtime as the P-value is higher than $\alpha$. The Sig. (2-Tailed) value for overtime is above .05 , it can be concluded that there is no significant difference between genders for overtime.

Tables 30 and 31 include only participants who are considered overworkers (their combined hours of hours worked during the whole week are above 48). The aim of this is to examine whether there is a difference between genders in the mean hours worked by participants who work overtime. 
Table 30. Group Statistics between Gender and Overwork

\begin{tabular}{|ll|r|r|r|r|}
\hline & Gender & N & Mean & Std. Deviation & Std. Error Mean \\
\hline Combined hours worked & Male & 114 & 59.272 & 9.7323 & .9115 \\
during the whole week & Female & 93 & 58.247 & 8.5245 & .8839 \\
\hline
\end{tabular}

Table 31. Independent Samples T-test between Gender and Overwork

\begin{tabular}{|c|c|c|c|c|c|c|c|c|c|}
\hline & \multicolumn{2}{|c|}{$\begin{array}{l}\text { Levene's } \\
\text { Test for } \\
\text { Equality of } \\
\text { Variances }\end{array}$} & \multicolumn{7}{|c|}{ t-test for Equality of Means } \\
\hline & $\mathrm{F}$ & Sig. & $\mathrm{t}$ & df & $\begin{array}{l}\text { Sig. (2- } \\
\text { tailed) }\end{array}$ & $\begin{array}{c}\text { Mean } \\
\text { Difference }\end{array}$ & $\begin{array}{l}\text { Std. Error } \\
\text { Difference }\end{array}$ & $\begin{array}{r}95 \% \text { Con } \\
\text { Interval } \\
\text { Differe }\end{array}$ & $\begin{array}{l}\text { fidence } \\
\text { of the } \\
\text { ence }\end{array}$ \\
\hline Equal variances assumed & & & & & & & & Lower & Upper \\
\hline $\begin{array}{l}\text { Combined hours worked during } \\
\text { the whole week }\end{array}$ & .554 & .458 & .796 & 205 & .427 & 1.0246 & 1.2869 & -1.5126 & 3.5619 \\
\hline
\end{tabular}

The Levene's Test for Equality of Variances shows that equal variances can be assumed for overtime as the P-value is higher than $\alpha$. The Sig. (2-Tailed) value for overworkers is above .05 , it can be concluded that there is no significant difference between genders in the mean number of hours worked by overworkers.

Next, the effect of gender on whether or not individuals work more than 48 hours is examined. This is done using Chi-Square Tests. This evaluates whether participants working more than 48 hours is independent of gender by seeing if the proportion of males in each group is the same. The null hypothesis is that the proportion of participants working more than 48 hours is the same for each gender. If the null hypothesis is true, then a $\chi^{2}$ statistic from a contingency table should have a Chi-square. More males are overworkers $(\mathrm{N}=114)$ than for females $(\mathrm{N}=93)$.

Table 32 shows the chi-square table of observed frequencies for each possible combination of the two variables. It can be seen that not only are there more males that work more than 48 hours, but, that a higher proportion of males work more than 48 hours as opposed to females. 
Table 32. Gender and whether Participants Work more than 48 Hours

\begin{tabular}{|c|c|c|c|c|}
\hline & \multicolumn{2}{|c|}{ More than 48 hours } & \multirow[b]{2}{*}{ Total } \\
\hline & & Yes & No & \\
\hline Gender & Male & 114 & 52 & 166 \\
\hline & Female & 93 & 70 & 163 \\
\hline Total & & 207 & 122 & 329 \\
\hline
\end{tabular}

Table 33. Chi-Square Tests of Gender and whether Participants Work more than 48 Hours

\begin{tabular}{|c|c|c|c|c|c|}
\hline & Value & $\mathrm{df}$ & $\begin{array}{l}\text { Asymp. Sig. (2- } \\
\text { sided) }\end{array}$ & $\begin{array}{c}\text { Exact Sig. (2- } \\
\text { sided) }\end{array}$ & $\begin{array}{c}\text { Exact Sig. (1- } \\
\text { sided) }\end{array}$ \\
\hline $\begin{array}{l}\text { Pearson Chi-Square } \\
\text { Continuity Correction }{ }^{\mathrm{b}} \\
\text { Likelihood Ratio } \\
\text { Fisher's Exact Test } \\
\text { Linear-by-Linear Association } \\
\text { McNemar Test } \\
\mathrm{N} \text { of Valid Cases }\end{array}$ & $\begin{array}{r}4.759^{\mathrm{a}} \\
4.274 \\
4.772 \\
4.745 \\
329\end{array}$ & $\begin{array}{l}1 \\
1 \\
1\end{array}$ & $\begin{array}{l}.029 \\
.039 \\
.029\end{array}$ & $\begin{array}{c}.031 \\
.0010\end{array}$ & .019 \\
\hline
\end{tabular}

a. 0 cells $(.0 \%)$ have expected count less than 5 . The minimum expected count is 60.44 .

b. Computed only for a $2 \times 2$ table

c. Binomial distribution used.

Table 33 gives the value of the chi-squared test in the first row. The value of the chisquared statistic is 4.759 . The chi-squared statistic has 1 degree of freedom. The third column gives the two-tailed p value associated with the chi-squared value. In this case, the $\mathrm{p}$ value equals .029. As the $\mathrm{p}$ value is less than or equal to the $\alpha$ value (.05) the null hypothesis is rejected. That is, there is sufficient evidence to conclude that gender influences whether participants work more than 48 hours. Therefore this suggests that the alternative hypothesis $\mathbf{H 7}$ can only be partially accepted as there is no difference between genders in overtime or hours worked by overworkers but there is a significant difference between genders in the proportion of overworkers.

As a side note, the relationship between the Workaholism Composite Score and long hours, overtime and overwork was examined. This was done to provide additional insight into the area of Workaholism for this particular population as the data had 
already been collected and there was a possibility that an interesting aspect may have been drawn out for future research. By examining this (the relationship between the Workaholism Composite Score and long hours, overtime and overwork) as well the relationship between the definition of Workaholism (used in this study) and participants' definition, in the next section, a more composite approach using both the deductive, in answering the research question, and inductive approach. This was done to contextualise the design and findings in order to relate Workaholism to management theories and allowed for prediction while elucidating more diverse trends such as exceptions to what theory may predict which may be unique to the sample. This combined approach enables the study to provide a broad range of data on the phenomenon.

Workaholism is defined as the tendency towards heavy work investment and involvement (the behavioural dimension) with considerable allocation of time to workrelated activities and work-related thoughts and the combination of high-drive with lowenjoyment (the cognitive dimension), which manifests itself in working compulsively, being obsessed with work for reasons that are not derived from external necessity (Spence and Robbins, 1992 in combination with Snir and Harpaz, 2004). This definition excludes any referral to hours worked, overtime or overwork. Accordingly, there should be a moderate but significant correlation between the Workaholism composite Score and hours worked, overtime and overwork.

\section{Workaholism Composite Score and Long Hours, Overtime and Overwork}

A comparison between the Workaholism Composite Score and Overtime; the Workaholism Composite Score and whether respondents work more than 48 hours; and the Workaholism Composite Score and combined number of hours worked per week was carried out to quantify the association between the two variables. The correlation matrixes are displayed in Table 34, Table 35 and Table 36. These results demonstrate there is no correlation between the Workaholism Composite Score and each of the variables. 
Table 34. Correlations between Workaholism Composite Score and Overtime

\begin{tabular}{|ll|r|r|}
\hline & & $\begin{array}{c}\text { Workaholism } \\
\text { Composite Score }\end{array}$ & Overtime \\
\hline Workaholism Composite & Pearson Correlation & 1 & .072 \\
Score & Sig. (2-tailed) & 331 & .231 \\
& $\mathrm{~N}$ & .072 & 280 \\
\hline Overtime & Pearson Correlation & .231 & 1 \\
& Sig. (2-tailed) & 280 & 280 \\
\hline
\end{tabular}

Table 35. Correlations between Workaholism Composite Score and hours worked over 48 hours

\begin{tabular}{|ll|r|r|}
\hline Spearman's rho & \multicolumn{2}{|c|}{$\begin{array}{c}\text { Workaholism } \\
\text { Composite Score }\end{array}$} & $\begin{array}{r}\text { More than } \\
48 \text { hours }\end{array}$ \\
\hline Workaholism Composite & Correlation Coefficient & 1.000 & -.020 \\
Score & Sig. (2-tailed) & .721 \\
& $\mathrm{~N}$ & 331 & 329 \\
\hline More than 48 hours & Correlation Coefficient & -.020 & 1.000 \\
& Sig. (2-tailed) & .721 & \\
& $\mathrm{~N}$ & 329 & 329 \\
\hline
\end{tabular}

Table 36. Correlations between Workaholism Composite Score and Combine Hours Worked per Week

\begin{tabular}{|c|c|c|c|}
\hline & & $\begin{array}{c}\text { Workaholism } \\
\text { Composite Score }\end{array}$ & \begin{tabular}{|c} 
Combined \\
hours worked \\
per week
\end{tabular} \\
\hline \multirow{3}{*}{$\begin{array}{l}\text { Workaholism Composite } \\
\text { Score }\end{array}$} & Pearson Correlation & 1 & -.011 \\
\hline & Sig. (2-tailed) & & .840 \\
\hline & $\mathrm{N}$ & 331 & 330 \\
\hline \multirow{3}{*}{$\begin{array}{l}\text { Combined hours worked } \\
\text { during the whole week }\end{array}$} & Pearson Correlation & -.011 & 1 \\
\hline & Sig. (2-tailed) & .840 & \\
\hline & $\mathrm{N}$ & 330 & 330 \\
\hline
\end{tabular}

\section{Study Definition and Participants definition}

The relationship between the definition of Workaholism (used in this study) and participants' definition was also examined. This was done by examining the frequencies of the responses to different aspects of possible definitions, as well as the other 
responses given in the open ended text box provided. The frequencies can be seen below in Table 37.

Table 37. Workaholism Definition

How would you describe a Workaholic?

\begin{tabular}{|l|r|r|r|}
\hline & Frequency & Percent & Valid Percent \\
\hline Works hard over long hours & 292 & 88.2 & 88.2 \\
\hline $\begin{array}{l}\text { Motivated by a strong } \\
\text { internal drive }\end{array}$ & 210 & 63.4 & 63.4 \\
\hline $\begin{array}{l}\text { Constantly thinks/talks about } \\
\text { work }\end{array}$ & 255 & 77.0 & 77.0 \\
\hline $\begin{array}{l}\text { Is highly involved with their } \\
\text { work }\end{array}$ & 222 & 67.1 & 67.1 \\
\hline $\begin{array}{l}\text { Motivated by external or } \\
\text { contextual factors (i.e. Financial } \\
\text { problems, supervisory pressure, } \\
\text { desire for career advancement) }\end{array}$ & 97 & 29.3 & 29.3 \\
\hline $\begin{array}{l}\text { Able to maintain a healthy } \\
\text { work-life balance }\end{array}$ & 14 & 4.2 & 4.2 \\
\hline $\begin{array}{l}\text { Enjoys their work } \\
\text { Does not enjoy their work }\end{array}$ & 101 & 30.5 & 30.5 \\
\hline
\end{tabular}

As seen above, in Table 37, there a high number of respondents who would define Workaholism to include working hard over long hours $(88.2 \%)$, motivated by a strong internal drive (63.4\%), constantly thinking/talking about work (77\%), highly involved with their work (67.1\%). A very small number of respondents would define Workaholism as including not enjoying work (7.3\%) and a slightly larger number of respondents would define Workaholism as including enjoying work (30.5\%) and being motivated by external or contextual factors $(29.3 \%)$.

This final question on the survey provides an option to include other descriptions of a Workaholic. Several respondents chose to do this, providing further information on participants", definition of Workaholism. In particular, a large number of respondents (36 out of 69) stated in one way or another that Workaholics were unable to maintain a healthy work-life balance (for example, "Compromises other aspects of life for work (other aspects suffer because of the amount of work being done)" and "Gives insufficient time to other important relationships and responsibilities, including own health"). Other aspects that came up included "Can't stop working, even though that will 
have negative outcomes" which was suggested by seven respondents. There were also other interesting responses:

- "Somebody who is egotistic and works excessively hurting themselves and those around them";

- "Needs to be needed; self-esteem comes solely from work";

- "Not necessarily a hard or productive worker";

- "Gives insufficient time to other important relationships and responsibilities, including own health";

- "Someone who uses work the avoid other aspects of life";

- "Someone who is obsessive-compulsive about work, and who can't not work";

- "Someone who derives all their self worth from work to the exclusion of everything else";

- "Unreasonable belief that one is indispensible".

In particular, one respondent stated that a Workaholic is someone who "works longer hours than the job requires; cannot be content doing anything else; works needlessly even when it makes them miserable; works at the expense of family, health and other important things in life". There were also some responses that did not fall in line with theory on Workaholism these were:

- "Difficulties in managing external pressure (intuitional and from peers)";

- "Efficient and organized to deal with an issue and complete it rather than try to have many things half done";

- "Someone who does not necessarily recognise that other people may have different work/life priorities";

- "Commitment to students"; "wants recognition internationally".

The present comparison of an inductively and deductively generated definition illustrates that academics in this field have a very similar view of Workaholism as 
academics as a whole in New Zealand (there were only a very small number of respondents who demonstrated otherwise). This involves: working hard over long hours; a strong internal drive to work; constantly thinks/talks about work; highly involved with their work; and unable to maintain a healthy work-life balance. One aspect of participants' definition that contradicted the definition used in this study was Work Enjoyment as mentioned above.

\section{Summary}

To summarise, this chapter presents the results of this study. Gender differences were found in several of the aspects examined in this study. A statistically significant difference was found in the Workaholism Composite Score between genders, therefore the alternative hypothesis H1 was accepted - There is a difference between the Workaholism composite score of males and females. It was also found that there was a statistically significant difference between genders in the Work Involvement and Drive, therefore the alternative hypotheses $\mathbf{H 2}$ and $\mathbf{H 3}$ were accepted - There is a difference between the work involvement of males and females and there is a difference between the drive of males and females. There was no significant difference between genders in the Work Enjoyment, therefore the null hypothesis was accepted and the alternative hypothesis $\mathbf{H 4}$ was rejected. Again there no significant difference between genders in the Workaholism perceptions, therefore the null hypothesis was accepted and the alternative hypothesis $\mathbf{H 5}$ was rejected.

No correlations were found between the Workaholsm Composite Score and any of participants' hours worked, overtime or overwork, therefore the alternative hypothesis H6 - There is a moderate but significant correlation between the Workaholism composite Score and hours worked, overtime and overwork - was also rejected. There was no significant difference between genders in overtime when examining all participants or hours worked when examining only those who are overworkers. There was, however, a significant difference between genders in the proportion of overworkers. H7 - There is a difference between the overtime and overwork of males and females - can therefore only be partially accepted. 
The study also found that participants' definition included the Work Enthusiast as a Workaholic, whereas this study excluded those who are considered to be Work Enthusiasts. The difference in definitions lay specifically in the notion of work enjoyment. A summary of the results can be seen below in Table 18, and the overall framework of these results are summarised in Figure 4.

Table 38. Summary of Results

\begin{tabular}{|c|c|c|c|}
\hline \multicolumn{2}{|l|}{ Relationship } & Test & Results \\
\hline \multirow{2}{*}{\multicolumn{2}{|c|}{ Gender Perceptions }} & $\begin{array}{l}\text { Discriminant } \\
\text { Analysis }\end{array}$ & $\begin{array}{l}\text { There is a significant difference } \\
\text { between genders in the mean for gender } \\
\text { perceptions }\end{array}$ \\
\hline & & $\begin{array}{l}\text { Independent } \\
\text { Sample T-test }\end{array}$ & $\begin{array}{l}\text { There is a significant difference } \\
\text { between genders in the mean for gender } \\
\text { perceptions in the workplace. } \\
\text { Females believe there is inequality, } \\
\text { males don't. }\end{array}$ \\
\hline \multirow{2}{*}{\multicolumn{2}{|c|}{$\begin{array}{l}\text { Gender and Workaholism } \\
\text { Composite Score (WCS) }\end{array}$}} & $\begin{array}{l}\text { One-way } \\
\text { ANOVA }\end{array}$ & $\begin{array}{l}\text { There is a significant difference } \\
\text { between genders }\end{array}$ \\
\hline & & $\begin{array}{l}\text { Independent } \\
\text { Sample T-test }\end{array}$ & $\begin{array}{l}\text { There is a significant difference } \\
\text { between genders. } \\
\text { Females show a higher WCS. }\end{array}$ \\
\hline \multirow[b]{4}{*}{$\begin{array}{l}\text { Gender and } \\
\text { Workaholism } \\
\text { Characteristics }\end{array}$} & $\begin{array}{l}\text { Work } \\
\text { Involvement }\end{array}$ & \multirow{3}{*}{$\begin{array}{l}\text { Independent } \\
\text { Sample T-test }\end{array}$} & $\begin{array}{l}\text { There is a significant difference } \\
\text { between genders. } \\
\text { Females show a higher Work } \\
\text { Involvement. }\end{array}$ \\
\hline & Drive & & $\begin{array}{l}\text { There is a significant difference } \\
\text { between genders. } \\
\text { Females show a higher Drive. }\end{array}$ \\
\hline & $\begin{array}{l}\text { Work } \\
\text { Enjoyment }\end{array}$ & & $\begin{array}{l}\text { There is no significant difference } \\
\text { between genders }\end{array}$ \\
\hline & $\begin{array}{l}\text { Between } \\
\text { measures }\end{array}$ & $\begin{array}{l}\text { Pearson } \\
\text { Correlation }\end{array}$ & $\begin{array}{l}\text { Both males and females reported a } \\
\text { substantial positive correlation between } \\
\text { Work Involvement and Work } \\
\text { Enjoyment and between Work } \\
\text { Involvement and Drive. } \\
\text { Females reported a substantial positive } \\
\text { correlation between Drive and Work } \\
\text { Enjoyment. } \\
\text { Males reported a modest but still } \\
\text { significant correlation between Drive } \\
\text { and Work Enjoyment. }\end{array}$ \\
\hline
\end{tabular}


Table 38. Continued

\begin{tabular}{|c|c|c|}
\hline Relationship & Test & Results \\
\hline \multirow{4}{*}{$\begin{array}{l}\text { Gender and Workaholism } \\
\text { Perceptions }\end{array}$} & $\begin{array}{l}\text { Independent } \\
\text { Sample T-test }\end{array}$ & $\begin{array}{l}\text { There is no significant difference } \\
\text { between genders. }\end{array}$ \\
\hline & $\begin{array}{l}\text { Pearson } \\
\text { Correlation }\end{array}$ & $\begin{array}{l}\text { Both males and females reported a } \\
\text { substantial positive correlation } \\
\text { between the Workaholism } \\
\text { Perceptions items. }\end{array}$ \\
\hline & $\begin{array}{l}\text { Paired Sample } \\
\text { T-test }\end{array}$ & $\begin{array}{l}\text { Females show a higher mean } \\
\text { difference between the two } \\
\text { Workaholism Perceptions items. }\end{array}$ \\
\hline & $\begin{array}{l}\text { Independent } \\
\text { Sample T-test of } \\
\text { Overworkers }\end{array}$ & $\begin{array}{l}\text { There is no significant difference } \\
\text { between genders. }\end{array}$ \\
\hline Gender and Overwork & Chi-Square Test & $\begin{array}{l}\text { More males work more than } 48 \\
\text { hours. } \\
\text { A higher proportion of males } \\
\text { work over } 48 \text { hours. }\end{array}$ \\
\hline \multirow{3}{*}{$\begin{array}{l}\text { WCS and } \\
\text { Overtime/Overwork }\end{array}$} & $\begin{array}{l}\text { Pearson } \\
\text { Correlation }\end{array}$ & $\begin{array}{l}\text { No significant correlations } \\
\text { between WCS and Overtime. }\end{array}$ \\
\hline & $\begin{array}{l}\text { Spearman } \\
\text { Correlation }\end{array}$ & $\begin{array}{l}\text { No significant correlations } \\
\text { between WCS and whether } \\
\text { participants work more than } 48 \\
\text { hours. }\end{array}$ \\
\hline & $\begin{array}{l}\text { Pearson } \\
\text { Correlation }\end{array}$ & $\begin{array}{l}\text { No significant correlations } \\
\text { between WCS and participants } \\
\text { combined hours worked during } \\
\text { the whole week. }\end{array}$ \\
\hline
\end{tabular}




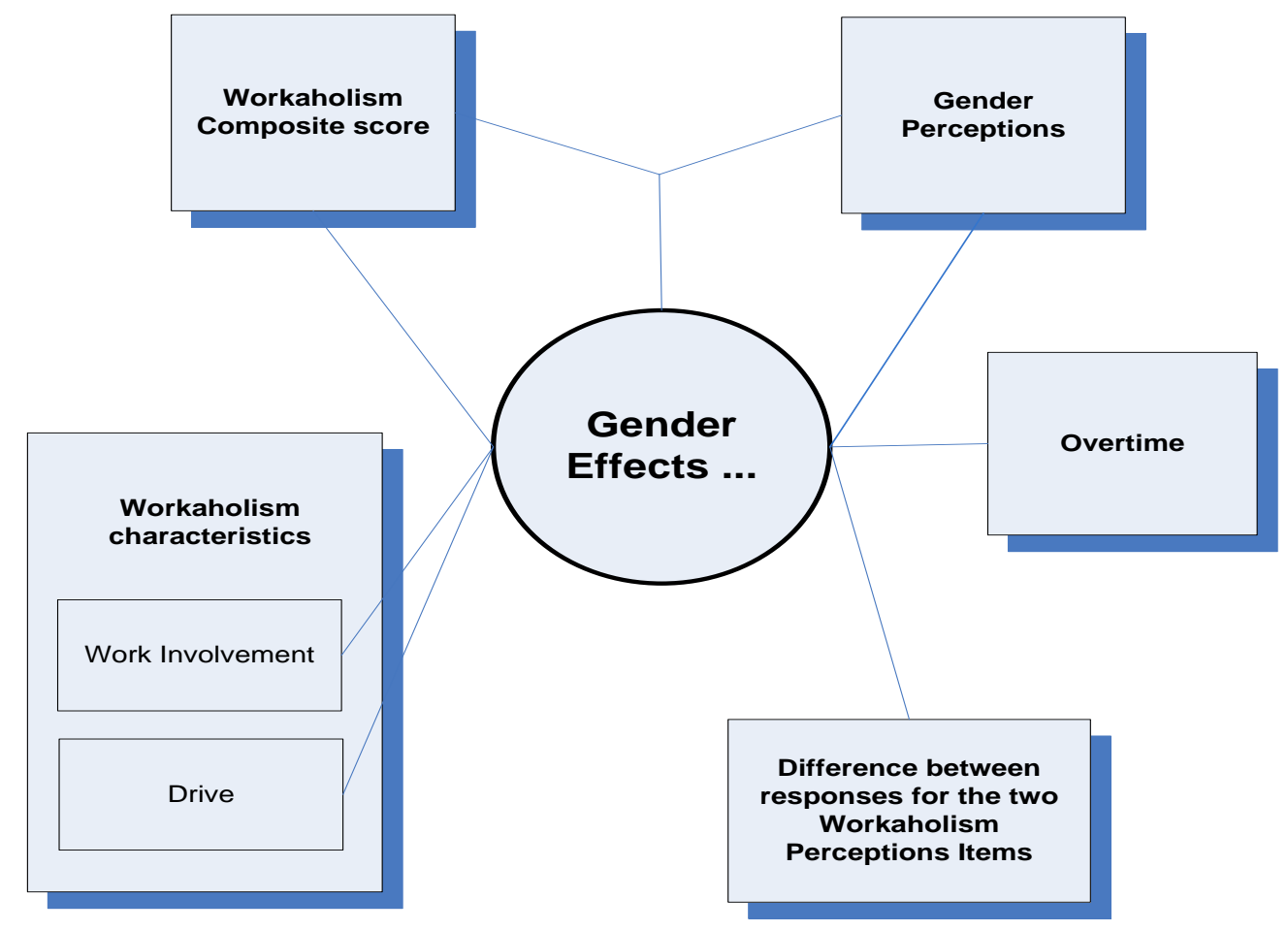

Finally, as the aim of this Thesis was to examine the differences in the degree of Workaholism and Workaholism-related variables between genders, a summary for the results highlighting the differences found between genders can be seen below in Table 39.

Table 39. Summary Gender Differences Found

\begin{tabular}{|l|l|}
\hline Males & Females \\
\hline No perception of gender inequality & Perception of gender inequality \\
\hline Drive and Work Enjoyment less correlated & Higher Work Involvement \\
\hline More Overwokers & Higher Drive \\
\hline More likely to be Overworkers & $\begin{array}{l}\text { Bigger difference between Workaholism } \\
\text { Perceptions items }\end{array}$ \\
\hline $\begin{array}{l}\text { No correlation between WCS and } \\
\text { Workaholism Perception items }\end{array}$ & $\begin{array}{l}\text { Correlation between WCS and } \\
\text { Workaholism Perception items }\end{array}$ \\
\hline
\end{tabular}




\section{Chapter 7: Discussion, Implications, Limitations and Conclusions}

\section{Introduction}

This chapter provides a discussion on the results of this research presented in Chapter 6 .

This is done by looking at each of the areas under investigation, the Workaholism Composite Score, Workaholism characteristics, Workaholism perceptions, gender and overtime/overwork, and the study definitions and participants' definition, consecutively. Areas for future study that are brought about due to the results of this study are highlighted. The next section, in outlining the implications, covers why study in this area is important and how these results can help further understanding.

This is followed with the limitations and credibility of this study, providing suggestions for areas of future research. Finally conclusions are formed and Workaholism as a field of study is summarised.

\section{Discussion}

This investigation examined differences in the degree of Workaholism characteristics as defined by Spence and Robbins (1992) and Workaholism-related variables between genders in a sample of academics in New Zealand. Gender differences were found in several of the aspects examined in this study.

\section{Workaholism Composite Score}

A statistically significant difference was found in the Workaholism Composite Score between genders, therefore the alternative hypothesis $\mathbf{H 1}$ was accepted - There is a difference between the Workaholism composite score of males and females. This study found female academics in New Zealand exhibit a higher Workaholism Composite Score than males. It can therefore be posited that females have higher levels of Workaholism as the Workaholism Composite Score represents the extent which respondents exhibit Workaholic behaviours. This supports Spence and Robbins (1992) findings from which they suggested that women have a greater tendency to show at least 
some characteristics of Workaholism, although the characteristics differed. They found females to exhibit higher Drive and Work Enjoyment as opposed to Drive and Work Involvement as found in this study. This may represent the difference in the country of the population. Additionally, the findings on gender perceptions of the study population showed that there were significant differences between genders on the perceptions of the gender culture in the workplace, suggesting that females feel that they the need to prove themselves to be equal and work harder and longer hours to be accepted. This may explain why female academics in New Zealand exhibit a higher Workaholism Composite Score than males.

\section{Workaholism Characteristics}

Workaholism characteristics were subsequently examined in order to explore, in more detail, the gender differences found in the Workaholism Composite Score. This produced results further detailing the gender differences in the Workaholism Composite Score by examining how these differences were configured in the Workaholism characteristics.

This examination showed that there was a statistically significant difference between genders in both the Work Involvement and Drive, therefore the alternative hypotheses $\mathrm{H} 2$ and H3 were accepted - There is a difference between the work involvement of males and females and there is a difference between the drive of males and females. There was no significant difference between genders in Work Enjoyment. This shows that gender difference found were due to two of the three Workaholism characteristics (Work Involvement and Drive). It may, therefore be concluded that the ways in which Workaholism characteristics are enacted in the workplace are different for males and females. This supports research by Burgess et al, (2006) which concluded that it is ways in which Workaholism components are enacted in the workplace that may be different between females and males. It is, therefore in these two areas (Drive and Work Involvement) that gender targeted support mechanism need to be explored. For example, this may require the organisation to place additional focus on reducing females Work Involvement by appointing managers to help and encourage delegation of work or, as 
Haas (1991) suggested, managers meet with employees daily to discuss what has been accomplished during the day and plan for the following day, including specific times to take breaks. This may ensure that employees do not become over involved, rather that they work efficiently during designated periods but are then able to "let go" during designated breaks. This can play a role in assisting Workaholic employees to change their behaviour.

When examining the Workaholism characteristics further, through looking at the relationships between the characteristics, a further gender difference was found. Females reported a substantial positive correlation between Drive and Work Enjoyment, whereas males only reported a modest but still significant correlation between these two scales. This suggests that when designing interventions to reduce/prevent Workaholism for males it may be pertinent to focus on Drive.

Both males and females reported a substantial positive correlation between Work Involvement and Work Enjoyment and between Work Involvement and Drive. Although both males and females reported a substantial positive correlation between Work Involvement and Work Enjoyment, the correlation for females was significantly higher. The gender differences in these findings, though, were minimal and it is therefore concluded that the correlations between Workaholism characteristics are similar for each of the sexes. These findings supported those reported by Spence and Robbins (1992), who found these correlations to demonstrate the similarity of the sexes with relationships among the variables.

\section{Workaholism Perceptions}

No significant differences between genders in the Workaholism perceptions were found. This allows the conclusion that, although there are in fact significant differences in the Workaholism between genders, no difference is perceived. This raised an interesting issue as it may suggest that either females underestimate their Workaholic tendencies or that males overestimate theirs. This could be for many reasons. One possibility may be that perceptions of females' work behaviours more accurately represent how they 
actually behave. Males may also be more likely to hold inaccurate opinions of themselves, which may produce these discrepancies when reporting on Workaholism. Another possible explanation for this difference may be that the survey items for the Workaholism triad are more reliable for female participants. Another possible explanation for this may, as suggested by Bielby and Bielby (1989), be that centuries of gender discrimination and cultural learning that have shaped role identifications (men closely relate to work and women to family) and therefore, men might be more likely to identify themselves as Workaholics. This interpretation has to be made with some caution, but provides an interesting theme to carry out further research.

Again, the correlations between variables also demonstrated no significant differences between genders. There were, however, differences between genders in the correlations between the Workaholism Composite Score and each of the Workaholism perception scores. These correlations demonstrate that females' perceived Wokaholism is significantly correlated to their Workaholism Composite Score. This though, is not the case for males as no significant correlation was found. This is supports the supposition above that the findings may be due to males overestimating their Workaholic tendencies.

\section{Gender and Overtime/Overwork}

There was no significant difference between genders in overtime when examining all participants or when examining only those who are overworkers. There was, however, a significant difference between genders in overwork. Males were found to be more likely to be overworkers. For the purpose of this study, overwork was defined as working at least 48 weekly hours. An explanation may be the fact that females typically have greater time commitment to family responsibilities (what Hochschild (1989) terms second 'shift work'). This interpretation has to be made with some caution as the difference in the number of hours worked between the genders was only modestly different during the week and similar during the weekend.

\section{Workaholism Composite Score and Overtime/Overwork}

No correlations were found between the Workaholism Composite Score and participants hours worked, overtime or overwork, this supports the plethora of literature (Scott et al., 
1997; Malcholwitz, 1980; Holland, 2008) stating that a Workaholic cannot just be considered as someone who works a lot and that considering Workaholism exclusively in terms of the number of working hours is misleading as it excludes the addictive nature. Excessive working hours is only a small aspect involved in Workaholism (often described as a symptom).

\section{Study Definition and Participants' Definition}

The last part of analysis involved comparisons between the definition used in this study and participants' definition of Workaholism. The purpose of this examination was to discover if the widely accepted definition of Workaholism used in this study was consistent with that of the respondents in order to examine whether there may be dilution of the reliability of the results of this study. The study found that participants' definition included the Work Enthusiast as a Workaholic, whereas this study excluded those who are considered to be Work Enthusiasts. The difference in definitions lay specifically in the Characteristic of Work Enjoyment. This obstructs the addictive nature implied in Workaholism and the destructive pattern of work addiction (Porter, 2004) as Workaholism goes beyond the 'want' to work from work enjoyment to the 'need' to work of a work addict. This may produce some dilution in the results of the two items on Workaholism perceptions, but the results pertaining to the Workaholism Composite Score and the Workaholism characteristics are not impacted by participants' divergent views on Workaholism due to the nature of the items and how they were presented (as relating to work behaviours rather than Workaholism). It may be prudent in future research to provide a definition before asking about Workaholism specifically.

Another interesting aspect found in this research was the lack of response to the item "I get bored and restless when I don't have anything to do at work". Most of these non responses, as well as some of those that responded, included comments written in the margin stating "never happens" and "as if" in regards to never having anything to do. Others had the last part of the item underlined or circled. This highlights the nature of work among academics, and the importance of studying Workaholism in this industry. 
These responses suggest a more in-depth qualitative study into the meaning behind such comments written in the margin may be beneficial.

Although additional research is needed on Workaholism, such results represent some first steps on this path of discovery. The real challenge is changing the perception that Workaholism is a positive and even desirable trait. Change will occur only when all of the stakeholders (Workaholics, families and organisation) are convinced that Workaholism is truly an undesirable and unhealthy condition (Holland, 2007).

\section{Implications}

The current study moved beyond previous research in several ways. First, gender, an important construct that has been, until recently, limited in the Workaholism literature, was incorporated into the examination of Workaholism in this study. Second, no studies have tested this in New Zealand, where there may be a unique culture in respect to gender equality. New Zealand women have made significant progress in terms of employment and education; they are considered pioneers of equal rights, having been the first in a self-governing nation to win the right to vote in general elections. New Zealand is also a country that unlike many others is noted for women having held the top four public posts - Prime Minister, Governor General, Attorney General and Chief Justice.

There is always concern that people working long hours are under stressful conditions and that those conditions may lead to health problems or strain on interpersonal relations. It is important to acknowledge that there may be important differences based on the individual's motive for working so hard. Both work enjoyment and feelings of being driven to work heighten Workaholic behaviours; the former fosters satisfaction and well-being while the latter diminishes both. This is a challenge for organisations, but it is easy to see how this is an important one.

This study has found that there is a difference between genders in how Workaholism is exhibited in academics in New Zealand. In order for this knowledge to directly 
contribute towards benefiting practitioners further study is needed, focussing on targeting the methods of addressing Workaholism on the differences found between genders in how Woraholism is exhibited. This will allow actions taken to reduce/prevent Workaholism to be tailored to the specific needs of employees.

The current study suggests that blanket policies designed to promote work-life balance are unlikely to benefit all employees. Indeed, it appears that although both males and females experience similar levels of Workaholism, the two may require different support mechanisms in order to achieve greater work-life balance. This study highlights the need for the development of alternative methods of dealing with Workaholism that target each gender, and possibly even specific individuals. I therefore recommend that further psychological research is required in this specific area to provide practical benefits of this knowledge.

A discussed in Chapter 3, it is only the one of the six respondent types based on the Workaholism triad identified and labelled by Spence and Robins (1992) that produces the may negative outcome discussed previously. This is due to the fact that Workaholics score high on Work Involvement and Drive to work and low on Work Enjoyment. It seems that the drive component makes the difference as it is negatively related to work outcomes, quality of social relationships, and perceived health (Schaufeli, Taris, and Van Rhenen, 2008). As females were found to exhibit higher drive, this may suggest that when developing methods to tackle Workaholism among females the aspect of drive needs a stronger focus. Males on the other hand, were found to be more likely to be overworkers. This suggests that the focus in addressing Workaholism among males should focus more on reducing hours worked, making better use of time away from work in order to recuperate and making provision for physical and emotional needs, as these are neglected by an overworker as suggested by Rhoads (1997, taken from Burke, 2006) and discussed in Chapter 2.

These findings provide insight into possible directions for future research as well as influence treatment for work addiction. By understanding gender differences and the 
individual's perception of their own Workaholism, treatment could be tailored specifically for the individual. Therefore, managers as well as Human Resource professionals responsible for academic staff would find the results pertinent to them. In conclusion, organisation leaders should care why people work so many hours. If it is extreme Workaholism with little or no joy in work, there will likely be negative interpersonal relations that can spread and interfere with general efficiency.

Given the nature and results of this research it is acknowledged that further studies will need to be undertaken to further explore the findings of this research. As the current study found individual differences, further research can focus on the work addiction risk for individuals rather than looking at work addiction risk at the group level.

\section{Limitations}

All data in the current study are based on self-reports, which means that the magnitude of the effects that were reported may have been biased. This is centred upon the social desirability issue or the wish to answer consistently. For example, an employee who is questioned about Workaholism is likely to respond in one of two ways. They may indicate either that they exhibit Workaholic characteristics (implying that they are a contributing member of the organisation) or that they do not exhibit Workaholic characteristics (implying that they can handle the work load provided). In both cases, social desirability affects the individual's account. Future research could greatly benefit from including more objectively measured variables such as company records. Another potential limitation of this study is the cross-sectional nature of this study that precludes cause-effect relationships from being uncovered. A longitudinal study could, for example, allow gender comparisons on the effects of Workaholism which could provide important information when looking for gender specific methods of reducing Workaholism levels. Furthermore, the lack of agreement on a unified definition of Workaholism may influence the generalisability of the results.

One feature of this study was the use of the Internet as a research tool, which can be considered as a strength and a weakness. On the negative side, Internet surveys usually 
attract participants of a higher socio-economic and educational status and thus suffer from selection bias. This is not the case in this study due to the chosen population. On the positive side, this study was able to include participants from all of the Universities in New Zealand and from a wide range of academic positions, schools and departments, covering the entire academic industry in New Zealand. Using traditional sampling techniques, it would have been difficult to obtain such a large and heterogeneous sample.

As this study has found significant differences in the degree of Workaholism and Workaholism-related variables between genders future research should also consider examining gender differences in personality traits and their development towards Workaholism. Since personality traits can play a major role in generating addictions (Eysenck, 1997), greater dominance of certain traits promote addiction and can make people become Workaholics (Ng et al., 2007; Scott et al., 1997). Characteristics such as perfectionism; conscientiousness; obsessive-compulsive personality; achievementoriented traits can promote Workaholism by predisposing individuals to become more addicted to working.

\section{Credibility}

I believe truth is dependent on the cultural context. This corresponds with the literature stating that Workaholism is culturally dependent. This study takes this value in its exploration of the New Zealand context. This research is subjective as it is dependent on the responses of the participants which may be socially biased. I have tried to remove this bias by referring to work behaviours rather than Workaholism which may be perceived to have either a positive or negative connotation. Additionally, I have not labelled the scales by the characteristics they represent (for example, Work Involvement and Drive) as this may cause additional bias; for example the participants may want to consider themselves to be driven and therefore respond appropriately. Instead, the scales have been labelled as numbered sections.

\section{Conclusions}

The study's goal was to determine whether gender had significant effects on Workaholism and related constructs. Findings revealed that there are gender differences 
in the Workaholism Composite Score, and that these are observable in the Workaholism triad characteristics exhibited as well as in perceived Workaholism.

It is important to note that these findings should be considered preliminary in nature. Although the picture is slowly changing, relatively little empirical research has been carried out on Workaholism, with only a handful of studies considering gender differences. Thus, there is too little information yet available to draw meaningful conclusions. The present study merely contributes additional data to consider. More research findings have to be generated before an understanding of gender differences surrounding Workaholism in organisations can be achieved. It is important to specify the nature of jobs or professions examined since differences in Workaholism have been shown to exist. Additionally, this is the only research of this type in New Zealand. The results of this study supports the theory that country or cultural differences in Workaholism and the Workaholism characteristic may be observed, highlighting the need to analyse New Zealand individually in future research. As an implication of this, future research specifically aimed at New Zealand is needed in this topic. Antecedents of these characteristics need to be looked at in detail in order to provide a better understanding of the unique gender differences found in this study.

This study suggests that organisations could benefit a great deal by implementing interventions aimed to assist males and females to deal with Workaholism, work stress, and the struggles of balancing work and personal life. For example, the organisational climate could be improved by focusing on the significance of work-life balance. Furthermore, stress and time management programs could be implemented to reduce Workaholism. It would be beneficial to tailor these to the specific characteristics exhibited by each gender in order to better target the different problem areas for each gender. By researching the antecedents of the Workaholism characteristics exhibited at a higher level, for both genders, information on how to tailor interventions may be established. This study also highlights that it may not always be suitable to replicate action taken in other countries in New Zealand. 
Summarising gender differences in Workaholism, with its many facets and opinions, and in as much flux as the concept of gender differences itself, seems almost impossible. Yet, with so many stresses on people from work, technology, the economy, social issues, and more, it seems it is a very important one. The best summation might be from Dov Zohar (2006).

"The study of Workaholism has a long way to go before it reaches the mature state of Consolidation and Accommodation. As noted above, by such a time a dominant definition would have emerged accompanied by standardized methodology and measurement scales. All of which suggests that students of Workaholism need to identify ways leading to convergence and shared understandings as a condition for continued progress.” (p. 481).

The field is continually fluctuating, and there are several fascinating avenues of study; but most would agree that Workaholism has serious and far-reaching effects particularly in the current economic climate/the $21^{\text {st }}$ century. Workaholism is real, and it has real implications for the individual, co-workers, supervisors, family, and community. This study provides further knowledge in this; monitoring future research should be both fascinating and useful.

\section{Final Remark}

This study suggests that 'good' Workaholism is an entirely separate concept and should not be referred to as Workaholism at all. The description in literature of 'good' Workaholism coincides with work engagement or work enthusiasm or other such terms.

This study focuses the definition of Workaholism consisting of the characteristic of low Work Enjoyment. Overall, it seems that working excessively but in particular, compulsively, is 'bad' for individuals' well-being.

These findings provide insight into possible directions for future research as well as influence treatment for work addiction. In order for this knowledge to benefit practitioners further study is needed, leading to the ability for interventions, taken to 
reduce/prevent Workaholism, to be tailored to the specific needs of employees. By understanding gender differences and the individual's perception of their own Workaholism, treatment could be tailored specifically for the individual. This study suggests that blanket policies designed to promote work-life balance are unlikely to benefit all employees. 


\section{References}

Averill, J. R. (1982), Anger and aggression: An essay on emotion, New York: SpringerVerlag.

Aziz, S. and Zickar, M.J. (2006), A cluster analysis investigation of Workaholism as a syndrome, Journal of Occupational Health Psychology, Vol. 11, pp. 52-62.

Bakker, A.B., Demerouti, E. and Burke, R.J. (2009), Workaholism and relationship quality: a spillover crossover perspective, Journal of Occupational Health Psychology, Vol. 14, pp. 23-33.

Bakker, A.B. (2008), Building engagement in the workplace, In: The peak performing organization, Cooper CL and Burke RJ (Eds.), pp. 50-72, Routledge, Oxon.

Bern, S.L. (1974), The measurement of psychological androgyny, Journal of Consulting and Clinical Psychology, Vol. 42, pp. 115-162.

Bielby, W.T., Bielby, D.D. (1989), Family ties: balancing commitments to work and family in dual earner households, American Sociological Review, Vol. 54 pp. 77689.

Barnett, R.C., Gareis, K.C., Brennan, R.T. (1999), Fit as a mediator of the relationship between work hours and burnout, Journal of Occupational Health Psychology, Vol. 4, No. 4, pp. 307-17.

Boyd, S., and Wylie, C. (1994), Workload and Stress in New Zealand Universities, New Zealand Council for Educational Research and the Association of University Staff of New Zealand.

Buelens, M., and Poelmans, S.A.Y. (2004), Enriching the Spence and Robbins' typology of Workaholism: Demographic, motivational and organizational correlates, Journal of Organizational Change Management, Vol. 17, pp. 440-458.

Burgess, Z., Burke, R.J. and Oberklaid, F. (2006), Workaholism amoung Australian psychologists: gender differences, Equal Opportunities International, Vol. 25, No. 1, pp. 48-59.

Burke, R.J. (1999a), Are Workaholics job satisfied and successful in their careers? Career Development International, Vol. 4, No. 5, pp. 277-82.

Burke, R.J. (1999b), It's not how hard you work but how you work hard: evaluating Workaholism components, International Journal of Stress Management, Vol. 6 No. 4, pp. 225-39.

Burke, R.J. (1999c), Workaholism and extra-work satisfaction, International Journal of Organisational Analysis, Vol. 7, No. 4, pp. 352-64. 
Burke, R.J. (1999d), 'Workaholism in orgnaizations: gender differences', Sex Roles, Vol. 27, pp. 196-203.

Burke, R.J. (2000a), Workaholism components, job satisfaction, and career progress, Journal of Applied Social Psychology, Vol. 31, pp. 2339-56.

Burke, R.J. (2000b), Workaholism and divorce, Psychological Reports, Vol. 86, pp. 219-220.

Burke, R.J. (2000c), Workaholism in organizations: Psychological and physical wellbeing consequences, Stress Medicine, Vol. 16, pp. 11-16.

Burke, R.J. (2000d), Workaholism among women managers: personal and workplace correlates, Journal of Managerial Psychology, Vol. 15, No. 6. pp. 520-534.

Burke, R.J., Richardsen, A.M. and Mortinussen, M. (2004), Workaholism among Norwegian managers: work and well-being outcomes, Journal of Organisational Change Management, Vol. 17, pp. 459-70.

Burke, R.J. and Mattis, M.C. (2005), Supporting Women's Career Advancement, Edward Elgar, Cheltenham.

Burke, R.J., Matthiesen, S.B., Pallesen, S. (2005), Personality correlates of Worlaholism, Personality and Individual Differences, Vol. 40, p. 1223-1233.

Burke, R.J. (2006), Research Companion to Working Time and Work Addiction, Great Britain, Edward Elgar Publishing.

Burke, R.J., McAteer, T. (2007), Work hours and work addiction: work now, pay later, in Langan-Fox, J., Cooper, C.L., Klimoski, R.J. (Eds), Research Companion to the Dysfunctional Workplace, Edward Elgar, Cheltenham.

Burke, R.J., Koyuncu, M. and Fiksenbaum, L. (2008), Workaholism, work and extrawork satisfactions and psychological well-being among professors in Turkey, Cross Cultural Management: An International Journal, Vol. 15, Issue.4, pp. 353366.

Burke, R.J. (2008), Work hours, work intensity, and work addiction, in Burke, R.J. and Cooper, C.L. (Eds), The Long Work Hours Culture: Causes, Consequences and Choices, Emerald Publishing, Bingley, pp. 3-36.

Carver, R. and Nash, J., (2006), Doing Data Analysis with SPSS, Version 14, Thomson Brooks/Cole, Canada.

Cattell, R. B. (1965), The scientific analysis of personality, Baltimore, MD: Penguin. 
Chamberlin, C.M. and Zhang, N. (2009), Workaholism, Health and Self-Acceptance, Journal of Counceling and Development, Vol. 87, pp. 159-169.

Ciulla, J.B. (2000), The Working Life: The Promise and Betrayal of Modern Work, Random House, New York, NY.

Davidson, M.J. and Burke, R.J. (2004), Women in Management Worldwide: Facts, Figures and Analysis, Ashgate Publishing, Aldershot.

Doerfler, M.C. and Kammer, P.P. (1986), Workaholism, sex and sex-role stereotyping among female professionals, Sex Roles, Vol. 14, pp. 551-60.

Dougherty, S.E. (1989), Analysis of a Selected Number of Female Workaholics (Doctoral Dissertation, The George Washington Universuty, 1989), Dissertation Abstracts International, Vol. 50, No. 06, pp. 1642.

Eisenberg, N., Fabes, R.A., Schaller, M. and Miller, P.A. (1989), Sympathy and personal distress: Development, gender differences, and interrelations of indexes, New Directions for Child Development, Vol. 44, pp. 107- 126.

Fassel, D. (1990), Working Ourselves to death, New York: HarperCollins.

Fassel, D., and Schaef, A.W. (1991), A Feminist Perspective on Work Addiction, In N.Van Den Bergh (Ed.), Feminist Perspectives on Addictions, New York: Springer, pp. 199-211.

Feingold, A. (1994), Gender differences in personality: A meta-analysis, Psychological Bulletin, Vol. 116, pp. 429-456.

Fielden, S. and Cooper, C.L. (2002), Managerial stress: Are women more at risk? In: DL Nelson, RJ Burke (Eds), Gender, Work Stress, and Health, Psychological Association, pp. 19-34.

Fisher, S. (1994), Stress in Academic Life: The Mental Assembly Line, Buckingham: Open University Press.

Flowers, C.P., and Robinson, C. (2002), A structural and discriminant analysis of the Work Addiction Risk Test, Educational and Psychological Measurement, Vol. 62, No. 3, pp. 517-526.

Fujita, F., Diener, E. and Sandvik, E. (1991), Gender differences in negative affect and well-being: The case for emotional intensity, Journal of Personality and Social Psychology, Vol. 61, pp. 427-434.

Furnham, A. (1997), The psychology of behaviour at work, Hove: Psychology Press. 
Garson, B. (2005), Work addiction in the age of information technology: an analysis, IIMB Management Review, Vol. 15, No. 21, pp. 21.

Gillespie, N., Walsh, M., Winefiels, A., Dua, J. and Stough, C., (2001), Occupational stress in universities: staff perceptions of the causes, consequences and moderators of stress, Work and Stress, Vol. 15, No. 1, pp. 53- 72.

Goldenhar, L.M., Swanson, N.G., Hurrell, J.J., Jr. and Ruder, A., and Deddens, J. (1998), Stressors and adverse outcomes for female construction workers, Journal of Occupational Health Psychology, Vol. 3, No. 1, pp. 19-32.

Griffiths, M. (2005), Workaholism is still a useful construct, Addiction Research and Theory, Vol. 13, No. 2, pp. 97-100.

Greenberg, J. (1987), Comprehensive stress management, Dubuque, IA: William C. Brown Publishers.

Grossman, M. and Wood, W. (1993), Sex differences in intensity of emotional experience: A social role interpretation, Journal of Personality and Social Psychology, Vol. 65, No. 5, pp. 1010-1022.

Glyllensten, K. and Palme, S. (2005), The Role of Gender in Workplace Stress: A Critical literature Review, Health Education Journal, Vol. 64, No. 3, pp. 271-288.

Hanson, P. (1985), Stress for success: How to make stress on the job work for you, New York: Doubleday.

Harrington, J.M. (1994), Shift work and health - a critical review of the literature on working hours, Annals of Academic Medicine, Vol. 23, No. 5, pp. 699-705.

Harrison, Y. and Horne, J. (2000), The impact of sleep deprivation on decision-making: A review, Journal of Applied Experimental Psychology, Vol. 6, No. 3, pp. 236246.

Harpaz, I., Snir, R. (2003), Workaholism: its definition and nature, Human Relations, Vol. 56, No.3, pp. 291-319.

Harpaz, I., Snir, R. (2009), Cross-Cultural Differences Concerning Heavy Work Investment, Cross-Cultural Research, Vol. 43: 4 pp. 309-320

Herr Van Nostrand, C., (1993), Gender-Responsible Leadership: Detecting Bias, Implementing Interventions, Sage, Newbury Park, CA.

Holland, D.W. (2008), Work Addiction: Costs and Solutions for Individuals, Relationships and Organizations, Journal of Workplace Behavioural Health, Vol. 22, No. 4, pp. 1-15. 
Ishiyama, F.I. and Kitayama, A. (1994), Overwork and Career-centred Self-validation among the Japanese: Psychosocial Issues and Counseling Implications, International Journal for the Advancement of Counceling, Vol 17, pp. 167-182.

Iwasaki, K., Takahashi, M. and Nakata, A. (2006), Health Problems due to Long Working Hours in Japan: Working Hours, Workers' Compensation (Karoshi), and Preventive Measures, Industrial Health, Vol. 44, pp. 537-540.

Jackson, D.L. (1992), Correlates of Physical and Emotional Health among Male and Female Workaholics (Doctoral Dissertation, University of Oregon, 1993), Dissertation Abstracts International, Vol. 53, No. 10, pp. 5446.

Johnson, L.B., (1991). Job strain among police officers: Gender comparisons. Police Studies, Vol. 14, No. 1, pp. 12-16.

Kanai, A., Wakabayashi, M., and Fling, S. (1996), Workaholism among employees in Japanese corporations: An examination based on the Japanese version of the Workaholism Scales, Japanese Psychological Research, Vol. 38, pp. 192-203.

Karasek, R.A. (1985), Job Content Instrument: Questionnaire and User's Guide.

Kinman, G., (1998), Pressure Points: A survey into the causes and consequences of occupational stress in UK academic and related staff, Association of University Teachers, Egmont House, UK

Kling, K.C, Hyde, J.S., Showers, C.J. and Buswell, B.N. (1999), Gender differences in self-esteem: A meta-analysis, Psychological Bulletin, Vol. 125, No. 4, pp. 470500 .

Koyuncu, M., Burke, R.J. and Fiksenbaum, L. (2006), Work experience and satisfaction of male and female professors in Turkey: signs of progress?, Equal Opportunities International, Vol. 25, No. 1, pp. 38-47.

Liang and Chu, (2009), Personality Traits and Personal and Organizational Inducements: Antecedents of Workaholism, Social Behavior and Personality, Vol. 37, No. 5, pp. 645-660

Luthans, F., Avey, J.B. and Patera, J.L. (2008), Experimental analysis of a web-based training intervention to develop positive psychological capital, Academic Management Learning Education, Vol. 7, pp. 209-21.

Lynn, R. and Martin, T. (1997), Gender differences in extraversion, neuroticism, and psychoticism in 37 countries, Journal of Social Psychology, Vol. 137, No. 3, pp. 369-373.

Maccoby, E.E. and Jacklin, C.N. (1974), The psychology of sex differences, Stanford, CA: Stanford University Press. 
Machlowitz, M.M. (1978), Determining the Effects of Workaholism (Doctoral dissertation, Yale University, 1979), Dissertation Abstracts International, Vol. 40, No. 1, pp. 480.

Machlowitz, M. (1980), Workaholics: Living with Them, Working with Them, Addison-Wesley, Reading, MA.

McClure, E.B. (2000), A meta-analytic review of sex differences in facial expression processing and their development in infants, children, and adolescents, Psychological Bulletin, Vol. 126, No. 3, pp. 424-453.

McMillan, J.J. And Northern, N.A. (1995), Organizational co-dependency: The Creation and Maintenance of closed systems, Management Communication Quarterly, Vol. 9, No. 1, pp. 6-45.

McMillan, L.H.W., Brady, E.C., O’Driscoll, M.P. and Marsh, N. (2002), A multifaceted validation study of Spence and Robbins' (1992) Workaholism Battery, Journal of Occupational and Organizational Psychology, Vol. 75, pp. 357-368.

McMillan, L.H.W., O’Driscoll, M.P. and Burke, R.J. (2003), Workaholism: A review of theory, research, and future directions, In C.L. Cooper and I.T. Robertson (Eds.), International Review of Industrial and Organizational Psychology, Vol. 18, pp. 167-189, New York: Wiley.

McMillan, L. and O'Driscoll, M. (2004), Workaholism and Health: Implications for organisations, Journal of Organisational Change Management, Vol.17, No. 5, pp. 509.

McPherson, M. (2010), Women in Senior Management - Why Not?, Labour, Employment and Work in New Zealand, Equal Employment Opportunities Trust.

Morley, L. (2005), Gender equity in Commonwealth higher education, Women's Studies International Forum, Vol. 28, Issues 2-3, pp. 209-221.

Mudrack, P.E. and Naughton, T.J. (2001), The Assessment of Workaholism as Behavioral Tendencies: Scale Development and Preliminary Empirical Testing, International Journal of Stress Management, Vol. 8, No. 2, pp. 108.

Ng, T.W.H., Sorensen, K.L., and Feldman, D.C. (2007), Dimensions, antecedents, and consequences of Workaholism: A conceptual integration and extension, Journal of Organizational Behaviour, Vol. 28, pp. 111-136.

Nolen-Hoeksema, S. (1987), Sex differences in unipolar depression: Evidence and theory, Psychological Bulletin, Vol. 101, No. 2, pp. 259-282.

Oates, W.E. (1968), On being a "Workaholic" (A serious jest), Pastoral Psychology, Vol. 19, pp. 16-20. 
Organisation for Economic Co-operation and Development, (2011), Statistics Extract (accessed May 30, 2011), Online at http://stats.oecd.org/Index.aspx?DataSetCode=ANHRS

"Syndrome," Oxford English Dictionary, (accessed Mar. 31, 2011), Online at http://www.oed.com/view/Entry/196454?redirectedFrom=syndrome\#eid

Porter, G. (1996). Organizational impact of Workaholism: Suggestions for researching the negative outcomes of excessive work. Journal of Occupational Health Psychology, Vol. 70, pp. 70-83.

Porter, G. (2001), Workaholic Tendencies and the High Potential for Stress among CoWorkers, International Journal of Stress Management, Vol. 8, No. 2, pp. 147164.

Porter G. (2004), Work, work ethic, work excess, Journal of Organizational Change Management, Vol. 17 No. 5, pp. 424-439.

Quick, J., Murphy, L., Hurrel, J. and Orman, D. (1992), Stress and well being at work: Assessments and interventions for occupational mental health, Washington, DC.

Reeves, S. (2005), Addicted to work, Forbes, November 17.

Reich, R.B. (2000), The Future of Success, Knopf, New York, NY.

Robinson, B.E. (1989), Work Addiction, Deerfield Beach, Florida: Health Communications.

Robinson, B.E., and Post, P. (1994), Validity of the Work Addiction Risk Test, Perceptual and Motor Skills, Vol. 78, pp. 337-338.

Robinson, B.E. (1998b), The Workaholic Family: A Clinical Perspective, The American Journal of Family Therapy, Vol. 26, No. 1, pp. 65-75.

Robinson, B.E. (1999), The Work Addiction Risk Test: Development of a tentative measure of Workaholism, Perceptual and Motor Skills, Vol. 88, Issue 1, pp. 199-210.

Robinson, B.E., Flowers, C. and Carroll, J. (2001), Work stress and marriage: a theoretical model examining the relationships between Workaholism and marital cohesion, International Journal of Stress Management, Vol. 8, pp. 165-175.

Robinson, B. E. (2007), Chained to the Desk: A Guidebook for Workaholics, Their Partners, and Children and the Clinicians Who Treat Them, New York: New York Univ. Pr.

Robinson, R. (1989), Work addictions: Hidden legacy of adult children, Deerfield Beach, FL: Health Communities, Inc. 
Rosa, R.R. (1995), Extended workshifts and excessive fatigue, Journal of Sleep Research, Vol. 4, Suppl. 2, pp. 51-6.

Ross, C.E. and Van Willigen, M. (1996), Gender, parenthood, and anger. Journal of Marriage and the Family, Vol. 58, pp. 572-584.

Salmela-Aro, K., and Nurmi, J. (2004), Employees' motivational orientation and wellbeing at work, Journal of Organizational Change Management, Vol. 17, No. 5, pp. 471-489.

Schein, V. and Mueller, R. (1992), Sex role stereotyping and requisite management characteristics: a cross cultural look, Journal of Organisational Behaviour, Vol. 13, No. 5, pp. 439-447.

Schaufeli, W.B., Salanova, M., Roma, V.G., and Bakker, A.B. (2002). The measurement of engagement and burnout: A two sample confirmatory factor analytic approach. Journal of Happiness Studies, Vol. 3, No. 1, pp. 71-92.

Schaufeli W.B., Bakker, A.B. (2004), Job demands, job resources, and their relationship with burnout and engagement: a multi-sample study, Journal of Organisational Behaviour, Vol. 25, Issue 3, pp. 293-315.

Schaufeli, W.B., Taris, T.W. and Bakker, A.B. (2006), Dr Jekyll or Mr Hyde? On the differences between work engagement and Workaholism. In: Research companion to working time and work addiction, Burke RJ (Ed.), pp. 193-217, Edward Elgar, Cheltenham.

Schaufeli, W.B., Taris, T.W. and Van Rhenen, W. (2008), Workaholism, burnout and engagement: three of a kind or three different kinds of employee well-being, Applied Psychology International Review, Vol. 57, No. 2, pp. 173-203.

Schaufeli, W.B., Shimazu, A. and Taris, T.W., (2009), Being Driven to Work Excessively Hard: The Evaluation of a Two-Factor Measure of Workaholism in the Netherlands and Japan, Cross-Cultural Research 2009, Vol. 43, No. 4, pp. 320.

Schein, V., Mueller, R., Lituchy, T. and Liu, J. (1996), Think Manager - Think Male: a global Phenomenon, Journal of Organisational Behaviour, Vol. 17, No. 1, pp. 3341.

Scherwitz, L., Perkins, L., Chesney, M. and Hughes, G. (1991), Cook- Medley Hostility Scale and subsets: Relationship to demographic and psychosocial characteristics in young adults in the CARDIA study, Psychosomatic Medicine, Vol. 53, No. 1, pp. 36-49.

Schor, J.B. (1992), The Overworked American: The Unexpected Decline of Leisure, HarperCollins, New York, NY. 
Scott, K.S., Moore, K.S., and Micell, M.P. (1997), An exploration of the meaning and consequences of Workaholism, Human Relations, Vol. 50, pp. 287-314.

Shimazu, A. and Schaufeli, W. (2009), Is Workaholism Good or Bad for Employee Well-being? The Distinctiveness of Workaholism and Work Engagement among Japanese Employees, Industrial Health, Vol. 47, pp. 495-502.

Sparks, K., Cooper, C., Fried, Y., and Shirom, A. (1997), The effects of hours of work on health: A meta-analytic review. Journal of Occupational and Organizational Psychology, Vol. 70, No. 4, pp. 391-408.

Spence, J.T. and Robbins, A.S. (1992), Workaholism: definition, measurement, and preliminary results, Journal of Personality Assessment, Vol. 58, pp. 160-78.

Still, V. (1994), Where to from Here? Women in Management: The Cultural Dilemma, Women in Management Review, Vol. 9 No. 4, pp. 3-10, MCB University Press, Western Australia.

Taris, T.W., Schaufeli, W.B. and Verhoeven, L.C. (2005), Internal and external validation of the Dutch Work Addiction Risk Test: implications for jobs and nonwork conflict, Applied Psychological International Review, Vol. 54, pp. 37-60.

Taris, T.W., Schaufeli, W.B., and Verhoeven, L.C. (2005a), Workaholism in the Netherlands: Measurement and implications for job strain and work-nonwork conflict, Applied Psychology: An International Review, Vol. 54, No. 3, pp. 7-60.

Tertiary Education Commission, (2003), Performance-Based Research Fund, Evaluation Strategy Proposed by the Ministry of Education and the Tertiary Education Commission, found at http://www.tec.govt.nz/upload/downloads/pbrfevaluation-strategy.pdf found on September 27, 2008.

Tertiary Education Commission, (2009), Performance-Based Research Fund, Evaluation Strategy Proposed by the Ministry of Education and the Tertiary Education Commission, found at http://www.tec.govt.nz/Funding/Fundfinder/Performance-Based-Research-Fund-PBRF-/Purpose/ found on October 10, 2011

Trueman, A.L. (1995), Socialization and Workaholism: A Lifestyle Perspective (Master's Thesis, Dalhousie University, 1996), Dissertation Abstracts International, Vol. 34, No. 04, pp. 1700.

Van Teijlingen, E. and Hundley, V. (2001), Social Research Update, Department of Sociology, University of Surrey, Issue 35, Guildford, England, found at http://sru.soc.surrey.ac.uk/SRU35.pdf 
Wiggins, J.S. (1979), A psychological taxonomy of trait-descriptive terms: The interpersonal domain, Journal of Personality and Social Psychology, Vol. 37, pp. $395-412$.

Wiggins, J.S. and Broughton, R. (1985), The interpersonal circle: A structural model for the integration of personality research, In R. Hogan and W. H. Jones (Eds.), Perspectives in personality, Vol. 1, pp. 1-47. Greenwich, CT: JAI Press.

Winstead, B.A., Derlega, V.J. and Unger, R.K. (1999), Sex and gender, In V. J. Derlega, B. A. Winstead, and W. H. Jones (Eds.), Personality: Contemporary theory and research, 2nd ed., pp. 257-281. Chicago: Nelson-Hall.

Wood, J.T., (1994), Gendered Lives: Communication, Gender and Culture, Wadsworth Publishing, Belmont, CA.

Worrall, L., Cooper, C.L., Campbell, F. (2000), The impact of organizational change on the work experiences and perceptions of public sector managers, Personnel Review, Vol. 29, No.5, pp. 613-36.

Zohar, D., (2006), On the Vicissitudes of the Study of Workaholism: A Construct at a Crossroad, Career Development International, Vol. 11, No. 5, pp. 478-82. 
Appendix A: Human Ethics Committee Application 


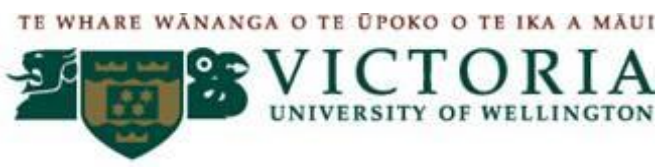

\section{Application for Approval of Research Projects}

Please email Pipitea (Faculty of Commerce and Administration and Faculty of Law) applications to your supervisor who will then email it to a Pipitea HEC member for a preliminary review.

Note: The Pipitea Human Ethics Committee attempts to have all applications approved within three weeks but a longer period may be necessary if applications require revision.

1 NATURE OF PROPOSED RESEARCH:

(a) Student Research (delete one)

(b) If Student Research Degree MCA Course Code MGMT 591

(c)Project Title: Gender and Workaholism: A Study of New Zealand Academics

2 INVESTIGATORS:

(a) Principal Investigator Name Amanda Crabbe e-mail address: crabbeaman@ myvuw.ac.nz

School/Dept/Group VMS, Management

(b) Other Researchers Name Position

(c) Supervisor (in the case of student research projects) Dr Kala S Retna and Eric Chong

3 DURATION OF RESEARCH

(a) Proposed starting date for data collection - After HEC approval has been granted Immediately after approval

(b) Proposed date of completion of project as a whole: $31^{\text {st }}$ May 2011

4 PROPOSED SOURCE/S OF FUNDING AND OTHER ETHICAL CONSIDERATIONS

(a) Sources of funding for the project

Please indicate any ethical issues or conflicts of interest that may arise because of sources of funding e.g. restrictions on publication of results

NA

(b) Is any professional code of ethics to be followed

$\mathbf{N}$

If yes, name

(c) Is ethical approval required from any other body

If yes, name and indicate when/if approval will be given 
Briefly Outline:

(a) The objectives of the project

The aim of this study is to provide further knowledge of the area of gender and Workaholism within academic organisations in New Zealand. This is important as Workaholism has been found to affect health and well-being. Gender effects on Workaholism may be culturally dependent. There is a need for further research into how these differences may affect Workaholism and how such affects on Workaholism may vary between countries and cultures.

(b) Method of data collection

Data will be collected using an online survey (Qualtrics survey software). The link will be emailed to randomly selected academic staff from the eight New Zealand Universities.

(c) The benefits and scientific value of the project

The results will have particular interest to higher institutions of learning and policy-makers.

(d) Characteristics of the participants

The research involves two distinct groups - males and females. The target group will be academics, from the eight New Zealand Universities, ensuring both genders are equally represented.

(e) Method of recruitment

Using the staff directories, emails will then be sent to academic staff from each of the eight New Zealand Universities asking them to take part in the survey, a link to the survey will be contained in the email. The email will state that by participating they will be giving consent.

Once results are received, using stratified random sampling, select an equal number of participants for gender and the institution.

(f) Payments that are to be made/expenses to be reimbursed to participants NA

(g) Other assistance (e.g. meals, transport) that is to be given to participants NA

(h) Any special hazards and/or inconvenience (including deception) that participants will encounter

NA

(i) State whether consent is for (delete where not applicable):
(i) the collection of data
$\mathbf{Y}$
(ii) attribution of opinions or information
$\mathbf{N}$
(iii) release of data to others
$\mathbf{N}$
(iv) use for a conference report or a publication
$\mathbf{Y}$ 
(v) use for some particular purpose (specify)

\section{Masters' Thesis report.}

Attach a copy of any questionnaire or interview schedule to the application

(j) How is informed consent to be obtained (see sections 4.1, 4.5(d) and 4.8(g) of the Human Ethics Policy)

(i) the research is strictly anonymous, an information sheet is supplied and informed consent is implied by voluntary participation in filling out a questionnaire for example (include a copy of the information sheet)

\section{Y}

(ii) the research is not anonymous but is confidential and informed consent will be obtained through a signed consent form (include a copy of the consent form and information sheet)

\section{$\mathbf{N}$}

(iii) the research is neither anonymous or confidential and informed consent will be obtained through a signed consent form (include a copy of the consent form and information sheet)

$\mathbf{N}$

(iv) informed consent will be obtained by some other method (please specify and provide details)

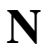

With the exception of anonymous research as in (i), if it is proposed that written consent will not be obtained, please explain why

(k)If the research will not be conducted on a strictly anonymous basis state how issues of confidentiality of participants are to be ensured if this is intended. (See section 4..1(e) of the Human Ethics Policy). (e.g. who will listen to tapes, see questionnaires or have access to data). Please ensure that you distinguish clearly between anonymity and confidentiality. Indicate which of these are applicable.

(i) access to the research data will be restricted to the investigator $\quad \mathbf{N}$

(ii) access to the research data will be restricted to the investigator and their supervisor (student research)

(iii) all opinions and data will be reported in aggregated form in such a way that individual persons or organisations are not identifiable

(iv) Other (please specify)

(1) Procedure for the storage of, access to and disposal of data, both during and at the conclusion of the research. (see section 4.12 of the Human Ethics Policy). Indicate which are applicable:

(i) all written material (questionnaires, interview notes, etc) will be kept in a locked file and access is restricted to the investigator

(ii) all electronic information will be kept in a password-protected file and access will be restricted to the investigator 
(iii) all questionnaires, interview notes and similar materials will be destroyed:
(a) at the conclusion of the research
$\mathbf{N}$
or (b) 2 years after the conclusion of the research
Y

(iv) any audio or video recordings will be returned to participants and/or electronically wiped

NA

(v) other procedures (please specify):

If data and material are not to be destroyed please indicate why and the procedures envisaged for ongoing storage and security

NA

(m) Feedback procedures (See section 7 of Appendix 1 of the Human Ethics Policy). You should indicate whether feedback will be provided to participants and in what form. If feedback will not be given, indicate the reasons why.

Feedback will be provided in the form of summary on request (as indicated in the email).

(n) Reporting and publication of results. Please indicate which of the following are appropriate. The proposed form of publications should be indicated on the information sheet and/or consent form.

(i) publication in academic or professional journals $\quad \mathbf{Y}$

(ii) dissemination at academic or professional conferences $\mathbf{Y}$

(iii) deposit of the research paper or thesis in the University Library (student research)

Y

(iv) other (please specify)

Signature of investigators as listed on page 1 (including supervisors) and Head of School.

NB: All investigators and the Head of School must sign before an application receives confirmed approval

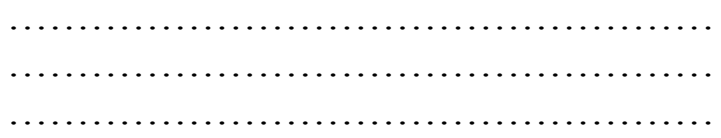

Date.

Date.

Date.

\section{Supervisors:}

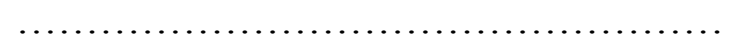

Date.

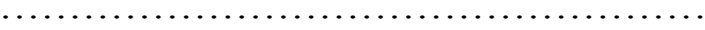

Date

\section{Head of School:}

Date 


\section{Information Sheet - In the form of an email}

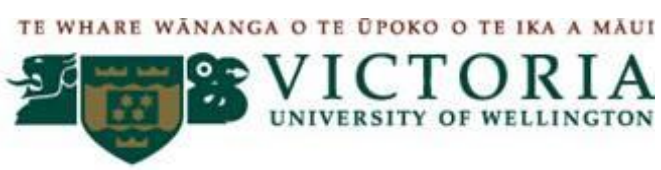

Dear Sir or Madam,

I am a Master's Student at Victoria University of Wellington. As part of my Masters program, I am conducting this study to identify differences in work behaviours between genders among academic staff in New Zealand. I would like to request the assistance of academic staff for this study.

Data collected will be anonymous. The information you provide will be confidential. Only my supervisors and I will have access to the data. The data will be reported in an aggregated form, generalising the findings beyond specific individuals and institutions, with consideration to the differences between genders.

Completion of the survey should take approximately ten minutes. By completing this survey, consent is assumed. If you choose to participate follow the link below to the survey. Please complete the survey by the <date>.

..link...

The findings have the potential to assist higher institutions of learning and policy makers to address issues regarding work conditions which may benefit academics.

If you would like to receive a summary of the results, please reply to this email stating so. You can expect to receive the summary of results after completion of the Masters' course, approximately mid 2011.

If you have any questions about the study, either now or in the future, please feel free to contact either myself or my supervisors

Yours sincerely,

Amanda Crabbe

MCA student

Victoria Management School

Victoria University of Wellington

crabbeaman@myvuw.ac.nz

\section{Supervisors:}

Dr Kala Retna

Victoria Management School

Victoria University of Wellington

PO Box 600

Phone: 044635066

Email: kala.retna@vuw.ac.nz

\section{Dr Eric Chong}

Victoria Management School

Victoria University of Wellington

PO Box 600

Phone: 044636942

Email: eric.chong@vuw.ac.nz 


\section{Survey- available online (participants provided with the website link)}

\section{Work Behaviours}

Please note: This survey is focused on work behaviours while working in New Zealand.

Section 1: The following questions relate to personal and work status

Sex: (drop box) M / F Children: (drop box) Yes / No

Marital status: (drop box)

Options: Married, Divorced/separated, Widowed, Never married, De facto relationship

Ethnicity: (drop box)

options: Maori, New Zealand European, European, Pacific Islander, Asian, Middle Eastern, Latin

American, African, Other

Employment position: (drop box)

options: Lecturer, Senior Lecturer, Associate/assistant professor, Professor, Other

Which tertiary institution do you work at: (drop box)

options: Otago University, University of Canterbury, Victoria University of Wellington, Waikato

University, Massey University, University of Auckland, Auckland University of Technology, Lincoln

University

Have you worked in New Zealand your whole career? (drop box) Yes / No (If answered yes the following question is skipped)

Have you worked in New Zealand for more than five years (drop box) Yes / No

Hours worked during an average work week: (insert number)

Hours worked during an average weekend: (insert number)

Hours of work per week are stated on your employment contract:

(insert number) 
Section 2: Personal Work Behaviours

Please indicate your level of agreement with the following statements:

Strongly

disagree

I use my time constructively

while on the job

I use my time constructively

while off the job

I get bored and restless when I

don't have anything to do at

work

I fully dedicate myself to

everything I do while on the job

I like to devote myself to

productive projects
Neither agree or disagree

Strongly agree

12

1

12

3

$4 \quad 5$

12

3

45

12

3

$4 \quad 5$
Most of the time I find my work very enjoyable

Sometimes I enjoy my work so much I don't want to stop

I enjoy my work so much I lose track of time when engaged in a project

I frequently look forward to going to work

Most of the time I am interested in the work I do

I tend to be proud of the work I do

I look at overcoming obstacles as positive experiences

$\begin{array}{ll}\text { Strongly } & \begin{array}{l}\text { Neither } \\ \text { agree or } \\ \text { disagree }\end{array}\end{array}$

Strongly

agree

$\begin{array}{lll}3 & 4 & 5\end{array}$

12

3

45

12

3

45

12

3

45

12

3

45

12

3

45

12

3

45 


\section{Section 2: Continued}

\section{Strongly \\ disagree}

I feel obligated to work hard, even if I don't enjoy the work

I often feel there's something inside me that drives me to work hard

I often find myself thinking about work, even when I want to get away from it for awhile

I feel I have high standards for all things I do

I often find it difficult to justify taking a vacation

It's important to me to work to my best abilities at all times

I often work until I'm too tired to do more

I often try to pinpoint what I need to do for ongoing success

I like to be challenged by my work

After attaining a goal, I look for a new and more challenging one

\section{Neither agree or disagree}

Strongly
agree

12

3

45

12

3

45

12

3

45

12

3

45

12

3

$4 \quad 5$

12

3

45

12

3

45

12

3

45

12

3

45

12

3

45 
Section 3: Gender in the New Zealand Workplace

Please indicate your level of agreement with the following statements:

$\begin{array}{ccccc}\begin{array}{r}\text { Strongly } \\ \text { disagree }\end{array} & \begin{array}{r}\text { Neither } \\ \text { agree or } \\ \text { disagree }\end{array} & \begin{array}{r}\text { Strongly } \\ \text { agree }\end{array} \\ 1 & 2 & 3 & 4 & 5 \\ 1 & 2 & 3 & 4 & 5 \\ 1 & 2 & 3 & 4 & 5 \\ 1 & 2 & 3 & 4 & 5 \\ 1 & 2 & 3 & 4 & 5\end{array}$




\section{Section 4: Workaholism}

Please indicate your level of agreement with the following statements:

$\begin{aligned} & \text { Strongly } \\ & \text { disagree }\end{aligned}$
d

\begin{tabular}{lr}
$\begin{array}{l}\text { Neither } \\
\text { agree or } \\
\text { disagree }\end{array}$ & $\begin{array}{r}\text { Strongly } \\
\text { agree }\end{array}$ \\
\hline
\end{tabular}

Would other people describe you as a Workaholic

Would you describe yourself as a Workaholic

12

3

45

How would you describe a Workaholic?

Please check the appropriate box/s

Works hard over long hours

Motivated by a strong internal drive

Constantly thinks/talks about work

Is highly involved with their work

Enjoys their work

Does not enjoy their work

Motivated by external or contextual factors (ie. Financial problems, supervisory pressure, desire for career advancement)

Able to maintain a healthy work-life balance

Other/s

Please define: 
Appendix B: Reliability 
Scale: Work Involvement

Case Processing Summary

\begin{tabular}{|ll|r|c|}
\hline & & N & $\%$ \\
\hline Cases & Valid & 53 & 68.8 \\
& Excluded & 24 & 31.2 \\
& Total & 77 & 100.0 \\
\hline
\end{tabular}

a. Listwise deletion based on all variables in the procedure.

Reliability Statistics

\begin{tabular}{|r|r|}
\hline Cronbach's Alpha & N of Items \\
\hline .399 & 6 \\
\hline
\end{tabular}

\section{Scale: Work Involvement}

(final)

Reliability Statistics

\begin{tabular}{|r|r|}
\hline Cronbach's Alpha & N of Items \\
\hline .598 & 4 \\
\hline
\end{tabular}

\section{Scale: Work Enjoyment}

Reliability Statistics

\begin{tabular}{|r|r|}
\hline Cronbach's Alpha & N of Items \\
\hline 811 & 7 \\
\hline
\end{tabular}

\section{Scale: Perceptions of being a Workaholic}

Reliability Statistics

\begin{tabular}{|r|l|}
\hline Cronbach's Alpha & Nof Items \\
\hline .931 & \\
\hline
\end{tabular}

Item-Total Statistics

\begin{tabular}{|c|c|c|c|c|}
\hline & $\begin{array}{c}\text { Scale } \\
\text { Mean } \\
\text { if Item } \\
\text { Delete } \\
\mathrm{d}\end{array}$ & \begin{tabular}{|c|} 
Scale \\
Variance if \\
Item \\
Deleted
\end{tabular} & $\begin{array}{l}\text { Corrected } \\
\text { Item-Total } \\
\text { Correlation }\end{array}$ & $\begin{array}{c}\text { Cronbach } \\
\text { 's Alpha if } \\
\text { Item } \\
\text { Deleted }\end{array}$ \\
\hline $\begin{array}{l}\text { Like to use time } \\
\text { constructively on job } \\
\text { Like to use time } \\
\text { constructively off job } \\
\text { I fully dedicate myself } \\
\text { to everything I do } \\
\text { while on the job } \\
\text { I like to devote myself } \\
\text { to productive projects } \\
\text { Consider job } \\
\text { important to who I am } \\
\text { Feels its difficult to } \\
\text { separate myself from } \\
\text { my work }\end{array}$ & $\begin{array}{l}20.06 \\
20.36 \\
21.04\end{array}$ & $\begin{array}{l}3.621 \\
4.439\end{array}$ & $\begin{array}{l}.148 \\
.226\end{array}$ & $\begin{array}{l}.379 \\
.330 \\
.489\end{array}$ \\
\hline
\end{tabular}




\section{Appendix C: Graphs for Biographical Data Variables}


Graph 1. Gender

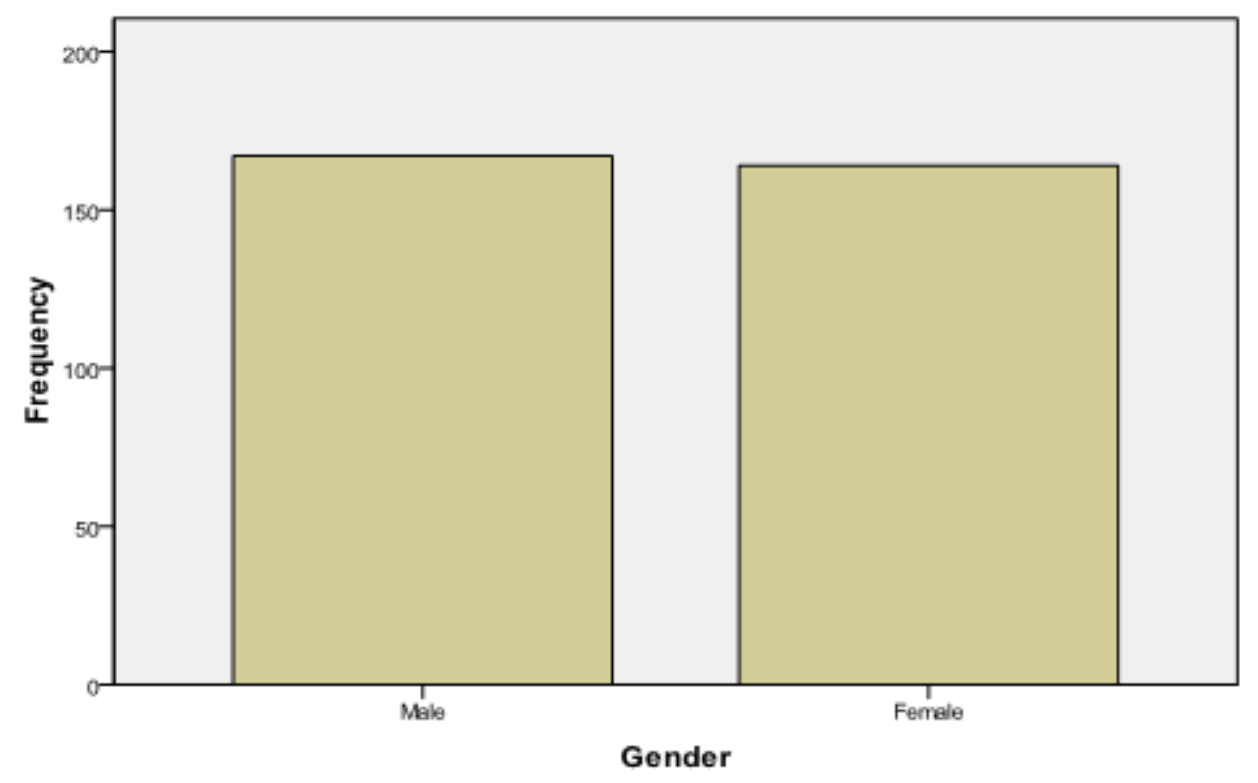

Graph 2. Marital Status

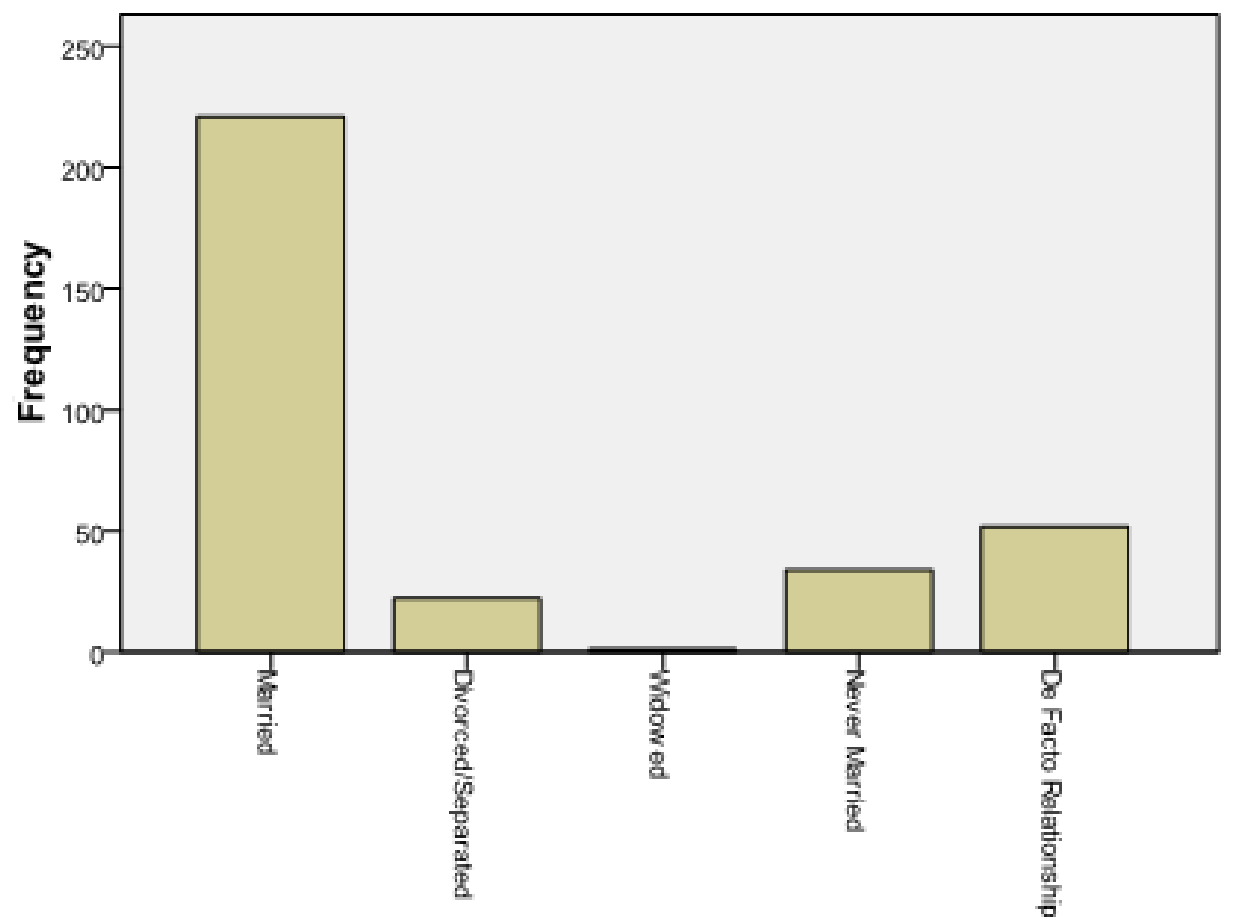

Marital Status 
Graph 3. Children

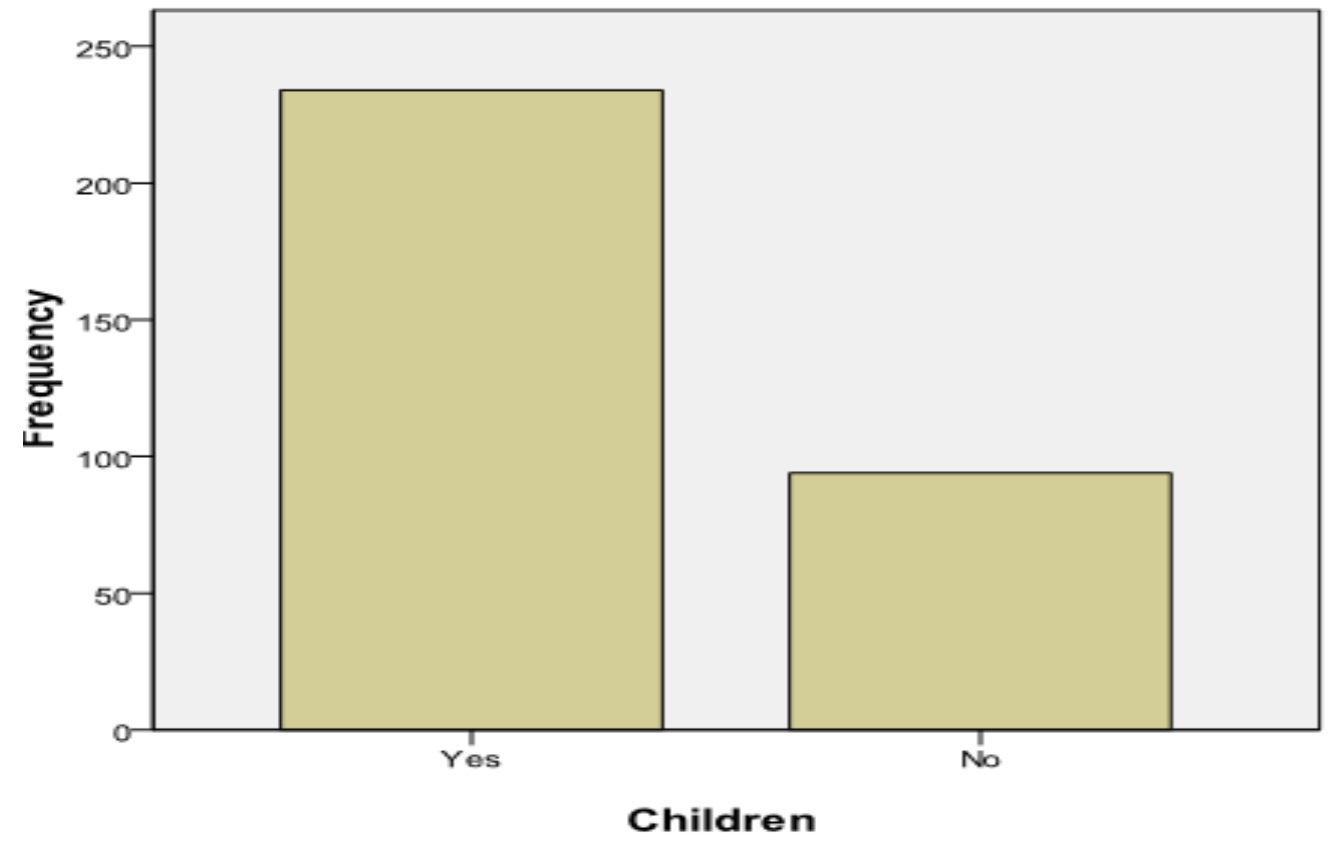

Graph 4. Ethnicity

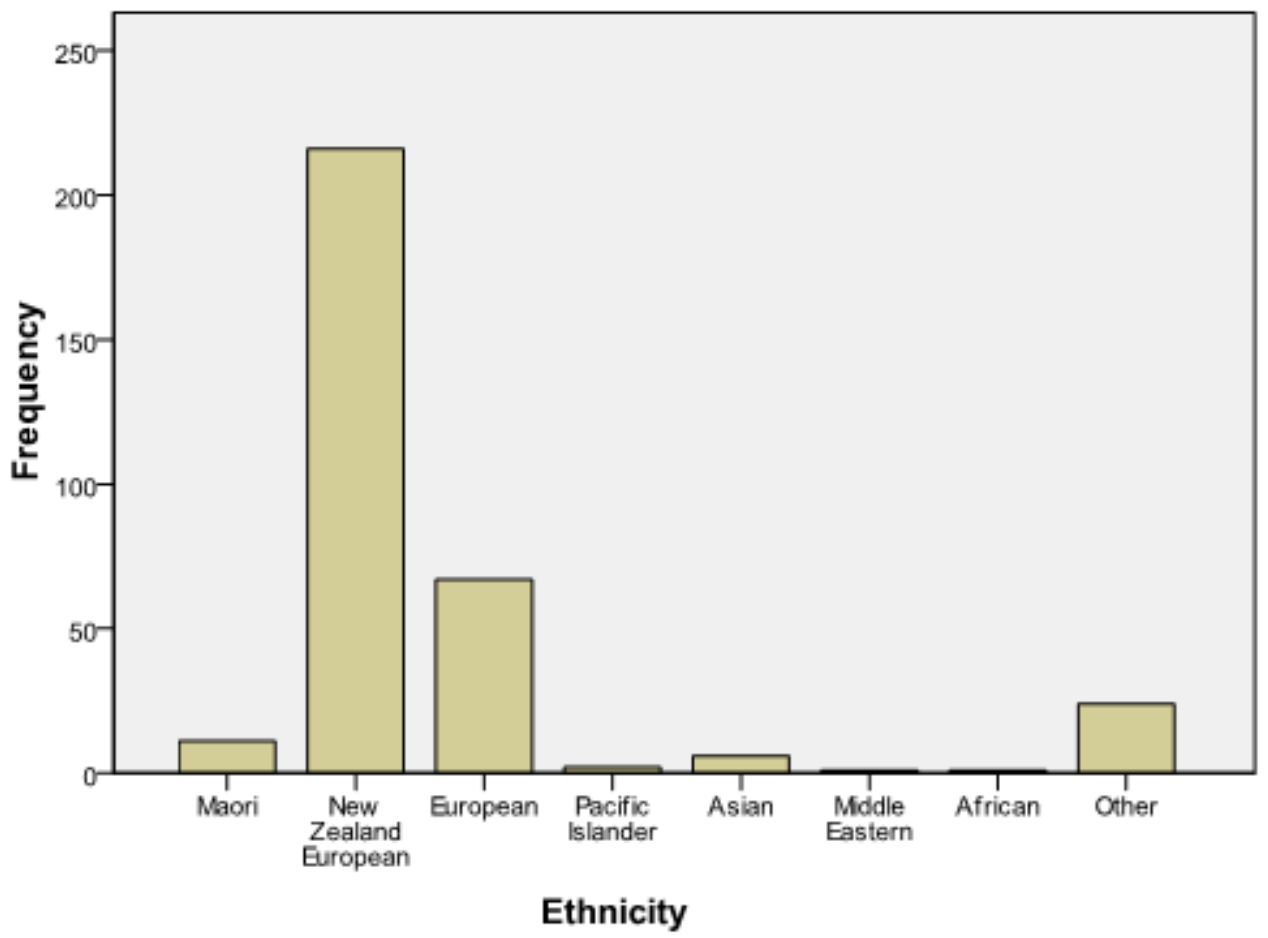




\section{Graph 5. Institution of Employment}

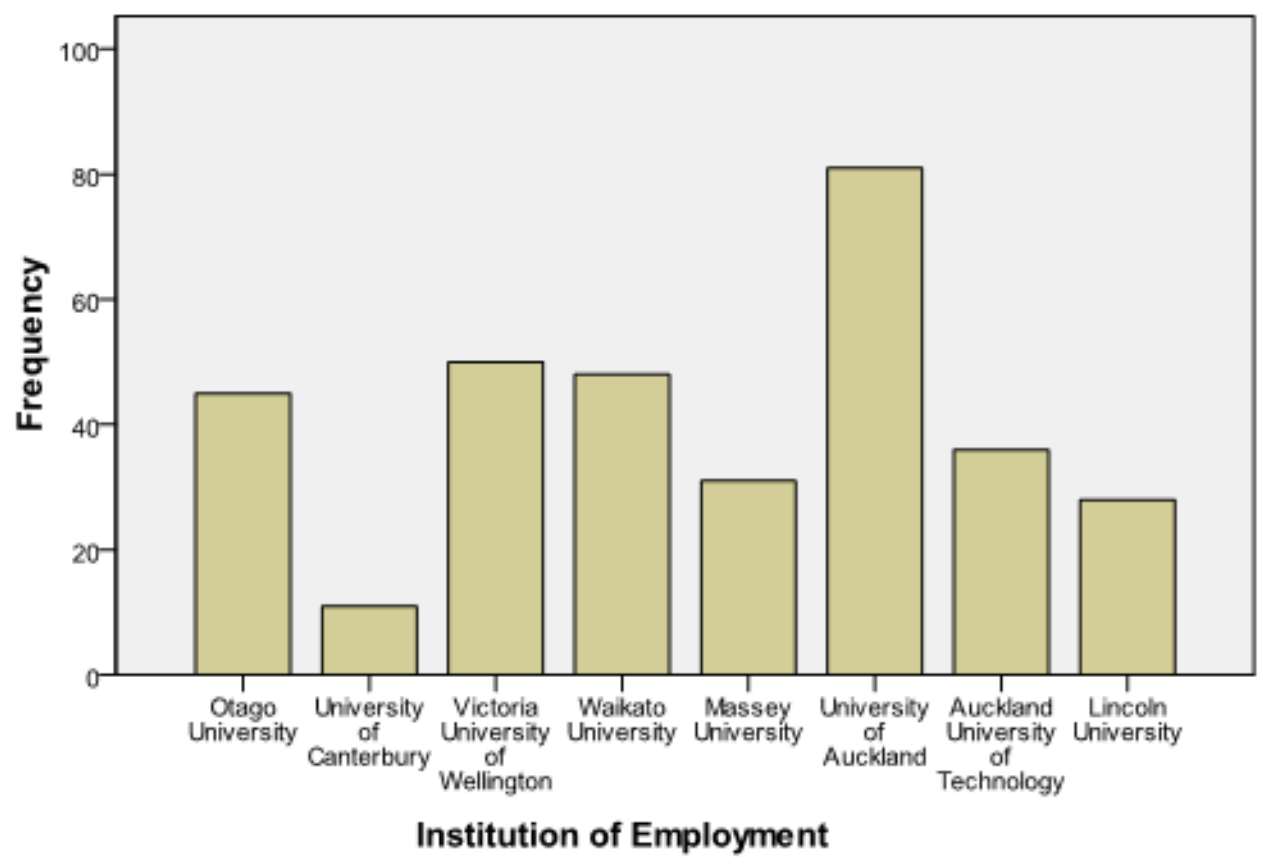

Graph 6. Employment Position

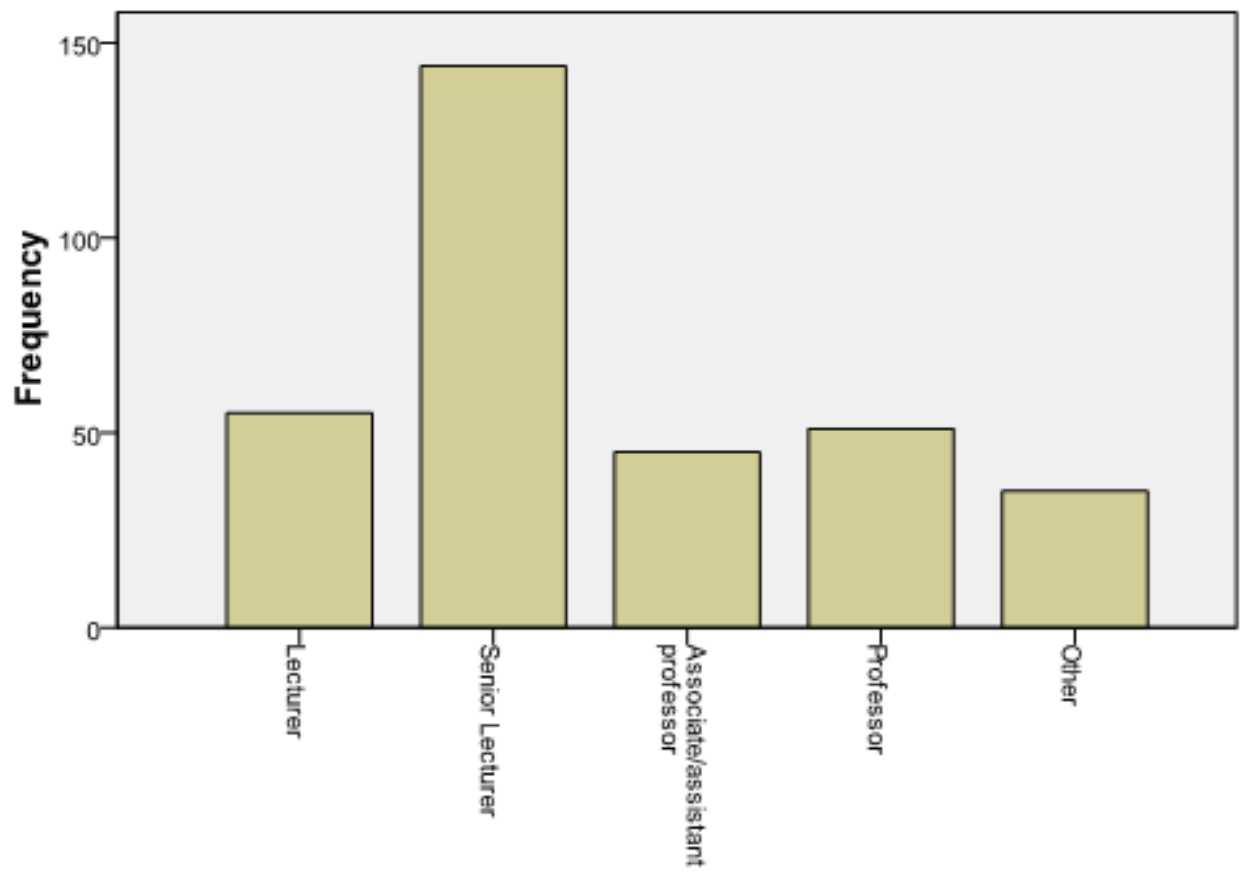

Employment Position 


\section{Appendix D: Separate-Groups Graphs for Gender Perceptions}


Graph 7. Separate-Group Graph $($ Gender $=$ Male $)$

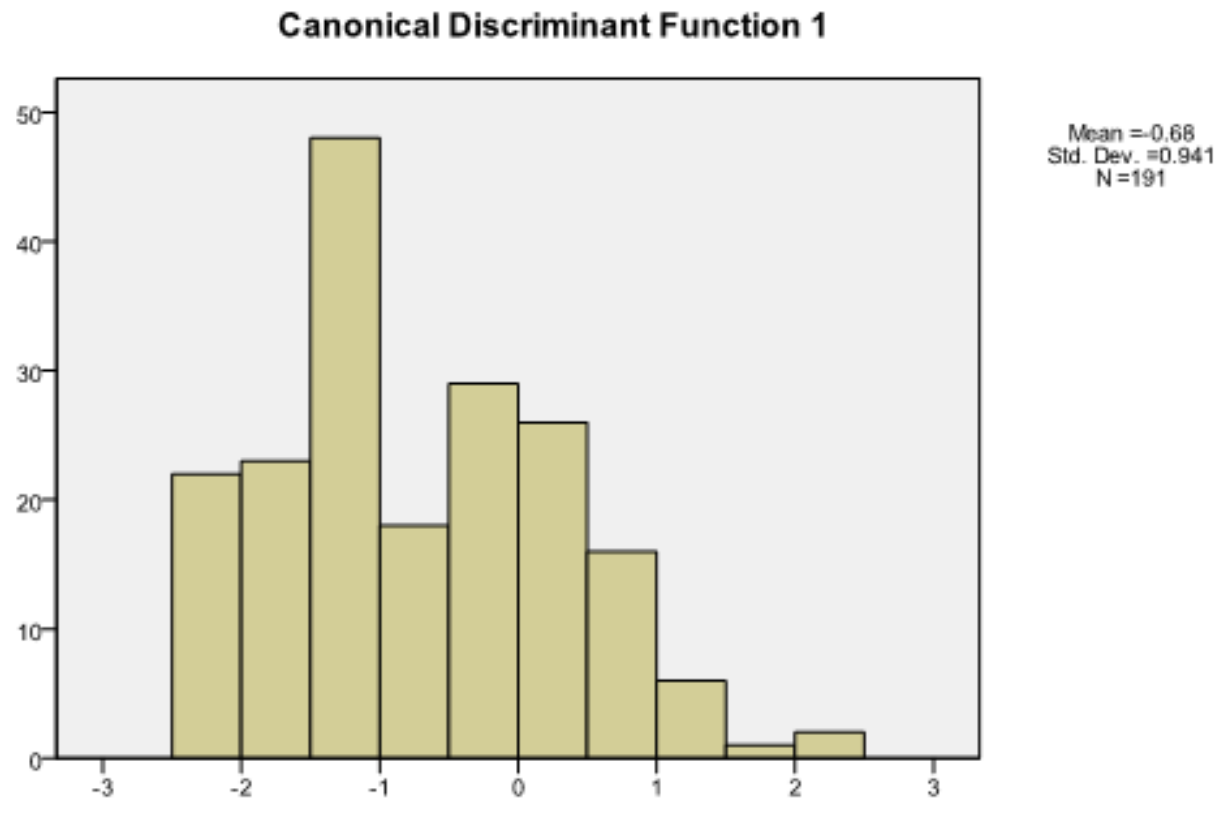

Graph 8. Separate-Group Graph (Gender $=$ Female $)$

Canonical Discriminant Function 1

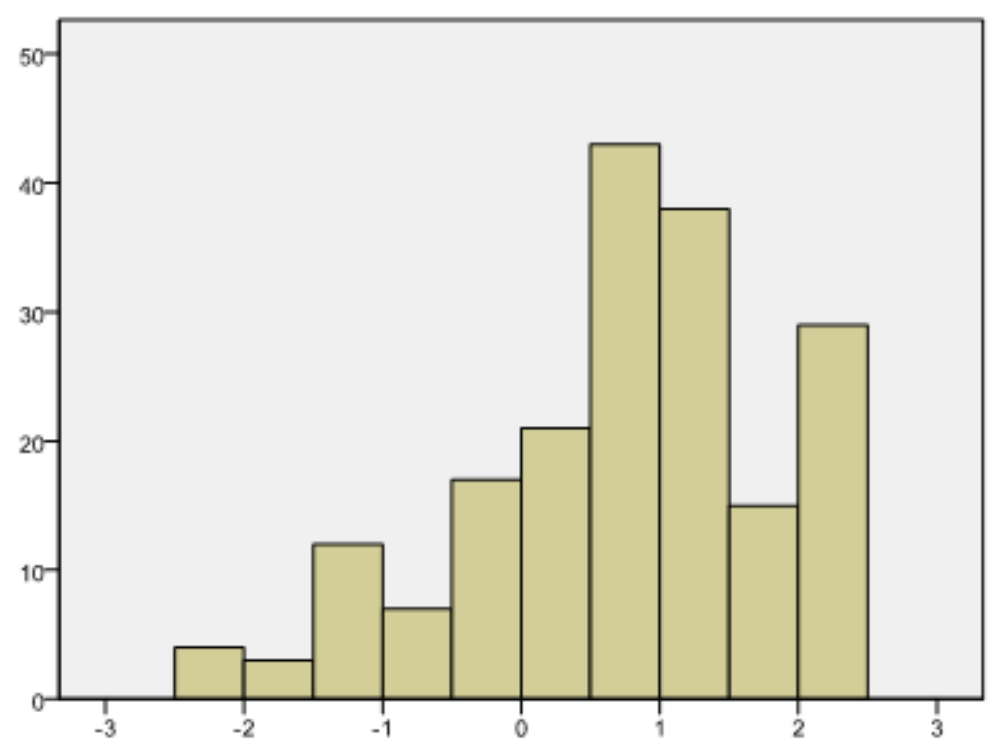

Mean $=0.69$

Std. Dev $=1.056$

$\mathrm{N}=189$ 